NBER WORKING PAPER SERIES

\title{
IMMIGRATION RESTRICTIONS AS ACTIVE LABOR MARKET POLICY: EVIDENCE FROM THE MEXICAN BRACERO EXCLUSION
}

\author{
Michael A. Clemens \\ Ethan G. Lewis \\ Hannah M. Postel \\ Working Paper 23125 \\ http://www.nber.org/papers/w23125 \\ NATIONAL BUREAU OF ECONOMIC RESEARCH \\ 1050 Massachusetts Avenue \\ Cambridge, MA 02138
}

February 2017, Revised July 2017

We acknowledge helpful feedback from Daron Acemoglu, Lee Alston, Alessandra Casella, Adam Chilton, Thomas Hertz, Gaurav Khanna, Ted Miguel, Melanie Morten, Suresh Naidu, Mead Over, Eric Posner, Raymond Robertson, C. Peter Timmer, two anonymous reviewers, and seminar participants at the University of Chicago, the University of Oslo, the Federal Reserve Bank of Philadelphia, Boston University, and the Center for Global Development. For archival assistance we are grateful to Stephanie Bartz, Dorie Bertram, Sheila Brushes, David Clark, Julie Day, Donna Daniels, David Holbrook, Jennifer Huck, Amber Kohl, Celina Nichols McDonald, Rudy Meixell, Nancy Mulhern, Amy Rian, and Amy Zimmer; for data entry to Nisha Binu and Marija Jovanovic; and for research assistance to José Elías Serranía Bravo. This work was supported by a generous grant from Good Ventures. The paper represents the views of the authors alone and not necessarily those of the authors' employers, or funders, or the National Bureau of Economic Research.

NBER working papers are circulated for discussion and comment purposes. They have not been peer-reviewed or been subject to the review by the NBER Board of Directors that accompanies official NBER publications.

(C) 2017 by Michael A. Clemens, Ethan G. Lewis, and Hannah M. Postel. All rights reserved. Short sections of text, not to exceed two paragraphs, may be quoted without explicit permission provided that full credit, including (C) notice, is given to the source. 
Immigration Restrictions as Active Labor Market Policy: Evidence from the Mexican Bracero

Exclusion

Michael A. Clemens, Ethan G. Lewis, and Hannah M. Postel

NBER Working Paper No. 23125

February 2017, Revised July 2017

JEL No. F22,J08,J38,J61

\section{ABSTRACT}

There has been little rigorous evaluation of immigration barriers intended to improve domestic terms of employment by shrinking the workforce. We study one such barrier, a policy change that excluded almost half a million Mexican bracero seasonal agricultural workers from the United States. Using novel data to measure state-level exposure to the policy, we reject the wage effect of bracero exclusion predicted by theory in the absence of induced technical change. We fail to reject the hypothesis that exclusion did not affect U.S. agricultural wages or employment. Important mechanisms include adoption of less labor-intensive technologies and shifts in crop mix.

Michael A. Clemens

Center for Global Development 2055 L Street NW, 5th floor

Washington, DC 20036

and IZA

mclemens@cgdev.org

Ethan G. Lewis

Department of Economics

Dartmouth College

6106 Rockefeller Hall

Hanover, NH 03755

and NBER

ethan.g.lewis@dartmouth.edu
Hannah M. Postel

Princeton University

hpostel@princeton.edu 
A large literature evaluates how active labor market policy affects workers' wages and employment (LaLonde 2016; Crépon and van den Berg 2016). One class of these interventions is littlestudied relative to its policy importance: specific immigration policy interventions designed to raise domestic wages and employment by reducing the total size of the workforce. Recent theoretical contributions suggest that labor scarcity can have ex ante ambiguous effects on wages under endogenous technological advance that alters labor's marginal product. This can result in a flat or even upward-sloping labor demand curve-under models of directed technical change (Acemoğlu 2002, 2007; Acemoğlu and Autor 2011) or models where production technologies of differing input intensities co-exist in equilibrium (Beaudry and Green 2003, 2005; Caselli and Coleman 2006; Beaudry et al. 2010; Manuelli and Seshadri 2014). But the applicability of these models in practice remains an open empirical question (Acemoğlu 2010, 1071), and the limited rigorous evidence to date does not directly evaluate changes in workforce policy (Lewis 2011; Hornbeck and Naidu 2014; Hanlon 2015).

In this paper we evaluate the labor market effects of a large active labor market policy experiment in the United States, a change in immigration barriers excluding roughly half a million seasonally-employed Mexican farm workers from the labor force. This was the December 31, 1964 abrogation of the manual laborer ('bracero') agreements between the United States and Mexico. Bracero exclusion was conceived and executed as a federal policy measure to improve wages and employment for domestic farm workers. We build a simple model to clarify assumptions about the production function that would or would not lead this policy change to meet its goals as active labor market policy. We gather novel, primary archival data on the geographic locations of bracero workers, allowing us to construct the first complete database of state-level exposure to nationwide bracero exclusion. This allows us to test the model's prediction that the economy adjusts to bracero exclusion by technological advance in subsectors where that is possible, and by Rybczynski adjustment otherwise-in either case without substantial labor-market effects.

The contribution of this work is to test a model of endogenous technical change stimulated by a very large reduction in labor supply with a natural quasi-experiment, and to evaluate the impact of a type of active labor market policy that is rarely directly evaluated. The literature testing models of endogenous technical change, going back to Hayami and Ruttan (1970), lacks a policy 
experiment of deliberate labor supply reduction. And much of the literature using natural quasiexperiments to evaluate the labor-market effects of immigration evaluates the effects of changes in the 'push' of political refugees overseas, rather than changes in the 'pull' of immigration regulation. ${ }^{1}$ But 'refugee push' and 'policy pull' effects could differ, given that refugees enter the labor market differently from other migrants (e.g. Cortes 2004), and the large majority of migrants are not refugees. Very recently the immigration literature has turned to evaluating labor-market effects of real-world changes to immigration policy restrictions (e.g. Beerli and Peri 2015; Kennan 2017), but evidence remains scant, and the bracero program in particular remains little-studied (Kosack 2016). ${ }^{2}$ This is in part because immigration policies-like licensing restrictions in trade policy-are inherently difficult to quantify (Beine et al. 2015). Historical quasi-experiments are a largely untapped resource, both to establish short-run causal identification and to explore the speed of adjustment over time (Lewis 2013, 177, 182).

We find that bracero exclusion had little measurable effect on the labor market for domestic farm workers. Pre- and post-exclusion farm wages and farm employment were similar in states highly exposed to exclusion-which lost roughly one third of hired seasonal labor-and in states with no exposure. Bracero workers were not substantially replaced in the years immediately following exclusion with domestic workers, unauthorized Mexican workers, or authorized nonMexican foreign workers. We find instead that employers adjusted to exclusion, as predicted by our model of endogenous technical change, with large changes in technology adoption and crop production. We reject the semielasticity of wages to labor scarcity implied by the model in the absence of endogenous technical change, and offer direct evidence of induced technical change. These findings suggest that new theories of technological change can inform the design and evaluation of active labor market policy.

Below in Section 1 we describe the exclusion of bracero workers and prior research on its eco-

\footnotetext{
${ }^{1}$ Studies exploiting overseas refugee 'push' for identification include most influential studies of the labor-market effects of immigration based on natural experiments: Card (1990); Hunt (1992); Carrington and de Lima (1996); Friedberg (2001); Angrist and Kugler (2003); Gandal et al. (2004); Glitz (2012); Braun and Omar Mahmoud (2014); Borjas and Doran (2015); Foged and Peri (2016).

${ }^{2}$ Studies that have evaluated the effect of immigration on firms' technological choices do not evaluate the impact of a specific policy decision to admit or exclude migrants (e.g. González and Ortega 2011; Lafortune et al. 2015). A small strand of literature evaluates the effect of changes in immigration policy on migration, finding that visa requirements tend to markedly reduce bilateral mobility, but does not test the effects of these changes on labor-market conditions or technological change in the migrant-destination country (Ortega and Peri 2013; Freier 2014; Bertoli and FernándezHuertas 2015; Lawson and Roychoudhury 2016).
} 
nomic effects. Section 2 then presents a stylized model of the labor-market effects of active labor supply reduction policy under endogenous technical advance. We also consider alternative modeling approaches which yield similar results. Section 3 describes our novel archival data. Sections 4 and 5 present empirical tests of the model, and Section 6 concludes.

\section{The exclusion of bracero workers}

The exclusion of bracero workers from the United States was one of the largest-ever active labormarket policies of workforce reduction designed to improve domestic terms of employment within the targeted sector. Here we review the history of the intervention and the literature that has sought to evaluate its effects.

\subsection{The bracero agreements}

The United States and Mexico made a set of three bilateral agreements to regulate Mexico-U.S. flows of temporary low-skill labor, spanning almost the entire period from 1942 through $1964 .^{3}$ At first this bracero program supplied Mexican labor to a mix of manual jobs in U.S. agriculture, railroads, mining, and construction, raising remittance receipts and human capital investment in Mexico (Kosack 2016). After World War 2 the program evolved to focus almost entirely on agriculture, and grew to supply almost half a million seasonal workers each year to U.S. farms, with contracts typically lasting between six weeks and six months (Salandini 1973, 158). The Kennedy administration began the process of bracero exclusion in March 1962, by making braceros "far less attractive" to farmers by greatly raising the required wage rate (Craig 1971, 180). The Johnson administration completed bracero exclusion at the end of 1964 by fully terminating the final iteration of these agreements. To date, the program "has been widely criticized and not thoroughly studied" (Durand 2007, 25).

The bracero agreements are sometimes portrayed as a government policy to 'import' labor to offset shortages originating in the absence of U.S. workers during World War Two (e.g. Scruggs 1963) and the Korean War (e.g. Morgan 2004, 127). They are more correctly described as a re-

\footnotetext{
${ }^{3}$ The two countries created much smaller bilateral labor agreements, also sometimes called bracero agreements, in 1910 and during 1919-1921.
} 
laxation of restrictions on private employers' contracting with Mexican workers, given that the principal lever of government policy in regulating migration-as in regulating trade-is the degree of restriction on private firms. ${ }^{4}$ Long before the bracero agreements, there was large-scale private-sector Mexican labor supply to the U.S. Southwest and Great Plains states, from the late $19^{\text {th }}$ century through the 1920s (Clark 1908; Gamio 1930; Smith 1981; Durand et al. 2000). In Arizona, Kansas, and New Mexico, the Mexican-born fraction of the labor force was much higher in 1930-in peacetime-than it would be again until after 1990 (Borjas and Katz 2007, 19). In 1929 began 13 years of tight restrictions including mass deportations that reduced the Mexican-born fraction of the U.S. by a third. ${ }^{5}$ The bracero agreements temporarily eased these restrictions, from the 1940s until bracero exclusion after 1964. The beginning of the bracero program did not create U.S. demand for Mexican labor or Mexican supply of that labor, but the termination of the program did tightly restrict supply, as the 1929-1942 restrictions had previously done.

\subsection{Bracero exclusion as active labor market policy}

The principal policy goal of excluding braceros starting in 1965 was to improve labor-market conditions for U.S. farm workers by reducing the size of the workforce. "The main reason given for the discontinuation of the program at the time was the assertion that the Bracero Program depressed the wages of native-born Americans in the agricultural industry" (Borjas and Katz 2007, 16). The year before Congress voted to exclude braceros, president John F. Kennedy stated, "The adverse effect of the Mexican farm labor program as it has operated in recent years on the wage and employment conditions of domestic workers is clear and cumulative in its impact" (Vialet and McClure 1980, 52). This was seen as a straightforward consequence of economic principles: a University of California at Berkeley sociologist testified to Congress that, in voting to extend the program, it had "passed a law which repeals the law of supply and demand", tantamount to "repealing the law of gravity" (Anderson 1961, 361).

\footnotetext{
${ }^{4}$ The bracero agreements did not subsidize U.S. employers' hiring of Mexican workers, as employers paid for the wages, housing, and transportation of those workers.

${ }^{5}$ Most Mexican departures during the 1930s arose from an organized deportation campaign begun by President Herbert Hoover-the first important de facto restriction of labor mobility across the border-though roughly 40 percent of emigrants departed voluntarily as jobs dried up (Taylor 1934, pp. 23-25; Gratton and Merchant 2013, 957-959). Before 1929 there was very little restriction on labor mobility: "As late as 1928, [the Border Patrol] had only 747 men to police the vast international boundaries (Canadian and Mexican) under its jurisdiction. Nor did members of the organization ever consider the apprehension of would-be illegal Mexican immigrants to be their primary function until the very end of the decade: most of their efforts went towards the enforcement of customs regulations and prohibition laws" (Cardoso 1980, 84).
} 
The main evidence base for these claims at the time was the finding of a commission created by U.S. Secretary of Labor James P. Mitchell in 1959. ${ }^{6}$ President Kennedy $(1962,639)$ was referring to this study when he declared in October 1961, while reluctantly signing the law extending the program for two more years, "Studies of the operation of the Mexican labor program have clearly established that it is adversely affecting the wages, working conditions, and employment opportunities of our own agricultural workers." The purpose of the commission was to independently and definitively assess whether or not the presence of braceros had adversely affected labor market conditions for U.S. workers. The commission concluded that it had, but not through an investigation that would be considered credible and transparent by economists or other social scientists today. Its analysis focused on anecdotes regarding the difficulty of measuring the 'prevailing wage' that braceros were required to receive, and the failure of some employers to pay braceros the prevailing wage (Garrett et al. 1959). But this was not direct evidence of changes to U.S. workers' terms of employment. The commission did not use the systematic farm wage data that had been available from the Department of Agriculture for many years, nor the systematic data on unemployment available from the Bureau of the Census since $1957 .^{7}$

In retrospect, the 1959 commission was not qualified to provide a disinterested, quantitative evaluation of the economic impact of this policy. The senior commissioner and only member with research training was Rufus von KleinSmid, who had co-founded an influential society of eugenicists that advocated blocking Mexican immigration due to their view that Mexicans constituted a genetically inferior race. ${ }^{8}$ This fact has gone unremarked in discussions of the 1959

\footnotetext{
${ }^{6}$ The centrality of this commission's findings in the anti-bracero arguments of the Administration and Congress is apparent in e.g. Williams $(1962,29)$. The commission's report also spurred an influential House Subcommittee report on the condition of farm workers in 1960, but that report did not assess the effect of bracero workers on domestic workers.

${ }^{7}$ Direct evidence of the effects on U.S. workers was considered only in a brief passage: "Between 1953 and 1958, the hourly farm wage rate in the U.S. increased 14 percent, according to the Department of Agriculture. An examination of wage surveys made by state agencies in areas using Mexican nationals showed that the average rate paid to domestic workers in these areas either remained unchanged or decreased in three-fifths of the cases" (Garrett et al. 1959, 294). But it is difficult to assess this claim, as the authors did not display the data underlying the quoted sentence. They did not specify which area(s) of which state(s) they referred to, how many were examined, how they defined "using Mexican nationals", or the degree to which the areas they examined were representative of areas with braceros. The Current Population Survey was expanded in 1956 to 330 primary sampling units with 35,000 households, allowing monthly state-level unemployment rates to be published starting in 1957.

${ }^{8}$ Von KleinSmid was a lifelong advocate of eugenics (von KleinSmid 1913). He was 84 when the commission's work was published. At age 53, as a senior professor at the University of Southern California, he had become a charter member of the eugenicist Human Betterment Foundation, with his name printed on its letterhead. He continued as a leading participant for at least a decade (Gosney 1937). The officers and trustees of the Human Betterment Foundation advocated restricting Mexican immigration, as well as the sterilization of some Mexican-Americans, on the grounds that they believed science had proven Mexicans to constitute a genetically inferior race (Holmes 1929; Kuhl 2002,
} 
commission's findings, which typically describe the commission members as "impartial consultants" (Salandini 1973, 165). ${ }^{9}$ The commission's work has nevertheless been highly influential: it caused the formation of a Senate subcommittee to investigate migrant farm workers (Norris 2009, 148), was frequently cited by influential advocates of bracero exclusion (e.g. Galarza 1964, 199), and was considered authoritative long afterward by government analysts (Vialet and McClure 1980, 58).

A successor of Mitchell's as Secretary of Labor, Willard Wirtz, spent years personally advocating for bracero exclusion (Hawley 1966). Wirtz declared in 1964 his goal that large-scale use of any foreign workers in agriculture be "hopefully eliminated" (Secretary of Labor 1966, H-4). After the termination of the program, he issued a report stating that the exclusion had caused an improvement in the "terms and conditions of employment" for U.S. workers (Secretary of Labor 1966, 3, 11). The evidence offered to support this claim was the fact that farm wages across the nation rose during 1965 (p. 19). Secretary Wirtz likewise stated that "[t]ens of thousands of jobs were created for American workers" (p. 3), offering as evidence the fact that domestic seasonal farm employment rose between 1964 and 1965 in California, Michigan, and Texas (p. 10). There was no attempt to discern whether these trends preceded bracero exclusion, or happened to a different extent in states unaffected by the exclusion. Similarly, a report of the U.S. Senate $(1966,17)$ concluded that bracero exclusion had raised wages because agricultural wages rose between 1964 and 1965 in California, Arizona, and Texas-without comparing those increases to similar wage increases documented by the same report in dozens of states unaffected by bracero exclusion. Similar claims have persisted for decades: in 2004 Congressional hearings considering the creation of new temporary employment visas, both Democrats and Republicans asserted that the bracero agreements had reduced wages and employment for U.S. workers (U.S. House of Representatives 2004, 125, 130).

57; Stern 2005; Stern 2015, 164). The work of von KleinSmid and his colleagues on 'racial' purification in California was specifically cited by the National Socialist regime of Adolf Hitler as providing an "essential basis" for German compulsory sterilization laws in the 1930s (Kuhl 2002, 43).

${ }^{9}$ Beyond his eugenecist activism, Von KleinSmid was not an economist but a psychologist, born in 1875 and trained at a time when modern quantitative methods did not exist. He thus could not have possessed the tools to empirically evaluate the impact of a labor market policy. The other three members of the commission had no training in research methods: George Higgins was a labor activist and monsignor known as "the labor priest's priest" (Sullivan 2001); Edward Thye was a graduate of a vocational community college and a former dairy farmer and bureaucrat at statelevel farm agencies before becoming a career politican; and Glenn Garrett ran the Good Neighbor Commission in Texas. All four commission members were handpicked by a Secretary of Labor who had sought for years to restrict and terminate the bracero program (Vialet and McClure 1980, 45, 51). 


\subsection{Prior research findings on bracero exclusion}

The policy debate on bracero exclusion proceeded and ended without any rigorous or disinterested evidence. "Anti-braceroists produced statistics ...that increased employment of Mexicans had adversely affected the wages and working conditions of natives," wrote Craig $(1971,144)$. "Those supporting [the law] presented equally elaborate data indicating clearly that the bracero had, if anything, proved beneficial to the wages and working conditions of domestics." Years later, two studies in the economics literature sought to measure objectively and empirically the labor-market impacts of terminating the bracero agreements. But due to data and methods limitations, neither offers clear evidence for or against such impacts.

In the first of these studies, Jones and Rice (1980) measure farm wage and farm employment trends in four U.S. states 1954-1977, before and after the end of the bracero program, and do not detect any effects of the program's termination. But the authors do not have access to data on the number of Mexican workers in each state. They are thus unable to measure the intensity of exposure to the program, or establish a control group of states with little or no exposure to the program.

In the second, Morgan and Gardner (1982) likewise seek to measure the effects of bracero exclusion on farm wages. They attempt this using a state-year panel for seven bracero-intensive states during 1953-1978. In regressions with state-average farm wages as the dependent variable, they find that a dummy for the years of the bracero program (1953-1964) has a negative and statistically significant coefficient. But it is difficult to give this coefficient any interpretation, given that 1) average farm wages across the country rose greatly during the period of time they analyze, and 2) the regressions do not include any time dummies or time trends. Thus a dummy variable for the early years of that period would have a negative coefficient even in states with no exposure to the program. But they do not analyze states with few or no braceros, so they, like Jones and Rice, are unable to establish a credible counterfactual.

Despite this limited and problematic evidence on the labor-market effects of bracero exclusion, a long strand of literature has interpreted those effects as well-established. During the program, economists like Hadley $(1956,355)$ used anecdotes to claim that the presence of braceros reduced 
domestic wages. "The availability of [bracero] workers," wrote Briggs (1980) long after the program ended, "significantly depressed existing wage levels in some regions," citing a calibrated simulation of what the wage effect of bracero exclusion in two crops might have been during the program, but not an empirical measurement of the wage effect of actual bracero exclusion (Wise 1974). In arguing against a renewed US-Mexico temporary worker agreement in the 1990s, Martin $(1998,892)$ claimed that bracero exclusion caused farm wages to rise by 30 to 50 percent, without a source for this estimate. Grove (1996, 320), citing the problematic results of Morgan and Gardner, claimed that "employment of braceros reduced seasonal farm wages and domestic employment." Martin and Teitelbaum $(2001,194)$ claim, "The rise in farm workers' wages following the bracero program's termination also showed how much it had depressed wages"-but do not compare this rise in wages to wage trends prior to bracero exclusion, or to wage trends in places unaffected by bracero exclusion. A literature review by Levine $(2006,5)$ concludes that the bracero agreements caused "a decrease in domestic farm worker employment, and a decrease in farm wages," but without critical analysis of the evidence base. ${ }^{10}$ Social scientists outside of economics have made numerous similar claims. ${ }^{11}$

But a minor literature has dissented from this view. Just before bracero exclusion, Mamer (1961,

\footnotetext{
${ }^{10}$ In reviewing the evidence to draw her conclusion for the purposes of informing Congress in 2006 about the labor market effects of temporary work visas, Levine cites only the simulation of Wise (1974) and the regressions of Morgan and Gardner (1982) that did not account for the upward time-trend in wages nationwide, but omits the contradictory findings of Jones and Rice (1980).

${ }^{11}$ Some historians and legal scholars have made the same claim, but without systematic quantitative evidence. First, in an influential book that helped secure bracero exclusion, historian Ernesto Galarza $(1964,199-218)$ claimed that the effect of braceros on domestic workers' wages and employment was "severe". To support this claim he offered several pages of anecdotes about braceros being paid relatively low wages for certain crops in certain counties of California for work that in other years had been performed by domestic workers, but does not offer evidence on the wages earned by domestic workers for the work they performed instead. Second, law professor Austin Morris (1966, 1940) wrote, "It was charged that ... Bracero-users never seriously tried to attract domestic labor, and that wages were kept down, and even lowered. ... That little effort was made, either by administrative insistence or grower cooperation, to recruit local workers is evidenced by the fact that as the number of entrants was cut down toward the end of the program (from a high of 459,850 in 1956 to about 200,000 in 1964, and only 20,000 in 1965), their places were taken by domestic workers. If domestic workers could be recruited in 1965, as they were, then clearly they could have been recruited in 1956." He thus described it as "false, exaggerated, and baseless" to suggest that braceros had not displaced large numbers of domestic workers (p. 1943). But Morris-though he was writing two years after bracero exclusion and could have measured its observed effects-offers no evidence that hundreds of thousands of domestic workers did in fact enter seasonal farmwork to replace braceros as claimed. Third, Bickerton $(2000,910)$ decries the "low wages that resulted from the importation of foreign workers" under the agreements. To support this claim Bickerton cites a passage where Calavita (1992, 65 passim) discusses some bracero employers' violations of their wage contracts; but this does not constitute direct evidence of adverse effects on the wages of other workers. Fourth, Mitchell (2012, 396) suggests that due to the exclusion of bracero workers from California, "[w]ages to domestic workers went up 23 percent", but does not offer evidence that this trend was any different in places unaffected by bracero exclusion, or that a similar trend was not occurring in California prior to bracero exclusion.
} 
1205-1206) noted the absence of any systematic quantitative evidence for substantial labormarket effects of the program. And after exclusion was carried out, some economists predicted that rapid technological adjustment would negate its intended effects. Jones and Christian (1965, 528) predicted that any wage effects of bracero exclusion would be "almost completely nullified by an accompanying intensification of mechanization”. William E. Martin (1966, 1137), later president of the Western Agricultural Economics Association, wrote that due to sudden substitution of capital for Mexican workers, "excluding foreign labor will not have any lasting beneficial effects on the domestic farm labor force." However, these predictions-that bracero exclusion would fail as active labor market policy, and why it would fail-have never been systematically tested. More recently, Alston and Ferrie $(1999,112)$ observe that many growers perceived hiring braceros not as a way to pay lower wages for equal productivity, but as a way to achieve higher productivity and workforce reliability-in spite of the fact that "the total cost of bracero labor exceeded that of domestic farm workers and most likely the cost of illegal Mexican workers."

\section{A model of workforce reduction and technical advance}

Here we seek to clarify testable implications of the above, skeptical view of bracero exclusion. To do this, we construct a simple model to explore how technological and production adjustment could shape the labor-market effects of an active policy of workforce reduction. Following Acemoğlu (2010) we refer to a technical advance as either the creation of a new production technology or the adoption of an existing technology.

\subsection{Crop production in an open economy with alternative technologies}

Let there be several locations, indexed by $i$ (hereafter suppressed), each of which can produce a single crop (relaxed below). The crop can be sold to the world market (at price $p \equiv 1$ ) and is produced using capital $(K)$, labor $(L)$, land $(\tau)$ and materials $(M)$. The endowments of land is fixed at $\bar{T}$, and capital and materials are supplied elastically. The endowment of labor is initially

given by $\bar{L}$, but we will consider below what happens when it is reduced. Land and labor markets are competitive. Farmers rent land (from landowners) at rate $r_{T}$, hire workers at wage $w$, and purchase materials at price $m$. Landowners receive payment $\underline{r_{T}} \geqslant 0$ per acre if they do not rent 
to farmers.

A nested constant elasticity of substitution (CES) production technology using what will be called "traditional" or "old" capital, $K_{0}$, can be used to produce the output crop $Y$ :

$$
Y_{0}=\left\{K_{0}^{\frac{\mu-1}{\mu}}+\left[a L^{\frac{\sigma-1}{\sigma}}+(1-a) T^{\frac{\sigma-1}{\sigma}}\right]^{\frac{\sigma}{\sigma-1} \frac{\mu-1}{\mu}}\right\}^{\frac{\mu}{\mu-1}} .
$$

Land and materials are in another nest, for simplicity, $T \equiv \min \{\tau, M\}$. This allows us to mostly abstract from materials, though their costs will factor into the decision of how much land to use (in (2), below). We also assume, consistent with the evidence in Herrendorf et al. (2015) that $\mu, \sigma>1 . K_{0}$ is elastically supplied at rental rate $r_{0}$, so in equilibrium, ${ }^{12} r_{0}=\left\{K_{0}^{\frac{\mu-1}{\mu}}+\left[a L^{\frac{\sigma-1}{\sigma}}+(1-\right.\right.$ a) $\left.\left.T^{\frac{\sigma-1}{\sigma}}\right]^{\frac{\sigma}{\sigma-1} \frac{\mu-1}{\mu}}\right\}^{\frac{1}{\mu-1}} K_{0}^{\frac{-1}{\mu}}$, and thus $Y_{0}=\left(\frac{r_{0}^{\mu-1}}{r_{0}^{\mu-1}-1}\right)^{\frac{\mu}{\mu-1}}\left[a L^{\frac{\sigma-1}{\sigma}}+(1-a) T^{\frac{\sigma-1}{\sigma}}\right]^{\frac{\sigma}{\sigma-1}}$. Farmers are willing to rent land as long as $r_{T}+m$ is less than the marginal product of land. This implies that there is a cutoff $\bar{\phi}$ such that if $\bar{L} / \bar{T}<\bar{\phi}$, farmers will not rent all of the land available. This cutoff is defined by

$$
(1-a)\left(\frac{r_{0}^{\mu-1}}{r_{0}^{\mu-1}-1}\right)^{\frac{\mu}{\mu-1}}\left[a \bar{\phi}^{\frac{\sigma-1}{\sigma}}+(1-a)\right]^{\frac{\sigma}{\sigma-1}-1}=\underline{r_{T}}+m
$$

A potentially binding cutoff exists only if $\left(\frac{r_{0}^{\mu-1}}{r_{0}^{\mu-1}-1}\right)^{\frac{\mu}{\mu-1}}(1-a)^{\frac{\sigma}{\sigma-1}}<\underline{r_{T}}+m$ (which, notice, can occur even if $r_{T}=0$ ). The existence of this cutoff implies that the equilibrium wage never exceeds $\bar{w}=a\left(\frac{r_{0}^{\mu-1}}{r_{0}^{\mu-1}-1}\right)^{\frac{\mu}{\mu-1}}\left[a+(1-a) \bar{\phi}^{-\frac{\sigma-1}{\sigma}}\right]^{\frac{\sigma}{\sigma-1}-1}=\left[\left(\frac{r_{0}^{\mu-1}}{r_{0}^{\mu-1}-1}\right)^{-\frac{\mu(\sigma-1)}{\mu-1}}-(1-a)^{\sigma}\left(\underline{r_{T}}+m\right)^{1-\sigma}\right]^{-\frac{1}{\sigma-1}}$. If the cutoff binds, only $\bar{L} / \bar{\phi}$ acres of land will be used.

For some crop locations, the crop can alternatively be produced using an "advanced" or automated technology, where crop production $Y_{A}$ is given by

$$
Y_{A}=\left\{K_{A}^{\frac{\mu-1}{\mu}}+\left[b L^{\frac{\sigma-1}{\sigma}}+(1-b) T^{\frac{\sigma-1}{\sigma}}\right]^{\frac{\sigma}{\sigma-1} \frac{\mu-1}{\mu}}\right\}^{\frac{\mu}{\mu-1}}
$$

where $K_{A}$ is elastically supplied advanced-production capital. This technology is less laborintensive, that is, $b<a$. Its output is a perfect substitute for $Y_{0}$, so let $Y \equiv Y_{0}+Y_{A}$ represent

\footnotetext{
${ }^{12}$ Derived in the Online Appendix.
} 
total output of the crop. In equilibrium, advanced production satisfies $Y_{A}=\left(\frac{r_{A}^{\mu-1}}{r_{A}^{\mu-1}-1}\right)^{\frac{\mu}{\mu-1}}\left[b L^{\frac{\sigma-1}{\sigma}}+\right.$ $\left.(1-b) T^{\frac{\sigma-1}{\sigma}}\right]^{\frac{\sigma}{\sigma-1}}$. It also only meaningful to talk about there being an "alternative technology" if each technology would be employed at least some values of labor/land ratios, which requires that $\left(\frac{1-a}{1-b}\right)^{\sigma}<\left(\frac{r_{A}^{\mu-1}}{r_{A}^{\mu-1}-1} / \frac{r_{0}^{\mu-1}}{r_{0}^{\mu-1}-1}\right)^{\frac{\mu}{\mu-1}(\sigma-1)}<\left(\frac{a}{b}\right)^{\sigma}$. Thus, without loss of generality, we assume that this condition holds whenever an alternative technology exists. ${ }^{13}$

Because it is more land intensive, the advanced technology is more productive only at low levels of labor per unit of land. The advanced technology does not dominate the traditional technology in the sense of producing more from given inputs. The optimal choice of technology depends on highly localized conditions of land price and capital price. ${ }^{14}$ Indeed, farmers may use a combination of technologies in a competitive equilibrium. Let $\left[\phi_{\ell}, \phi_{u}\right]$ be the range of $\bar{L} / \bar{T}$ over which this occurs. That is, there exists an allocation of land $\left(T_{0}, T_{A}\right.$ with $\left.T_{0}+T_{A}=\bar{T}\right)$ and labor $\left(L_{0}, L_{A}\right.$ with $L_{0}+L_{A}=\bar{L}$ ) to each technology such that the marginal products of land and labor are the same in each technology-the cone of diversification. At the upper end, only the older technology is used, and at the lower end only the advanced technology is used. The cone of diversification is defined by the solution $\left[\phi_{\ell}, \phi_{u}\right]$ to

$$
\begin{gathered}
\hat{w}=a\left(\frac{r_{0}^{\mu-1}}{r_{0}^{\mu-1}-1}\right)^{\frac{\mu}{\mu-1}}\left[a+(1-a) \phi_{u}^{-\frac{\sigma-1}{\sigma}}\right]^{\frac{\sigma}{\sigma-1}-1}=b\left(\frac{r_{A}^{\mu-1}}{r_{A}^{\mu-1}-1}\right)^{\frac{\mu}{\mu-1}}\left[b+(1-b) \phi_{\ell}^{-\frac{\sigma-1}{\sigma}}\right]^{\frac{\sigma}{\sigma-1}-1} \\
\hat{r_{T}}=(1-a)\left(\frac{r_{0}^{\mu-1}}{r_{0}^{\mu-1}-1}\right)^{\frac{\mu}{\mu-1}}\left[a \phi_{u}^{\frac{\sigma-1}{\sigma}}+(1-a)\right]^{\frac{\sigma}{\sigma-1}-1}=(1-b)\left(\frac{r_{A}^{\mu-1}}{r_{A}^{\mu-1}-1}\right)^{\frac{\mu}{\mu-1}}\left[b \phi_{\ell}^{\frac{\sigma-1}{\sigma}}+(1-b)\right]^{\frac{\sigma}{\sigma-1}-1},
\end{gathered}
$$

where $\hat{w}$ and $\hat{r_{T}}$ are the fixed wage, and land rental rates, respectively, inside the cone. Dividing the first by the second equation reveals that $\phi_{u}=\left(\frac{1-b}{b} \frac{a}{1-a}\right)^{\sigma} \phi_{l}$, and hence that $\phi_{u}>\phi_{l}$, as is

\footnotetext{
${ }^{13}$ Specifically, this is a necessary condition for the cone of diversification to exist. In contrast, if $\left(\frac{1-a}{1-b}\right)^{\sigma}>$ $\left(\frac{r_{A}^{\mu-1}}{r_{A}^{\mu-1}-1} / \frac{r_{0}^{\mu-1}}{r_{0}^{\mu-1}-1}\right)^{\frac{\mu}{\mu-1}(\sigma-1)}$, then the alternative technology would produce less output than the traditional technology at all combinations of inputs (and so would never be used). The alternative technology will also never be used if $\bar{\phi}$ exceeds the labor/land ratio at the upper end of the cone of diversification, $\phi_{u}$, defined below.

${ }^{14}$ Even if capital is frictionlessly mobile, the price of hiring capital could vary from place to place. For example, the efficient use of a particular machine could depend on planting an improved seed variety, the suitability of which could depend on local soil conditions.
} 
required for the existence of a meaningful cone of diversification. Furthermore,

$$
\phi_{l}=\left(\frac{1-b}{b}\right)^{\frac{\sigma}{\sigma-1}}\left[\frac{\left(\frac{r_{A}^{\mu-1}}{r_{A}^{\mu-1}-1} / \frac{r_{0}^{\mu-1}}{r_{0}^{\mu-1}-1}\right)^{\frac{\mu}{\mu-1}(\sigma-1)}-\left(\frac{1-a}{1-b}\right)^{\sigma}}{\left(\frac{a}{b}\right)^{\sigma}-\left(\frac{r_{A}^{\mu-1}}{r_{A}^{\mu-1}-1} / \frac{r_{0}^{\mu-1}}{r_{0}^{\mu-1}-1}\right)^{\frac{\mu}{\mu-1}(\sigma-1)}}\right]^{\frac{\sigma}{\sigma-1}}
$$

Notice that the condition for the cone to exist is equivalent to $\phi_{l}>0$, that is, there are positive land/labor ratios in which each technology is used. The wage inside the cone can also be written as $\hat{w}=b^{\frac{\sigma}{\sigma-1}}\left(\frac{r_{A}^{\mu-1}}{r_{A}^{\mu-1}-1}\right)^{\frac{\mu}{\mu-1}}\left[\frac{\left(\frac{a}{b}\right)^{\sigma}-\left(\frac{1-a}{1-b}\right)^{\sigma}}{\left(\frac{r_{A}^{\mu-1}}{r_{A}^{\mu-1}-1} / \frac{r_{0}^{\mu-1}}{r_{0}^{\mu-1}-1}\right)^{\frac{\mu}{\mu-1}(\sigma-1)}-\left(\frac{1-a}{1-b}\right)^{\sigma}}\right]^{\frac{1}{\sigma-1}}$.

Why are wages invariant to factor supply inside the cone? It is because factor proportions are fixed within each technology. ${ }^{15}$ Regardless of factor supply, if the economy's labor/land ratio is inside the cone, i.e., if $\bar{L} / \bar{T} \in\left[\phi_{\ell}, \phi_{u}\right]$, then the advanced technology will be employed at labor/land ratio $\phi_{\ell}$ and the old technology will be employed at labor/land ratio $\phi_{u}$. In both cases, the marginal product of labor is given by $\hat{w}$, the market wage. To prove this, one needs only to show that there is an allocation of land and labor to each technology at these factor proportions that clears both markets. There is. Define $T_{A}$ and $L_{A}$, respectively, as the land and labor allocated to the advanced, and $T_{0}$ and $L_{0}$ as the land and labor allocated to the old technology. The share of land allocated to advanced and old technologies is given, respectively, by $\frac{T_{A}}{\bar{T}}=\frac{\phi_{u}-\bar{L} / \bar{T}}{\phi_{u}-\phi_{\ell}}$ and $\frac{T_{0}}{\bar{T}}=\frac{\bar{L} / \bar{T}-\phi_{\ell}}{\phi_{u}-\phi_{\ell}}$. Notice that if $\bar{L} / \bar{T} \in\left[\phi_{\ell}, \phi_{u}\right]$, these are both between zero and one and they add up to one. Finally, using the fixed factor ratios in each technology, $L_{A}=\phi_{\ell} T_{A}$ and $L_{0}=\phi_{u} T_{0}$, clears the labor market:

$$
L_{A}+L_{0}=\bar{T}\left(\phi_{\ell} \frac{T_{A}}{\bar{T}}+\phi_{u} \frac{T_{0}}{\bar{T}}\right)=\bar{T}\left(\phi_{\ell} \frac{\phi_{u}-\bar{L} / \bar{T}}{\phi_{u}-\phi_{\ell}}+\phi_{u} \frac{\bar{L} / \bar{T}-\phi_{\ell}}{\phi_{u}-\phi_{\ell}}\right)=\bar{L}
$$

Therefore, wages are constant within the cone of diversification. Figure 1 summarizes the model, juxtaposing the traditional production function (1) and the advanced production function (3). It shows that the existence of a cone of diversification is not dependent on functional form as-

\footnotetext{
${ }^{15}$ This "factor price insensitivity" result is the same as in the traditional two-sector small, open economy interpretation of this model. See Leamer (1995).
} 
sumptions made here. The appendix, for example, shows results with capital and labor in the inner nest instead, making the advanced technology explicitly more capital intensive. It would also be possible to model the advanced technology as more skill-intensive, similar to Beaudry et al. (2010). ${ }^{16}$ Indeed, any pair of production functions with output expansion paths that cross, like in Figure 1, will have a cone of diversification.

The cone of diversification is also not a rare state. Across a range of industries from brewing to railroads, major innovations were used alongside traditional technologies for several decades (Mansfield 1961). It is also typical of major innovations in agriculture; for example, horses existed alongside tractors and power-tillers in U.S. agriculture for half a century (Manuelli and Seshadri 2014).

\subsection{Workforce reduction policy}

We can now explore the impact of a policy change that excludes a portion of the labor force. Let labor consist of bracero workers $B$ and non-bracero workers $N$, such that $\bar{L} \equiv B+N$. (Later we will revisit the assumption that these workers are perfect substitutes.) Without loss of generality, if the alternative technology exists, assume $(B+N) / \bar{T}>\phi_{\ell}$; that is, at least one farm uses the traditional technology. When bracero workers are excluded, the relative change in labor supply is $\% \Delta(\bar{L} / \bar{T})=\frac{N / T-(B+N) / T}{(B+N) / T}=-\frac{B}{L}$. We explore the wage response to bracero exclusion (1) without the adjustment of capital, technology, or output (2) with the adjustment of capital, but not technology or output, and (3) with the adjustment of capital, technology, and output.

Without adjustment of capital, technology, or output. Using the traditional technology, the wage is given by

$$
w=a\left\{\left(\frac{K}{T}\right)^{\frac{\mu-1}{\mu}}+\tilde{L}^{\frac{\sigma}{\sigma-1} \frac{\mu-1}{\mu}}\right\}^{\frac{\mu}{\mu-1}-1} \tilde{L}^{\frac{\sigma}{\sigma-1} \frac{\mu-1}{\mu}-1}\left(\frac{L}{T}\right)^{\frac{-1}{\sigma}}
$$

where $\tilde{L} \equiv a\left(\frac{L}{T}\right)^{\frac{\sigma-1}{\sigma}}+(1-a)$. Thus in the absence of adjustment in capital, technology, or output,

\footnotetext{
${ }^{16}$ Harper (1967) argued that mechanized harvest of tomatoes was not really less labor intensive, but instead less low-skill labor intensive, replacing low- with high-skill labor (e.g. the harvester operator).
} 
exclusion causes the wage to rise:

$$
\frac{\partial \ln w}{\partial(B / L)} \approx-\frac{\partial \ln w}{\partial \ln (L / T)} \approx s_{K} \frac{s_{L}}{s_{L}+s_{T}} \frac{1}{\mu}+\frac{s_{T}}{s_{L}+s_{T}} \frac{1}{\sigma}>0
$$

where $s_{T}, s_{L}, s_{K}$ are the income shares of land (plus materials), labor, and capital, respectively. ${ }^{17}$ Using the parameter estimates of Herrendorf et al. (2015) for postwar U.S. agriculture, the semielasticity (7) would be large, approximately $0.4 .{ }^{18}$ In a typical high-bracero state with $B / L=0.3$, farm wages rise by approximately 12 percent after exclusion.

With adjustment of capital, but not technology or output. Most of the above response arises from the assumption that farms cannot purchase capital. If we allow capital to adjust, but not technology, equation (7) reduces to

$$
\frac{\partial \ln w}{\partial(B / L)} \approx \frac{s_{T}}{s_{L}+s_{T}} \frac{1}{\sigma}>0
$$

Under the same parameter assumptions, the magnitude of the semielasticity (8) is approximately 0.1 , or one quarter as large as without capital adjustment. In a typical high-bracero state farm wages rise by approximately 3 percent after exclusion.

With adjustment of capital, technology, and output. Now suppose that technology can adjust to bracero exclusion. Assume that both the traditional and advanced technologies are in use $\left((B+N) / \bar{T} \in\left[\phi_{\ell}, \phi_{u}\right]\right)$ and remain in use after exclusion $\left(N / \bar{T} \in\left[\phi_{\ell}, \phi_{u}\right]\right)$, or the crop is already at or below the shutdown margin $((B+N) / \bar{T} \leqslant \bar{\phi})$. The model then predicts three effects of exclusion. First, wages do not rise:

$$
\frac{\partial \ln w}{\partial(B / L)}=0
$$

thus the wage remains fixed at $w \equiv \hat{w}$ before and after exclusion. Second, the output share of the automatic harvest technology (or of less labor-intensive crops) rises in pre-exclusion Bracero

\footnotetext{
${ }^{17}$ Expression (7) is dervied in the Online Appendix.

${ }^{18}$ That is, with $\mu, \sigma \equiv 1.6, s_{K} \equiv 0.54, s_{T} \equiv 0.07$, and $s_{L} \equiv 0.39$. Herrendorf et al. (2015) specify the production function differently, imposing that capital and land are perfect substitutes. They estimate the elasticity of substitution between labor and this land-capital aggregate to be 1.6. They also estimate this aggregate's share of output at 0.61 ; separately, they report that land's share of output is around 0.07. A meta-analysis by Espey and Thilmany (2000) finds that the median wage elasticity of labor demand for hired farm workers across all published studies is -0.5 , which would imply even larger wage impacts, though more recent elasticity estimates tend to be larger in magnitude and be more in line with the magnitude of wage impacts predicted by Herrendorf et al. (2015)'s estimates.
} 
share:

$$
\frac{\partial \ln \left(Y_{A} / Y\right)}{\partial(B / L)}>0
$$

Third, the output of the traditional technology, or of labor-intensive crops without an alternative technology, falls:

$$
\frac{\partial Y_{0}}{\partial(B / L)}<0
$$

Intuitively, bracero exclusion does not affect wages within the diversification cone because any fall in the labor-land ratio only raises the fraction of farmers using the advanced technology, without changing the land/labor ratio that is employed in each technology and therefore without changing the marginal product of labor. Firms adopt the technology that emphasizes the factor whose relative supply has risen, without any necessary change in the price of the factor whose relative supply has fallen, as in Acemoğlu (1998). ${ }^{19}$ For crops that lack a feasible advanced technology $\left(L / T \gg \phi_{u}\right)$, output falls and wages rise, but only up to a point where the higher wages make it profitable to decrease production of that crop by switching land use-to an alternative crop, fallow land, or non-farm use. Notice that this model is isomorphic to a $2 \times 2$ small, open economy model in which adjustments to exclusion occurs through shifting production towards less labor-intensive crops. In practice, both types of adjustments can occur, and both reduce potential wage impacts. ${ }^{20}$

In Figure 1, Bracero exclusion represents a leftward movement, which leaves the wage fixed at $\hat{w}$ within the diversification cone $\left[\phi_{\ell}, \phi_{u}\right]$. For a crop that lacks advanced technology for production, the wage can rise, but stops at $\bar{w}>\hat{w}$ where $L / T$ reaches the shutdown margin $\bar{\phi}$.

\subsection{Extensions}

Domestic labor supply. Suppose non-bracero workers are drawn from a population $P$ and supply labor to farms as $\ln \frac{N}{P}=\varepsilon \ln w$, with $\varepsilon>0$. If $\frac{\partial \ln w}{\partial(B / L)}=0$, then excluded bracero workers will not be replaced with domestic (non-bracero) workers. Alternatively if $\frac{\partial \ln w}{\partial(B / L)}>0$, then

\footnotetext{
${ }^{19}$ Indeed, a broad set of directed technical change (e.g., Acemoğlu 2007) and choice-of-technique (e.g., Beaudry and Green 2003, 2005; Caselli and Coleman 2006) models allow for flat or (in the former case) even upward sloping factor demand curves (post-technology adjustment). The present model attempts to capture key features of farm production.

${ }^{20}$ Lafortune et al. (2015) find that in the early twentieth century, farms adjusted to immigration-driven labor supply shocks both by adjusting technology and crop mix. They provide suggestive evidence that the latter was important only on land that was well-suited to multiple kinds of crops.
} 
domestic workers will flow into the farm sector, further reducing the magnitude of the wage response. ${ }^{21}$ However, estimates of the domestic labor supply elasticity to the farm sector tend to be small (Devadoss and Luckstead 2008; Clemens 2017). Devadoss and Luckstead (2008) find that the simulated wage impacts of adding workers are nearly identical over a reasonable range of estimated supply elasticities.

Worker specialization. Now suppose there are two kinds of farm jobs, skilled $(S)$ and unskilled $(U)$, and redefine $L \equiv\left[\alpha_{L} U^{\frac{\rho-1}{\rho}}+\left(1-\alpha_{L}\right) S^{\frac{\rho-1}{\rho}}\right]^{\frac{\rho}{\rho-1}}$. The expression for how average wages respond to a differential change in $L / T$ remains as above, so to determine the impact of the bracero exclusion on average wages in this setup, we need only to update our expression for how it affects $L / T$. Log-differentiating, $d \ln (L / T)=\frac{s_{U}}{s_{L}} d \ln (U / T)+\frac{s_{S}}{s_{L}} d \ln (S / T)$, where $s_{U}$ is the unskilled share of output and $s_{S} \equiv s_{L}-s_{U}$. So regardless of whether the braceros are skilled or unskilled, we can continue to expect $d \ln (L / T)<0$, and thus weakly positive average wage impacts, as before.

The magnitudes may change, however. Consider briefly the specific case in which all braceros (and some non-braceros) are unskilled, so that $d \ln (L / T)=\frac{s_{U}}{s_{L}} d \ln (U / T)=\frac{s_{U}}{s_{L}} B /\left(B+N_{U}\right)$, where $N_{U}$ is the non-bracero unskilled workforce. Also define $N_{S}$ to be the skilled non-braceros workforce, so $N_{U}+N_{S}=N$. In this case, if $\frac{s_{U}}{s_{L}}<\frac{B+N_{U}}{B+N}$, then the average wage impact will be systematically smaller than was described above (and if $\frac{s_{U}}{s_{L}}>\frac{B+N_{U}}{B+N}$, it will be larger).

Furthermore, regardless of skill mix, the change in average wages is not necessarily the same as the change in wages for non-bracero workers. That is instead given by

$$
\frac{N_{U}}{N} \mathrm{~d} \ln w_{U}+\frac{N_{S}}{N} \mathrm{~d} \ln w_{S}=\mathrm{d} \ln w+\left[\frac{N_{S}}{N} \frac{s_{U}}{s_{L}}-\frac{N_{U}}{N} \frac{s_{S}}{s_{L}}\right] \frac{1}{\rho} \mathrm{d} \ln \left(\frac{U}{S}\right)
$$

where $w_{S}, w_{U}$ are skilled and unskilled wages. ${ }^{22}$ The term in brackets can be positive, which is especially likely when braceros are disproportionately unskilled. ${ }^{23}$ In this case $d \ln \left(\frac{U}{S}\right)<0$, so the average wages of non-bracero workers may even fall - rather than rise - after exclusion, an

\footnotetext{
${ }^{21}$ In this case, $\varepsilon$ could be estimated from the relative response of domestic employment, $\frac{\partial \ln N}{\partial(B / L)} / \frac{\partial \ln w}{\partial(B / L)}$.

${ }^{22}$ Expression (12) uses expressions for the change in the average wages of skilled and unskilled workers derived in the Online Appendix.

$23 \frac{N_{S}}{N} \frac{s_{U}}{s_{L}}-\frac{N_{U}}{N} \frac{s_{S}}{s_{L}}>0 \Leftrightarrow \frac{N_{S}}{N_{U}}>\frac{s_{S}}{s_{U}}=\frac{w_{S}\left(N_{S}+B_{S}\right)}{w_{U}\left(N_{U}+B_{U}\right)}=\frac{w_{S} N_{S} / N_{U}+w_{S} B_{S} / N_{U}}{w_{U}\left(1+B_{U} / N_{U}\right)}=\frac{w_{S}}{w_{U}\left(1+B_{U} / N_{U}\right)} \frac{N_{S}}{N_{U}}+\frac{w_{S} B_{S} / N_{U}}{w_{U}\left(1+B_{U} / N_{U}\right)}$, where $B_{U}$ are unskilled braceros and $B_{S}$ are skilled braceros. This holds for sufficiently high $B_{U} / N_{U}$, especially if $B_{S}$ is small. Suppose, for example, that there are no skilled braceros, i.e., $B_{S} \equiv 0$. In that case, a sufficient condition is that $\frac{w_{S}}{w_{U}}<1+\frac{B_{U}}{N_{U}}$.
} 
outcome that is more likely if skilled and unskilled labor are highly complementary ( $\rho$ small) or if we are in one of the cases where the average wage impact is near zero. Furthermore, this would lead to smaller magnitude increase (or even a decrease) in employment responses to the exclusion of braceros (using the model of labor supply above).

\section{Archival data on braceros, farm employment, and farm wages}

A dataset to test the above model did not exist when we began this investigation. No secondary source reported bracero employment by U.S. state for a substantial number of states, even though this information was collected and disseminated at the time in widely available government publications. Collection of these data required in-person visits to study primary print sources at government archives around Washington, DC and at presidential archives in Abilene, Kansas and Independence, Missouri. We also assembled primary data for a novel database of hired agricultural worker wages by state-quarter. Here we describe these new data sources and the regression models we use.

Data on seasonal hired farm workers (foreign and domestic) are monthly stocks of hired workers on farms by state from 1943 to 1973. State coverage is complete after 1953, the period relevant to the empirics below, but there are gaps before that. The information published in government sources over this time period was originally gathered through a monthly farm survey conducted by the Department of Labor's state-level employment service offices using the ES-223 form. The survey was conducted in areas estimated to employ over 500 migrant and/or seasonal farm workers during the enumeration period, typically completed by 20,000-25,000 farmers each month by mail (USDA 1958, 4). The form defined seasonal hired workers as those hired to work on a farm for fewer than 150 consecutive days. Domestic workers encompass three separate, mutually exclusive groups: local (those living within commuting distance); intrastate (those whose permanent residence is elsewhere in the state but who are temporarily residing in the area of employment for the purpose of farm work); and interstate (those whose permanent residence is in a state different from the area of farm employment). It is important to note that the form defined foreign workers as those "who have legally entered the continental United States but who normally reside in a foreign country," specifically indicating that "illegal entrants are not to 
be included" (DOL 1955). Data therefore exclude unauthorized farm workers.

Survey results were reported in the unpublished U.S. Department of Labor series 'In-Season Farm Labor Reports' for collation at the national level (USDA 1986, 17). Due to changes in bureaucratic organization and responsibilities over this time period, the final publication outlet for these data varies. Worker numbers for 1943-1947 and 1954-1973 were compiled from six different Department of Agriculture and Department of Labor publications held in four archival locations. Data was not compiled on a national level for 1948-1953; state-level information for this time period for 15 states was sourced from twelve archival locations and library systems. The Online Appendix reports further detail.

The same survey collected information on farm wage rates on a quarterly basis. Each survey respondent was asked to report average wage rates for hired farm labor in his/her locality on the date of enumeration. Farm wages were reported in the Department of Agriculture publication Farm Labor, available online through Cornell University's Mann Library. We utilize two different wage measures with varying coverage. The first, the hourly composite wage rate, is a weighted average of reported per-hour rates calculated by the Department of Agriculture. These data are available from 1948-1970 with full geographic coverage. As a robustness check, we also use the daily wage without board, which covers more years but omits three states in most years (California, Oregon, and Washington). We report our findings using both wage measures. ${ }^{24}$

We are unable to directly observe the degree of sampling error or respondent bias in these farm surveys. But there is little evidence that these were large. First, the Departments of Agriculture and Labor constructed the samples to be representative of farms in each state. Contemporary criticism of the surveys centered on inconsistent definitions of hired 'workers' and treatment of family labor (Johnson and Nottenburg 1951)-neither of which are an important concern with bracero workers-and did not mention concerns with sampling. Second, the same farms reported both the numbers of hired workers on their own farms and wages "in your locality". If there were

\footnotetext{
${ }^{24}$ Farmers were asked about the going rate for hired farm labor in their locality. Thus if bracero workers were paid less than domestic workers, we would predict a purely compositional effect on the average wage in a locality due to removing braceros, separate from the equilibrium-price effect. Because no contemporary observers claimed that braceros were paid more than domestic workers, and many claimed the opposite (e.g. Galarza 1956), we thus interpret the wage effects we measure-comprising both compositional and price-equilibrium effects-as upper bounds on the pure price-equilibrium effect.
} 
discord between their survey reports of hired Mexican workers and reports from other sources, this would suggest that the sampled farms inadequately covered areas with Mexican workers and could miss any effects on wages those workers might have. But national totals of Mexican workers as reported in the farm surveys accord well with independent reports of bracero volumes departing Mexico, suggesting that the farm surveys exhibit good coverage of the establishments and geographic areas that employed Mexican seasonal labor. ${ }^{25}$ Third, some of the most obvious forms of possible respondent bias would tend to make the subsequent analysis overstate the effects of braceros on labor market conditions. For example, if employers systematically understated the number of Mexican workers they hired, this would tend to bias upward any estimated wage impact of those workers. ${ }^{26}$ Alternatively, if employers systematically reported agricultural wages as those paid only to non-Mexican workers, this would only make the wage reports more useful for the purpose of estimating the effect of Mexican workers on domestic workers.

\section{Results: Labor market adjustment}

The model in Section 2 predicts that even a large negative shock to the foreign labor supply in agriculture could have minimal effects on the domestic labor market, provided that capital, technology, and/or output can adjust. We begin by testing the predicted effects of bracero exclusion on labor market adjustment in this section, and proceed to test other adjustment margins in the following section. We use two regression specifications to estimate the effects of bracero exclusion on various economic outcomes. The first, quasi-experimental specification uses the natural experiment of bracero exclusion to estimate the effects of exclusion. As a robustness check, the second specification describes the observational relationship between bracero stocks and outcomes during the program.

\footnotetext{
${ }^{25}$ The data sources are compared in the Online Appendix.

${ }^{26}$ For instance, if 10,000 workers caused wages to fall by one percent, but the presence of only 5,000 was reported on the surveys, the wage decline per Mexican worker would be estimated as double its true value. In the Online Appendix we present independent corroborating data from the Mexican government suggesting that U.S. farmers did not greatly understate their employment of braceros in the U.S. Department of Agriculture surveys.
} 


\subsection{Quasi-experimental tests}

For each labor-market outcome, the first specification evaluates the effect of bracero exclusion as a quasi-experiment. Treatment is the degree of exposure to exclusion, defined as the fraction of seasonal agricultural labor in the state constituted by braceros at the program's height in the mid1950s. We use the differences-in-differences with continuous treatment specification, following Card (1992) and Acemoğlu et al. (2004), of

$$
y_{s t}=\boldsymbol{\alpha}^{\prime} \boldsymbol{I}_{s}+\boldsymbol{\beta}^{\prime} \boldsymbol{I}_{t}+\gamma\left(I_{t \geqslant 1965} \cdot \bar{\ell}_{s}^{1955}\right)+\varepsilon_{s t},
$$

where $y_{s t}$ is the outcome in state $s$ in year, quarter, or month $t, \boldsymbol{I}_{s}$ is a vector of state fixed effects, $\boldsymbol{I}_{\boldsymbol{t}}$ is a vector of time fixed effects, ${ }^{27} I_{t \geqslant 1965}$ is an indicator for an observation after bracero exclusion, $L_{s t}^{\mathrm{mex}}$ is the stock of Mexican hired seasonal workers, $L_{s t}$ is the stock of hired seasonal workers of any nationality (including domestic), and $\bar{\ell}_{1955}$ is the mean fraction of Mexican workers $\frac{L_{s t}^{\mathrm{mex}}}{L_{s t}}$ in state $s$ across all months of 1955, years before exclusion. The variable $\varepsilon_{s t}$ is an error term, $\boldsymbol{\alpha}$ and $\boldsymbol{\beta}$ are vectors of coefficients to be estimated, and $\gamma$ is the coefficient of interest. Assuming that trends in the outcome would have been similar in the states most affected by exclusion to trends in unaffected states had exclusion not occurred, the estimate $\hat{\gamma}$ captures the effect of exclusion. We compute Liang-Zeger (1986) standard errors, clustered by state. ${ }^{28}$

Wages: Figure 2 illustrates the core result of the paper, informally testing the zero wage-effect condition (9). The upper part, Figure 2a, shows the natural experiment of bracero exclusion. It shows the fraction of hired seasonal farm labor that is Mexican, averaged across states, within three groups of states. The group with high exposure to exclusion (black line) is the six states where braceros made up more than 20 percent of all seasonal agricultural labor in 1955: Arkansas, Arizona, California, New Mexico, South Dakota, and Texas. The group with low exposure to exclusion (gray line) is the states that had some braceros in 1955, but less than 20 percent of seasonal agricultural labor. The group with no exposure to exclusion (dashed line) is the states that had zero braceros in 1955.

\footnotetext{
${ }^{27}$ In annual regressions these are year fixed effects. In quarterly (monthly) regressions they are, in different specifications, either year and quarter (year and month) fixed effects or quarter-by-year (month-by-year) fixed effects.

${ }^{28}$ The Online Appendix presents a reanalysis of the results to follow with the 'treatment' year assumed to be 1962, when the first major restrictions on hiring braceros began, rather than 1965. The results are substantively unchanged.
} 
The lower part, Figure 2b, shows farm wage trends in the same three groups of states. ${ }^{29}$ It shows that pre- and post-exclusion trends in real farm wages are similar in high-exposure states and low-exposure states. It also shows that wages in both of those groups rose more slowly after bracero exclusion than wages in states with no exposure to exclusion. This pattern confirms systematically what was remarked on anecdotally by economists-albeit in contrast to the prevailing narrative-at the time of exclusion: Varden Fuller $(1967,288)$ wrote of California two years afterward, "Higher wage rates are believed to have been both a consequence of the departure of the Braceros and the means by which a greater supply of domestic workers was obtained. Surprisingly, however, in 1965 and 1966 California farm wages rose at virtually the same rate as in the nation at large."

Table 1 shows a linear parametric version of the same result, without classification of states into arbitrary groups, using the differences-in-differences with continuous treatment specification in equation (13). The first two columns use the hourly wage by state-quarter as the outcome; the second two columns use the daily wage without board. ${ }^{30}$ Within each pair, the second regression narrows the window of analysis to five years before and after the termination of the program. All regressions include state and full quarter-by-year fixed effects, and standard errors are clustered by state. The state fixed effects absorb the influence of time-invariant differences between states, such as differences in arable land $T$ in equation (6) or differences in the size of the overall state farm workforce at the time of exclusion. The difference-in-difference is negative-as predicted by equation (12) if braceros are relatively less-skilled than domestic workers-but statistically indistinguishable from zero in all cases.

The last three rows of Table 1 test the wage semielasticity prediction of the model. In all columns we reject at the 1 percent level the predicted wage semielasticity $\frac{\partial \ln w}{\partial(B / L)}$ of 0.4 without adjustment of capital, technology, or output, in equation (7). We likewise reject the predicted wage semielasticity of 0.1 with adjustment of capital but without adjustment of technology or output, in equation (8), at the one percent level for the hourly wage and at the five percent level for the daily wage. The results are therefore compatible with rapid adjustment of capital, technology, and output in equation (9). These conclusions are substantially unaffected by controlling for

\footnotetext{
${ }^{29}$ Hourly wage, constant 1965 US\$ deflated with Consumer Price Index.

${ }^{30}$ The hourly wage has full state coverage but fewer years (1948-1971); the daily wage has more years (1942-1975) but is missing three states (CA, OR, WA) for most years (1951-1962 and 1965-1975).
} 
pre-existing state-specific linear time trends in wages, using the specification of Wolfers (2006) (presented in the Appendix).

All differences-in-differences analysis rests on the Stable Unit Treatment Value Assumption (SUTVA, Rubin 1977). This could be violated in the present case if wages in states without braceros were affected by bracero exclusion from other states. Suppose for example that the presence of braceros kept wages low in Arkansas, but the mere threat of bringing in braceros allowed employers to likewise keep wages low in Vermont, without any braceros present. Exclusion from Arkansas and other states could then in principle affect wages in Vermont. The evidence does not support this possibility to the extent that such a threat would be more credible in states with small numbers of braceros than in states that never had any braceros: no matter which of these two types of states are chosen as the control group, the difference-in-difference estimate is materially unchanged (Figure 2b). SUTVA could also be violated if bracero exclusion caused large numbers of domestic workers to move between states; we will see below that this did not occur.

Employment: We now repeat the above analysis with employment of domestic seasonal farm workers as the outcome. Figure 3 a illustrates the core result. The left panel shows the average bracero stock in the three groups of states over time. Bracero exclusion removed tens of thousands of farm workers from the average high-exposure state. The right panel shows the average number of domestic seasonal farm workers in the same groups of states. The gap between highand low-exposure states is approximately constant before and after exclusion. The gap between high- and no-exposure states narrows during the program and remains approximately constant after exclusion-the opposite of what would be expected if bracero exclusion had crowded more domestic labor into farm work. There appears to be a slight upward deviation from trend in the high-exposure states during 1964-1966, but a similar bump occurs in zero-exposure states. In short, there is no clear sign that the exclusion of Mexican workers in the left panel caused employment of domestic workers in the right panel.

Figure $3 \mathrm{~b}$ decomposes the domestic workforce in Figure 3a into local, intrastate migrant, and interstate migrant farm workers. In all three groups, post-exclusion trends are similar to preexclusion trends. There was a modest, transitory upsurge in the employment of local workers 
in high-exposure states during 1964-1966, but this was accompanied by a similar surge in zeroexposure states.

This null result is confirmed by the corresponding parametric differences-in-differences analysis with continuous treatment, from equation (13), in Table 2. The unit of observation is statemonth. The first two columns use all available data, with the outcome as either total domestic seasonal farm employment or its natural logarithm. The second two columns again restrict the window of analysis to just five years before and after the termination of the program. The coefficient estimates are negative but statistically indistinguishable from zero. The fifth and sixth columns restrict the sample to states with nonzero exposure to bracero exclusion (states that had some braceros in 1955), given that pre-exclusion trends among these states are more similar than pre-exclusion trends in the zero-exposure states (Figure 3a). The coefficient estimates remain negative and statistically insignificant, suggesting that the result is not driven by heterogeneous pre-trends. Furthermore, the coefficient estimates shift but all remain statistically insignificant when the specification is adjusted to control for pre-existing state-specific linear time trends in domestic hired seasonal farm employment (presented in the Appendix). Table 3 then repeats this analysis for each type of domestic worker separately; the difference-in-difference estimate is negative and statistically indistinguishable from zero in all cases. ${ }^{31}$

This finding corroborates contemporary statements of the U.S. Department of Agriculture's Economic Research Service, which wrote two years after exclusion, "Neither the growers nor the State Employment Service were able to recruit a labor force which would take over the jobs formerly performed by the braceros" (Metzler et al. 1967, 5). This result came despite many years of state and federal efforts to actively recruit domestic farm workers, both prior to bracero exclusion and immediately afterward (U.S. Senate 1966; Metzler et al. 1967).

\footnotetext{
${ }^{31}$ In months where the source documents were published but no domestic worker stock is reported for a statemonth, the analysis in Tables 2 and 3 assumes domestic worker stocks to be zero. In subsection A5.4 we present the results under alternative assumptions: truncating missing values from the dataset in the linear specification, or assuming missing values to be zero and including them in the dataset in the nonlinear specification (using the inverse hyperbolic sine transformation rather than the logarithm). The results are qualitatively invariant to these alternative assumptions.
} 


\subsection{Observational robustness checks}

To probe the robustness of these results we present alternative, standard specifications that require fewer assumptions but do not utilize the natural quasi-experiment. For example, we might be concerned that the above tests are misspecified because they do not capture important relationships between bracero stocks and domestic labor-market outcomes prior to exclusion, both linear and nonlinear. The second type of regression specification evaluates the relationship between the outcome and increases or decreases in the stock of braceros during the program, with state and time fixed-effects:

$$
y_{s t}=\boldsymbol{\alpha}^{\prime} \boldsymbol{I}_{s}+\boldsymbol{\beta}^{\prime} \boldsymbol{I}_{t}+\delta \ln L_{s t}^{\mathrm{mex}}+\zeta X_{s t}+\varepsilon_{s t},
$$

where $X_{s t}$ is a time-variant state characteristic that in some regressions is the stock of nonMexican hired seasonal workers, $\ln \left(L_{s t}-L_{s t}^{\mathrm{mex}}\right)$. State fixed-effects capture any time-invariant state characteristics including initial bracero stocks, initial size of the domestic labor force, and initial crop specialization. The time fixed-effects capture any nationwide changes in the outcome during the period. We run both the linear specification in equation (14) and the corresponding semiparametric fixed-effects specification to allow for nonlinearities in the conditional relationship between bracero stocks and the outcome (Baltagi and Li 2002; Libois and Verardi 2013). In the fixed-effects regressions, too, we generally compute Liang-Zeger standard errors clustered by state to account for serially-correlated errors, but in some robustness checks we assume a first-order autoregressive structure of the error term.

Wages: Table 4 runs the fixed-effects specification (14) to test the observational relationship between real farm wages and bracero stocks under program exposure (that is, in state-quarters with nonzero bracero stocks). The outcome in the first two columns is the real hourly composite wage. While the state fixed effect captures the effect all time-invariant omitted confounders on the wage, including the initial size of the farm sector and farm workforce, we could be concerned that the size of the farm workforce does vary substantially over time; for example, state-month specific demand shocks (such as weather shocks) could generate correlation between Mexican worker shocks and wages, but we would expect such demand shocks to be at least partially reflected by demand for non-Mexican labor. Thus the second column controls for the size of 
the non-Mexican seasonal labor force in each state-month. The third and fourth columns repeat these tests with the real daily wage without board as the outcome. Rather than cluster standard errors by state, the fifth and sixth columns impose the assumption of first-order autoregressive errors within states.

Bracero stocks are positively correlated with farm wages throughout, again as predicted by equation (12) if braceros are typically less-skilled than domestic workers. But this correlation is statistically indistinguishable from zero in the most flexible specifications-columns 2 and 4-which allow for a time-varying overall farm workforce and an arbitrary structure of autocorrelated errors. The evidence thus fails to reject prediction (9) of no relationship between wages and declining bracero stocks.

We might be concerned that this linear fixed-effects specification conceals nonlinearities, such as if negative wage effects only set in at high concentrations of braceros. ${ }^{32}$ Figure 4 shows the Baltagi-Li semiparametric fixed-effects version of the parametric regression in Table 4, column 1. There is no evidence of marked nonlinearities in the relationship.

Employment: The fixed-effects regression of equation (14) takes log domestic seasonal farm employment as the outcome. Table 5 shows this regression in column 1. The remaining columns break down the three types of domestic seasonal employment as outcomes. None of the coefficient estimates are negative, and all are statistically distinguishable from zero. Controlling for state and month-by-year fixed effects, there is no evidence of a rise in domestic employment concurrent with declines in bracero employment in state-months with nonzero bracero employment. If anything, these results suggest a fall in domestic farm employment concurrent with falls in bracero stocks during the program, which is compatible with some degree of complementarity between Mexican and domestic labor as in equation (12). Figure 5 shows the semiparametric fixed-effects version of the regression in column 1 of Table 5, which shows no significant tendency for domestic employment to rise with falling bracero stocks even at very high bracero stocks.

\footnotetext{
${ }^{32}$ Braun and Omar Mahmoud (2014) find that postwar German expellees' displacement effects on incumbent workers are highly nonlinear, only setting in at the highest inflow rates.
} 


\subsection{Illegal migration and other labor-market explanations}

Before proceeding, we consider whether the above results are likely to arise from various adjustments within the labor market. The first is the possibility that when the program was terminated, braceros simply became unauthorized workers, or were replaced by unauthorized workers. Prima facie this appears unlikely to explain the lack of measurable increases in domestic wages or employment caused by exclusion, given that during the program-when employers could access Mexican labor without hiring on the black market-there is no negative relationship between bracero stocks and lower domestic wages or employment (Tables 4 and 5). We nevertheless consider more direct evidence below.

Very few Mexican workers overstayed their bracero visas when the program was terminated. This is evident in the statistics of the Mexican government, which conducted all recruitment under the agreements and tracked each bracero's exit from Mexico and reentry into Mexico (González 1974, 141, Cuadro 39). In 1963, for example, 189,528 braceros left Mexico and 188,512 returned the same year (a discrepancy of 1,106, or 0.54 percent). In 1964, the last year of the program, 179,298 braceros left Mexico and 179,535 returned (a discrepancy of 237, or 0.13 percent).

If it were the case that Mexican workers on the black market substituted for braceros in 1965, this would require a very large and immediate jump in new unlawful entries.

There is no evidence of such a jump. Figure 6 compares the total number of bracero visas given each year to the number of Mexican nationals apprehended by the U.S. Border Patrol. Apprehensions barely rose in the several years that followed bracero exclusion. There is no evidence of any stand-down in enforcement effort in the years just before or after 1965 that would allow minimal apprehensions to coincide with massive new illegal flows; Border Patrol staffing did not fall but in fact rose modestly during this period (North and Houstoun 1976, 53). Bibliometric analysis of contemporary newspaper content independently confirms that illegal migration remained very low for several years after bracero exclusion (Massey and Pren 2012, 10). ${ }^{33}$

\footnotetext{
${ }^{33}$ The analysis of Massey and Pren $(2012,10)$ counts in major newspaper content "the number of times undocumented, illegal, or unauthorized migrants or aliens were paired with Mexico or Mexicans and with the words crisis, flood, or invasion each year from 1965 through 2009”. They find that these mentions closely track trends in Border Patrol apprehensions after 1965, remaining very low until sharply rising in the early 1970s.
} 
Other alternative explanations are likewise unsupported by the data: 1) Excluded braceros were not replaced by lawful but non-Mexican foreign workers: stocks of Jamaican, Bahamian, and other non-Mexican foreign seasonal agricultural workers barely rose after bracero exclusion. ${ }^{34}$ 2) It is unlikely that the labor-market effects of bracero exclusion were offest by reduced labor demand due to the loss of local expenditures from bracero earnings, the effect posited by Altonji and Card (1991) and tested by Hong and McLaren (2015), since braceros tended to live in isolated work-camps and spend only a small fraction of their earnings in the United States. 3) There is no evidence that substantial numbers of domestic seasonal farm workers moved between states to offset the loss of bracero labor supply, the effect considered by Card and DiNardo (2000) and Hatton and Tani (2005), given the lack of response by domestic interstate migrants in Tables 3 and 5. This accords with the recent finding of Cadena and Kovak (2016) that domestic workers are far less mobile across U.S. states than Mexican workers. 4) Finally, it is unlikely that policy-generated wage rigidities are responsible for the lack of wage effects in Tables 1 and 4. Hired farm workers were exempt from the federal minimum wage until years after bracero exclusion (Gardner 1972). ${ }^{35}$ And even if there had been a binding minimum wage before and after exclusion, this would leave unexplained the lack of effects on employment.

\section{Results: Technology and production adjustment}

The above results suggest that bracero exclusion signally failed as an active labor market policy intended to cause increases in domestic wages and employment in farm work. Why? At the time of exclusion, as noted above, some economists predicted that its labor-market effects would be nullified by capital-labor substitution and technological adjustment (Jones and Christian 1965, 528; Martin 1966, 1137). These predictions equate to the model's predictions in equations (9)(11), and we can now test them.

Mechanization technology was available for some of the most important crops produced with bracero labor, but not for others. Table 6 shows the principal crops where bracero labor was em-

\footnotetext{
${ }^{34}$ Data presented in the Online Appendix.

${ }^{35}$ The federal minimum wage for farm workers was only effective after 1967 , and only covered about one third of hired domestic farm labor as it exempted all but the largest one percent of U.S. farms. Prior to this only five continential U.S. states had a state-level minimum for farm workers: California, Michigan, New Jersey, North Dakota, and Wisconsin (Koziara 1967). An immaterial exception to the lack of a federal minimum was sugar-beet workers, whose wage was regulated by a crop-specific minimum during the early postwar years (BLS 1946, 197).
} 
ployed. Advanced mechanization technology was available for adoption to produce tomatoes, cotton, and sugar beets. No comparable mechanization technology was then available for production of asparagus, strawberries, lettuce, celery, cucumbers, citrus, or melons (Sanders 1965; Harper 1967). Equation (10) therefore predicts that bracero exclusion would accelerate mechanization in the production of tomatoes, cotton, and sugar beets. In these crops, the decline in production will be offset commensurately with the easy of switching to the advanced technology. And for the other crops, in the absence of substantial wage effects, equation (11) predicts that there will be a fall in production at the shutdown margin $\bar{\phi}$ accompanied by capital-labor substitution under the traditional technology, perhaps accompanied by switching to other, nonmechanized production techniques. In order to be capable of offsetting effects in the seasonal market for labor, adjustment at these other margins must occur rapidly.

\subsection{Tomato mechanization}

At the time of bracero exclusion, no single activity employed more braceros than tomato harvesting. Harvesting machines had been available since the late 1950s, machines that roughly doubled harvest productivity per worker (Harper 1967, 12), but adoption was low for the first several years (Vandermeer 1986, 22). This placed tomato production within the technological diversification cone at the time of exclusion.

Figure 7a shows that bracero exclusion was followed immediately by a dramatic adoption of this existing technology, as predicted by equation (10). It compares bracero stocks in California, where most tomatoes were produced, to the fraction of California tomato production using a mechanical harvester. This corroborates qualitative studies claiming that exclusion caused sudden adoption of the harvester (Martin 1966, 1144; Martín 2001, 313). California is an appropriate state of focus because this mechanization episode mechanization covers the most important bracero crop nationwide, in the most important bracero state nationwide, as well as being the most important state for tomato production. To our knowledge, tomato mechanization time series data exist for only one other state, Ohio, which was essentially unaffected by bracero exclusion. An important falsification exercise is thus to contrast mechanization in Ohio with California. Figure $7 \mathrm{~b}$ does this. There was no leap in tomato harvest mechanization in Ohio that was comparable in timing or magnitude to the leap in California. 


\subsection{Cotton mechanization}

Another crop with coexisting traditional and advanced technologies was cotton. Commercialscale mechanical picking of cotton had been technically feasible since the 1920s. It took two decades to become practically feasible for a substantial number of farmers, after the development of technologies complementary to mechanical picking-including cotton plant varieties with taller and more uniformly opening bolls, chemical for weed control to reduce trash in machinepicked cotton, and gins apt for machine-picked cotton (Fite 1980, 191-5). These were in place by the late 1940s and harvesting of upland cotton entered the cone of diversification, with eight percent mechanical harvesting by 1950, rising to 78 percent by 1964 (USDA 1974, 218).

The literature broadly agrees that the presence of braceros slowed harvest mechanization (Grove 1996) and bracero exclusion accelerated mechanization (Vialet and McClure 1980, 46; Morgan and Gardner 1982, 399; Heinicke and Grove 2008, 288). McBride (1963) details how Labor Secretary James Mitchell's regulatory actions to restrict bracero usage caused cotton farmers to universally adopt mechanical harvesters in the Lower Rio Grande Valley of Texas.

We observe the effect of bracero exclusion on cotton mechanization in Table 7 . The table shows difference-in-difference regressions (13) in the first column, with state-year cotton harvest mechanization as the outcome, and shows in columns 3 and 4 the corresponding fixed-effects regressions (14). The first panel of Figure 8 shows the fixed-effects result graphically. The differencein-difference effect of exclusion is positive, and bracero stocks are negatively correlated with adoption during the program. We note that mechanical harvesting was only part of the technological change induced by bracero exclusion. Other labor-saving changes included pre-harvest technologies such as greater use of herbicides, flame cultivators, and rotary hoes (Martin 1966, 1144).

\subsection{Sugar beet mechanization}

At the time of bracero exclusion, the mechanization transition in sugar beet production was not in harvesting-where mechanization had been near universal since the early 1950s-but in field preparation and maintenance. Sugar beet cultivation requires blocking and thinning (the 
removal of some plants so that the eventually-harvested plants can thrive) as well as weeding, activities traditionally employing intensive field labor. Mechanization of these tasks had been technically feasible for two decades (Mervine and Barmington 1943), but its spread was slow until the concomitant spread of seed varieties that avoided irregular growth and clumping of plants that reduced the efficiency of such machines. At the time of exclusion about 40 percent of U.S. farms had adopted mechanized thinning and weeding (Rogers and Cohen 1963, 11, 22, Table 3), placing the crop near the middle of the diversification cone.

The literature broadly agrees that bracero exclusion created a large new incentive for mechanization (Rasmussen 1967, 35; USDA 1971, 16). The president of the American Society of Sugar Beet Technologists made this plain just before exclusion:

"In agriculture, complete mechanization from planting through harvest has been demonstrated and is practiced in limited areas. The demand for faster progress is being thrust upon us, however, by the imminent loss of a great proportion of the available hand labor through expiration of Public Law 78, commonly referred to as the Bracero Program.... Those who have depended upon availability of Mexican Nationals for thinning and weeding operations must look elsewhere to get this work accomplished. ...Work to bring about the desired full mechanization must be pushed with all speed and in an all-out cooperative effort" (Rorabaugh 1964, 2-3).

We also observe the effect of bracero exclusion on sugar beet mechanization in Table 7. Column 2 shows the difference-in-difference results for state-year adoption of mechanized thinning and weeding in sugar beet production. These are less reliable than the analogous figures for cotton, because data are available for a more limited window of time. ${ }^{36}$ Columns 5 and 6 show the corresponding fixed-effects regressions, shown graphically in the second panel of Figure 8. Just as for cotton, the difference-in-difference is positive and bracero stocks are negatively correlated with adoption.

\subsection{Production adjustment}

Equations (10) and (11) predict that bracero exclusion will cause a decline in production for all crops, a decline that is smaller in magnitude as there are lower barriers to technical advance. The

\footnotetext{
${ }^{36}$ The only state-year data of which we are aware for sugar beet thinning/weeding mechanization cover the period 1960-65, thus including only one post-exclusion year.
} 
model thus predicts only a small adjustment of production in tomatoes and cotton. It predicts a more substantial adjustment of production in sugar beets, where the spread of mechanization was limited by the spread of complementary technologies. And it predicts a large adjustment of production in crops where no feasible mechanization technology existed, so that capital-labor substitution must proceed under the traditional technology. Here we test and find support for all of these.

Crop production data are much more complete than surviving state-year data on mechanization. (Above, tomato mechanization data are available for only two states, sugar beet mechanization data for only four timepoints.) We thus test the model's predictions on production adjustment with the more flexible event-study specification (Jacobson et al. 1993):

$$
y_{s t}=\boldsymbol{\alpha}^{\prime} \boldsymbol{I}_{s}+\boldsymbol{\beta}^{\prime} \boldsymbol{I}_{t \neq 1964}+\gamma^{\prime} \cdot \boldsymbol{I}_{t \neq 1964} \cdot \bar{\ell}_{s}^{1955}+\varepsilon_{s t}
$$

similar to equation (13) but where $\boldsymbol{I}_{\boldsymbol{t} \neq 1964}$ is a vector of year dummies that omits the base-group 1964, and $\gamma$ is a vector of parameters to be estimated $\left(\gamma_{1964} \equiv 0\right)$. The outcome $y_{s t}$ is a stateand crop-specific index of physical production (e.g. pounds), scaled so that the index for each crop in each state equals 100 in 1964. Graphing the coefficient estimates $\hat{\gamma}_{t}$ against time shows how time-trends in crop production differed with the degree of state-level exposure to bracero exclusion.

Figure 9 shows the event-study coefficients from regression (15) for nine of the most important bracero crops. At the top of the figure, we see bracero exclusion followed by relative declines in tomato and cotton production that are modest and short-lived, as the model predicts. Here, frictions on technical advance existed-for example, the new machines were inapt for delicate, fresh-market tomatoes comprising about one fifth of production (Harper 1967, 11)-but were minor. For sugar beets, where adoption of the advanced technology faced greater frictions, the relative decline after exclusion is larger and longer.

Of the remaining six crops, where capital-labor substitution could only proceed under the traditional technology, we observe large and lasting relative declines in production in and after 1965 in five: asparagus, fresh strawberries, lettuce, celery, and pickling cucumbers. Contemporary experts stated qualitatively that exclusion had caused important declines in production of all of 
these crops (Martin 1966, 1141; Hirsch 1966, 2; Secretary of Labor 1966, 16-18). The exception is citrus, where relative production fell after 1962. Certainly bracero exclusion caused limited changes in production techniques for these six crops as well, even if cultivation processes could not be mechanized. For example, bracero exclusion caused lettuce growers to adopt less-selective cutting methods and more mechanized techniques for packing the harvest into shipping-boxes (DOL 1966, 17). Such adjustments appear insufficient to avoid production declines in exposed states relative to unexposed states. Collectively, these results provide empirical support for technical and production adjustment as important mechanisms for the lack of labor-market effects as predicted by equation (9), though they do not rule out other explanations.

\section{Conclusion}

The exclusion of Mexican bracero workers was one of the largest-ever policy experiments to improve the labor market for domestic workers in a targeted sector by reducing the size of the workforce. Five years after bracero exclusion, leading agricultural economist William E. Martin uncharitably assessed the advocates of exclusion in a little-read book chapter. Those who had believed exclusion would help domestic farm workers "were obviously... extremely naïve", he wrote, and the hoped-for effects in the labor market never arrived because "capital was substituted for labor on the farm and increased effort was exerted by the agricultural engineers in providing the farmers these capital alternatives" (Wildermuth and Martin 1969, 203). Exclusion advocates had mocked Martin's view as one that "repeals the law of supply and demand" (Anderson 1961, 361). The present study assembles the data to test Martin's claim for the first time. All of the data we use were available to contemporaries but were never, to our knowledge, compiled or analyzed.

The theory and evidence we discuss here contradicts a long literature claiming, largely without quantitative evidence, that bracero exclusion succeeded as active labor market policy. We find that bracero exclusion failed to raise wages or substantially raise employment for domestic workers in the sector. The theory of endogenous technical change suggests a mechanism for this null result: employers adjusted to foreign-worker exclusion by changing production techniques where that was possible, and changing production levels where it was not, with little change to 
the terms on which they demanded domestic labor.

The theory is supported by the relationship between novel archival data on state-level bracero stocks and data on domestic wages and employment, technological change in agriculture, and crop-specific production adjustment. We can reject the wage semielasticity to workforce reduction that is implied by a model without endogenous technical change, and we corroborate this with direct evidence of technical change causally linked to exclusion. This is the first evidence on endogenous technical change by labor scarcity arising from a natural policy experiment to deliberately reduce the labor supply. Promising paths for future research are to seek other natural experimental settings in which labor scarcity might cause endogenous technical change, as urged by Acemoğlu $(2010,1071)$, and to apply emerging theory and rigorous evaluation methods to other episodes of large changes in real-world immigration restrictions, as urged by Peri (2016, 25).

\section{References}

Acemoğlu, Daron, "Why Do New Technologies Complement Skills? Directed Technical Change and Wage Inequality," Quarterly fournal of Economics, 1998, 113 (4), 1055-1089.

_ , "Directed technical change," Review of Economic Studies, 2002, 69 (4), 781-809.

_ , "Equilibrium bias of technology," Econometrica, 2007, 75 (5), 1371-1409.

_ , "When Does Labor Scarcity Encourage Innovation?,' Journal of Political Economy, 2010, 118 (6), 10371078.

- and David H Autor, "Skills, tasks and technologies: Implications for employment and earnings," in Orley C. Ashenfelter and David Card, eds., Handbook of Labor Economics, Vol. 4B, Amsterdam: Elsevier, 2011, pp. 1043-1171.

_ , _ , and David Lyle, "Women, War, and Wages: The Effect of Female Labor Supply on the Wage Structure at Midcentury," fournal of Political Economy, 2004, 112 (3), 497-551.

Alston, Lee J and Joseph P Ferrie, "The Bracero Program and Wartime Farm Legislation," in "Southern Paternalism and the American Welfare State: Economics, Politics, and Institutions in the South, 18651965," New York: Cambridge Univ Press, 1999, pp. 99-118.

Altonji, J.G. and D. Card, "The effects of immigration on the labor market outcomes of less-skilled natives," in J.M. Abowd and R.F. Freeman, eds., Immigration, Trade and the Labor Market, University of Chicago Press, 1991, pp. 201-234.

Anderson, Henry P., Testimony at: Extension of Mexican Farm Labor Program Hearings before the Subcommittee on Equipment, Supplies, and Manpower of the Committee on Agriculture, House of Representatives, 87th Congress, 1st Session, on H.R. 2010, March 6-17, Washington, DC: U.S. Government 
Printing Office, 1961.

Angrist, J.D. and A.D. Kugler, "Protective or counter-productive? Labour market institutions and the effect of immigration on E.U. natives," Economic fournal, 2003, 113 (488), F302-F331.

Baltagi, Badi H and Dong Li, "Series estimation of partially linear panel data models with fixed effects," Annals of Economics and Finance, 2002, 3 (1), 103-116.

Beaudry, Paul and David Green, "Wages and Employment in the United States and Germany: What Explains the Differences," American Economic Review, 2003, 93 (3), 573-602.

_ and _, "Changes in U.S. Wages, 1976-2000: Ongoing Skill Bias or Major Technological Change?" fournal of Labor Economics, 2005, 23 (3), 609-648.

— , Mark Doms, and Ethan Lewis, "Should the Personal Computer Be considered a Technological Revolution? Evidence from U.S. Metropolitan Areas,” Journal of Political Economy, 2010, 118 (5), 9881036.

Beerli, Andreas and Giovanni Peri, "The Labor Market Effects of Opening the Border: New Evidence from Switzerland," Working Paper 21319, Cambridge, MA: National Bureau of Economic Research 2015.

Beine, Michel, Brian B Burgoon, Mary Crock, Justin Gest, Michael Hiscox, Patrick McGovern, Hillel Rapoport, and Eiko Thielemann, "Measuring immigration policies: Preliminary evidence from IMPALA,” CESifo Economic Studies, 2015, 61 (3-4), 527-559.

Bertoli, Simone and Jesús Fernández-Huertas, "The size of the cliff at the border," Regional Science and Urban Economics, 2015, 51, 1-6.

Bickerton, Maria Elena, "Prospects for a bilateral immigration agreement with Mexico: Lessons from the Bracero Program," Tex. L. Rev., 2000, 79, 895-919.

BLS, “Wartime Wages, Income, and Wage Regulation in Agriculture: Part 2-ï ¡ $i$ Comparative Wages and Wage Regulation," Monthly Labor Review, 1946, 63 (2), 195-204.

Borjas, George J and Kirk B Doran, "Cognitive Mobility: Labor Market Responses to Supply Shocks in the Space of Ideas," Fournal of Labor Economics, 2015, 33 (S1 Part 2), S109-S145.

- and Lawrence F Katz, "The Evolution of the Mexican-Born Workforce in the United States," in George J Borjas, ed., Mexican Immigration to the United States, Chicago: University of Chicago Press, 2007, pp. 13-55.

Braun, Sebastian and Toman Omar Mahmoud, "The employment effects of immigration: evidence from the mass arrival of German expellees in postwar Germany," fournal of Economic History, 2014, 74 (01), 69-108.

Briggs, Vernon M, Foreign Labor Programs as an Alternative to Illegal Immigration into the United States: a Dissenting View Vol. 2, Paper 28, Center for Philosophy and Public Policy. College Park, MD: University of Maryland, 1980.

Cadena, Brian C and Brian K Kovak, "Immigrants equilibrate local labor markets: Evidence from the Great Recession," American Economic Journal: Applied Economics, 2016, 8 (1), 257-290.

Calavita, Kitty, Inside the State: The Bracero Program, immigration, and the INS, New York: Routledge, 1992.

Card, David, "The impact of the Mariel boatlift on the Miami labor market," Industrial \& Labor Relations Review, 1990, 43 (2), 245-257.

_ , "Using regional variation in wages to measure the effects of the federal minimum wage," Industrial \& Labor Relations Review, 1992, 46 (1), 22-37. 
— and John DiNardo, "Do Immigrant Inflows Lead to Native Outflows?, American Economic Review, 2000, 90 (2), 360-367.

Cardoso, Lawrence A., "Mexican Emigration to the United States, 1897-1931: Socio-Economic Patterns", Tucson, AZ: University of Arizona Press, 1980.

Carrington, W.J. and P. de Lima, "The impact of 1970s repatriates from Africa on the Portuguese labor market," Industrial and Labor Relations Review, 1996, 49 (2), 330-347.

Caselli, Francesco and Wilbur John Coleman, "The World Technology Frontier," American Economic Review, 2006, 96 (3), 499-522.

Clark, Victor S., "Mexican Labor in the United States," Bulletin of the Bureau of Labor, 1908, 78 (September), 466-522.

Clemens, Michael A, "The Effect of Occupational Visas on Native Employment: Evidence from Labor Supply to Farm Jobs in the Great Recession," IZA Discussion Paper 10492. Bonn: IZA Institute for the Study of Labor 2017.

Cortes, Kalena E, "Are refugees different from economic immigrants? Some empirical evidence on the heterogeneity of immigrant groups in the United States," Review of Economics and Statistics, 2004, 86 (2), 465-480.

Craig, Richard B, The Bracero Program: Interest Groups and Foreign Policy, Austin: University of Texas Press, 1971.

Crépon, Bruno and Gerard J van den Berg, “Active Labor Market Policies," Annual Review of Economics, 2016, 8 (1), 521-546.

Devadoss, Stephen and Jeff Luckstead, "Contributions of immigrant farmworkers to California vegetable production," fournal of Agricultural and Applied Economics, 2008, 40 (3), 879-894.

DOL, "Part III, Chapter 4800 - Revision of ES-223, In-Season Farm Labor Report," Manual Transmittal Letter No. 414 1955. Dwight D. Eisenhower Presidential Library, Abilene, KS. U.S. President's Commission on Migratory Labor, Box 11, folder "Labor Dept. Committee on Coordination, Samuel Pierce, Chairman".

DOL, "Higher wages attract more California workers to agriculture," Farm Labor Developments, 1966, 1 (3, April), 9-18.

Durand, Jorge, “The Bracero Program (1942-1964): A Critical Appraisal,” Migración y Desarrollo, 2007, 2 (2), 25-40.

_ , Douglas S Massey, and Fernando Charvet, "The changing geography of Mexican immigration to the United States: 1910-1996," Social Science Quarterly, 2000, 81 (1), 1-15.

Espey, Molly and Dawn D Thilmany, "Farm Labor Demand: A Meta-Regression Analysis of Wage Elasticities," Journal of Agricultural and Resource Economics, 2000, 25 (1), 252-266.

Fan, Jianqing and Irene Gijbels, "Variable bandwidth and local linear regression smoothers," Annals of Statistics, 1992, 20 (4), 2008-2036.

Fite, Gilbert C, "Mechanization of cotton production since World War II," Agricultural History, 1980, 54 (1), 190-207.

Foged, Mette and Giovanni Peri, "Immigrants' Effect on Native Workers: New Analysis on Longitudinal Data," American Economic fournal: Applied Economics, 2016, 8 (2), 1-34.

Freier, Luisa Feline, "The Importance of Access Policies in South-South Migration Ecuador's Policy of Open Doors as a Quasi Experiment," Working Paper 103, International Migration Institute, University 
of Oxford 2014.

Friedberg, Rachel M, “The impact of mass migration on the Israeli labor market," Quarterly fournal of Economics, 2001, 116 (4), 1373-1408.

Fuller, Varden, “A new era for farm labor?," Industrial Relations: A fournal of Economy and Society, 1967, $6(3), 285-302$.

Galarza, Ernesto, Strangers in Our Fields, Washington, DC: U.S. Section, Joint United States-Mexico Trade Union Committee, 1956.

_ , Merchants of Labor: The Mexican Bracero Story, Charlotte: McNally \& Loftin, 1964.

Gamio, Manuel, Mexican Immigration to the United States: A Study of Human Migration and Adjustment, Chicago: University of Chicago Press, 1930.

Gandal, Neil, Gordon H Hanson, and Matthew J Slaughter, "Technology, trade, and adjustment to immigration in Israel," European Economic Review, 2004, 48 (2), 403-428.

Gardner, Bruce, "Minimum wages and the farm labor market," American fournal of Agricultural Economics, 1972, 54 (3), 473-476.

Garrett, Glenn E., George G. Higgins, Edward J. Thye, Rufus B. von KleinSmid, and William Mirongoff, Mexican Farm Labor Program: Consultants Report Published as evidence in "Extension of Farm Labor Program", Hearings before a subcommittee of the Committee on Agriculture and Forestry, U.S. Senate, 87th Congress, on S. 1466, S. 1945, and H.R. 2010, 1st session, June 12-13, 1961, pp. 267-325, Washington, DC: U.S. Department of Labor, 1959.

Gastelúm Gaxiola, María de los Angeles, La migración de los trabajadores mexicanos indocumentados a los Estados Unidos, Vol. 6, Colección Posgrado, México, DF: Universidad Nacional Autónoma de México, 1991.

Glitz, Albrecht, "The labor market impact of immigration: A quasi-experiment exploiting immigrant location rules in Germany," fournal of Labor Economics, 2012, 30 (1), 175-213.

González, Libertad and Francesc Ortega, "How do very open economies adjust to large immigration flows? Evidence from Spanish regions," Labour Economics, 2011, 18 (1), 57-70.

González Navarro, Moisés, Población y Sociedad en México (1900-1970), Vol. 2, México, DF: Universidad Nacional Autónoma de México, 1974.

Gosney, Ezra Seymour, "Human Sterilization Today," California and Western Medicine, 1937, 46 (6), 396398.

Gratton, Brian and Emily Merchant, "Immigration, Repatriation, and Deportation: The MexicanOrigin Population in the United States, 1920-1950," International Migration Review, 2013, 47 (4), 944975.

Grove, Wayne A., "The Mexican Farm Labor Program, 1942-1964: Government-Administered Labor Market Insurance for Farmers," Agricultural History, 1996, 70 (2), 302-320.

Hadley, Eleanor M, “A critical analysis of the wetback problem," Law and Contemporary Problems, 1956, 21 (2), 334-357.

Hanlon, W Walker, "Necessity is the mother of invention: Input supplies and Directed Technical Change," Econometrica, 2015, 83 (1), 67-100.

Harper, Robert G., "Mechanization and the Seasonal Farmworker," Farm Labor Developments, 1967, 1 (2, April), 8-20. 
Hatton, Timothy J and Massimiliano Tani, "Immigration and Inter-Regional Mobility in the UK, 19822000," Economic fournal, 2005, 115 (507), F342-F358.

Hawley, Ellis W, “The politics of the Mexican labor issue, 1950-1965," Agricultural History, 1966, 40 (3), 157-176.

Hayami, Yujiro and V. W. Ruttan, "Factor Prices and Technical Change in Agricultural Development: The United States and Japan, 1880-1960," fournal of Political Economy, 1970, 78 (5), 1115-1141.

Heinicke, Craig and Wayne A Grove, "'Machinery Has Completely Taken Over': The Diffusion of the Mechanical Cotton Picker, 1949-1964," Journal of Interdisciplinary History, 2008, 39 (1), 65-96.

Herrendorf, Berthold, Christopher Herrington, and Akos Valentinyi, "Sectoral technology and structural transformation,” American Economic fournal: Macroeconomics, 2015, 7 (4), 104-133.

Hirsch, Hans G, "Effects of change in use of seasonal workers on US-Mexican agricultural trade and balance of payments," Economic Research Service. Washington, DC: US Department of Agriculture 1966.

Holmes, Samuel J, "Perils of the Mexican invasion," The North American Review, 1929, 227 (5), 615-623.

Hong, Gihoon and John McLaren, “Are Immigrants a Shot in the Arm for the Local Economy?," NBER Working Paper 21123. Cambridge, MA: National Bureau of Economic Research 2015.

Hornbeck, Richard and Suresh Naidu, "When the levee breaks: Black migration and economic development in the American South," American Economic Review, 2014, 104 (3), 963-990.

Hunt, J., "The impact of the 1962 repatriates from Algeria on the French labor market," Industrial and Labor Relations Review, 1992, 45 (3), 556-572.

Jacobson, Louis S, Robert LaLonde, and Daniel Sullivan, "Earnings Losses of Displaced Workers," American Economic Review, 1993, 83 (4), 685-709.

Johnson, D Gale and Marilyn Corn Nottenburg, "A Critical Analysis of Farm Employment Estimates," Journal of the American Statistical Association, 1951, 46 (254), 191-205.

Jones, Lamar B and G Randolph Rice, "Agricultural Labor in the Southwest: The Post Bracero Years," Social Science Quarterly, 1980, 61 (1), 86-94.

— and James W Christian, "Some Observations on the Agricultural Labor Market," Industrial and Labor Relations Review, 1965, 18 (4), 522-534.

Kennan, John, "Open Borders in the European Union and Beyond: Migration Flows and Labor Market Implications Preliminary," NBER Working Paper 23048. Cambridge, MA: National Bureau of Economic Research 2017.

Kennedy, John F., "Statement by the President upon signing bill governing recruitment of Mexican agricultural workers, October 4, 1961," in "Public Papers of the Presidents of the United States: John F. Kennedy, 1961,” Washington, DC: Government Printing Office, 1962, p. 639.

Kosack, Edward, "Guest Worker Programs and Human Capital Investment: The Bracero Program in Mexico, 1942-1964,” Working Paper, Dept. of Economics, Xavier University 2016.

Koziara, Karen S., "The Agricultural Minimum Wage: A Preliminary Look," Monthly Labor Review, 1967, 90 (9), 26-29.

Kuhl, Stefan, The Nazi Connection: Eugenics, American racism, and German national socialism, Oxford: Oxford University Press, 2002.

Lafortune, Jeanne, José Tessada, and Carolina González-Velosa, "More hands, more power? Es- 
timating the impact of immigration on output and technology choices using early 20th century US agriculture," Journal of International Economics, 2015, 97 (2), 339-358.

LaLonde, Robert J., Active Labor Market Policies The International Library of Critical Writings in Economics 318, Northampton, MA: Edward Elgar, 2016.

Lawson, Robert A and Saurav Roychoudhury, "Do Travel Visa Requirements impede Tourist Travel?, Fournal of Economics and Finance, 2016, 40 (4), 817-828.

Leamer, Edward E, "The Heckscher-Ohlin Model in Theory and Practice," 1995.

Levine, Linda, "The Effects on US Farm Workers of an Agricultural Guest Worker Program," Washington, DC: Congressional Research Service 2006.

Lewis, Ethan G, "Immigration, skill mix, and capital skill complementarity," Quarterly fournal of Economics, 2011, 126 (2), 1029-1069.

_ , "Immigration and Production Technology," Annual Review of Economics, 2013, 5 (1), 165-191.

Liang, Kung-Yee and Scott L Zeger, "Longitudinal data analysis using generalized linear models," Biometrika, 1986, 73 (1), 13-22.

Libois, François and Vincenzo Verardi, "Semiparametric fixed-effects estimator," Stata fournal, 2013, 13 (2), 329-336.

Mamer, John W, "The Use of Foreign Labor for Seasonal Farm Work in the United States: Issues Involved and Interest Groups in Conflict," Fournal of Farm Economics, 1961, 43 (5), 1204-1210.

Mansfield, Edwin, "Technical Change and the Rate of Imitation," Econometrica, 1961, 29 (4), 741-766.

Manuelli, Rodolfo E and Ananth Seshadri, "Frictionless technology diffusion: The case of tractors," American Economic Review, 2014, 104 (4), 1368-1391.

Martín, Carlos E, “Mechanization And 'Mexicanization': Racializing California's Agricultural Technology," Science as Culture, 2001, 10 (3), 301-326.

Martin, Philip L, "Guest workers: Past and present," in "Migration between Mexico and the United States, Binational Study," Vol. 3: Research Reports and Background Materials, Washington, DC: U.S. Commission on Immigration Reform, 1998, pp. 877-896.

_ and Michael S Teitelbaum, "The Mirage of Mexican Guest Workers," Foreign Affairs, 2001, 80 (6), 117-131.

Martin, William E, "Alien Workers in United States Agriculture: Impacts on Production," fournal of Farm Economics, 1966, 48 (5), 1137-1145.

Massey, Douglas S and Karen A Pren, "Origins of the new Latino underclass," Race and Social Problems, 2012, 4 (1), 5-17.

McBride, John G, The Vanishing Bracero: Valley Revolution, San Antonio, TX: The Naylor Co., 1963.

Mervine, E.M. and R.D. Barmington, Mechanical Thinning of Sugar Beets Bulletin 476, Fort Collins: Colorado Agricultural Experiment Station, Colorado State College, 1943.

Metzler, William H., Ralph A. Loomis, and Nelson L. LeRay, The Farm Labor Situation in Selected States, 1965-66, Washington, DC: Economic Research Service, U.S. Dept. of Agriculture, 1967.

Mitchell, Don, They Saved the Crops: Labor, landscape, and the struggle over industrial farming in Braceroera California, Athens, GA: University of Georgia Press, 2012.

Morgan, Kristi L, "Evaluating guest worker programs in the US: a comparison of the Bracero Program 
and President Bush's proposed immigration reform plan," Berkeley La Raza Law fournal, 2004, 15, 125144.

Morgan, L. C. and B. L. Gardner, "Potential for a U.S. guest-worker program in agriculture: Lessons from the Braceros," in B. R. Chiswick, ed., The Gateway: U.S. Immigration Issues and Policies, Washington, DC: American Enterprise Institute, 1982, pp. 361-411.

Morris, Austin P, “Agricultural Labor and National Labor Legislation,” California Law Review, 1966, 54 (5), 1939-1989.

Norris, Jim, North for the Harvest: Mexican Workers, Growers, and the Sugar Beet Industry, St. Paul: Minnesota Historical Society Press, 2009.

North, David S and Marion F Houstoun, The Characteristics and Role of Illegal Aliens in the US Labor Market: An Exploratory Study Report ETA-DOL-20-1-74-21, Employment and Training Administration, Washington, DC: U.S. Department of Labor, 1976.

Ortega, Francesc and Giovanni Peri, “The effect of income and immigration policies on international migration," Migration Studies, 2013, 1 (1), 47-74.

Peri, Giovanni, "Immigrants, Productivity, and Labor Markets," Journal of Economic Perspectives, 2016, 30 (4), 3-29.

Rasmussen, Wayne D, “Technological Change in Western Sugar Beet Production,” Agricultural History, 1967, $41(1), 31-36$.

Rogers, Lawrence and Irving Cohen, Technological Changes in Sugar Beet Cultivation: Effect on Seasonal Hired Labor Bureau of Employment Security, Washington, DC: U.S. Department of Labor, 1963.

Rorabaugh, Guy, "Presidential Address," Journal of the American Society of Sugar Beet Technologists, 1964, 13 (1), 1-4.

Rubin, Donald B, “Assignment to Treatment Group on the Basis of a Covariate," fournal of Educational and Behavioral statistics, 1977, $2(1), 1-26$.

Salandini, Victor, “The political-economic dynamics of California's farm labor market-a highly specific model of international factor flows," Journal of Behavioral Economics, 1973, 2 (1), 144-246.

Sanders, Grover H., "Mechanization of Farm Operations in 1965," Farm Labor Developments, 1965, 1 (6, October), 13-32.

Scruggs, Otey M, “Texas and the Bracero program, 1942-1947,” Pacific Historical Review, 1963, 32 (3), 251-264.

Secretary of Labor, Year of Transition: Seasonal Farm Labor, Washington, DC: U.S. Department of Labor, 1966.

Smith, Michael M, "Beyond the borderlands: Mexican labor in the Central Plains, 1900-1930," Great Plains Quarterly, 1981, 1 (4), 239-251.

Stern, Alexandra Minna, "Sterilized in the name of public health: race, immigration, and reproductive control in modern California," American fournal of Public Health, 2005, 95 (7), 1128-1138.

_ , Eugenic Nation: Faults and frontiers of better breeding in modern America, 2nd ed., Berkeley, CA: University of California Press, 2015.

Sullivan, Patrick J., “Monsignor George G. Higgins: The Labor Priests' Priest,” U.S. Catholic Historian, 2001, 19 (4), 103-118.

Taylor, Paul Schuster, Mexican Labor in the United States: Migration Statistics IV University of California 
Publications in Economics, Vol. 12, No. 3, pp. 23-50, Berkeley, CA: University of California Press, 1934.

U.S. House of Representatives, How Would Millions of Guest Workers Impact Working Americans and Americans Seeking Employment? Hearing Before the Subcomm. on Immigration, Border Security and Claims of the H. Comm. on the Judiciary, 108th Cong., 2nd session, March 24, Serial No. 78, Washington, DC: U.S. Department of Labor, 2004.

U.S. National Archives, "Department of Agriculture Bureau of Agricultural Economics Organization Authority Record," National Archives Catalog Online.

U.S. Senate, The migratory farm labor problem in the United States Report of the Committee on Labor and Public Welfare, United States Sentate, made by its Subcommittee on Migratory Labor, purusant to S. Res. 188. 89th Congress, 2nd Session. August 30., Report 91-83. Washington, DC: Government Printing Office, 1966.

USDA, “Farm employment drops sharply; wage rates continue to climb," Farm Labor, 1958, 1 (1, January).

_ , Major Statistical Series of the U.S. Department of Agriculture, How They Are Constructed and Used Vol. 7, Farm Population and Employment, Washington, DC: United States Department of Agriculture, 1969.

USDA, Sugar Reports No. 225, February. Agricultural Stabilization and Conservation Service, Washington, DC: United States Department of Agriculture, 1971.

USDA, Statistics on Cotton and Related Data, 1920-73, Washington, DC: United States Department of Agriculture Economic Research Service, 1974.

USDA, Agricultural Labor Data Sources: An Update No. 658, August. Agriculture Handbook, Washington, DC: United States Department of Agriculture Economic Research Service, 1986.

Vandermeer, John H, "Mechanized agriculture and social welfare: The tomato harvester in Ohio," Agriculture and Human Values, 1986, 3 (3), 21-25.

Vialet, Joyce and Barbara McClure, Temporary Worker Programs: Background and Issues, A report prepared at the request of Senator Edward M. Kennedy, chairman, Committee on the Judiciary, United States Senate, for the use of the Select Commission on Immigration and Refugee Policy, Congressional Research Service. Washington, DC: Government Printing Office, 1980.

von KleinSmid, Rufus Bernhard, Eugenics and the State: A paper read before the Cincinnati Academy of Medicine, May 1913, Jeffersonville, IN: Indiana Reformatory Printing Trade School, 1913.

Wildermuth, John R. and William E. Martin, "People and Machines: Labor Implications of Developing Technology," in B.F. Cargill and G.E. Rossmiller, eds., Fruit and Vegetable Harvest Mechanization: Manpower Implications, East Lansing, MI: Rural Manpower Center, Michigan State University, 1969, pp. 197-207.

Williams, Lee G., "Recent Legislation Affecting the Mexican Labor Program," Employment Security Review, 1962, $29(1), 29-31$.

Wise, Donald E., "The effect of the bracero on agricultural production in California," Economic Inquiry, 1974, 12 (4), 547-558.

Wolfers, Justin, "Did unilateral divorce laws raise divorce rates? A reconciliation and new results," American Economic Review, 2006, 96 (5), 1802-1820. 
Figure 1: The diversification cone $\left[\phi_{\ell}, \phi_{u}\right]$ and shutdown margin $\bar{\phi}$

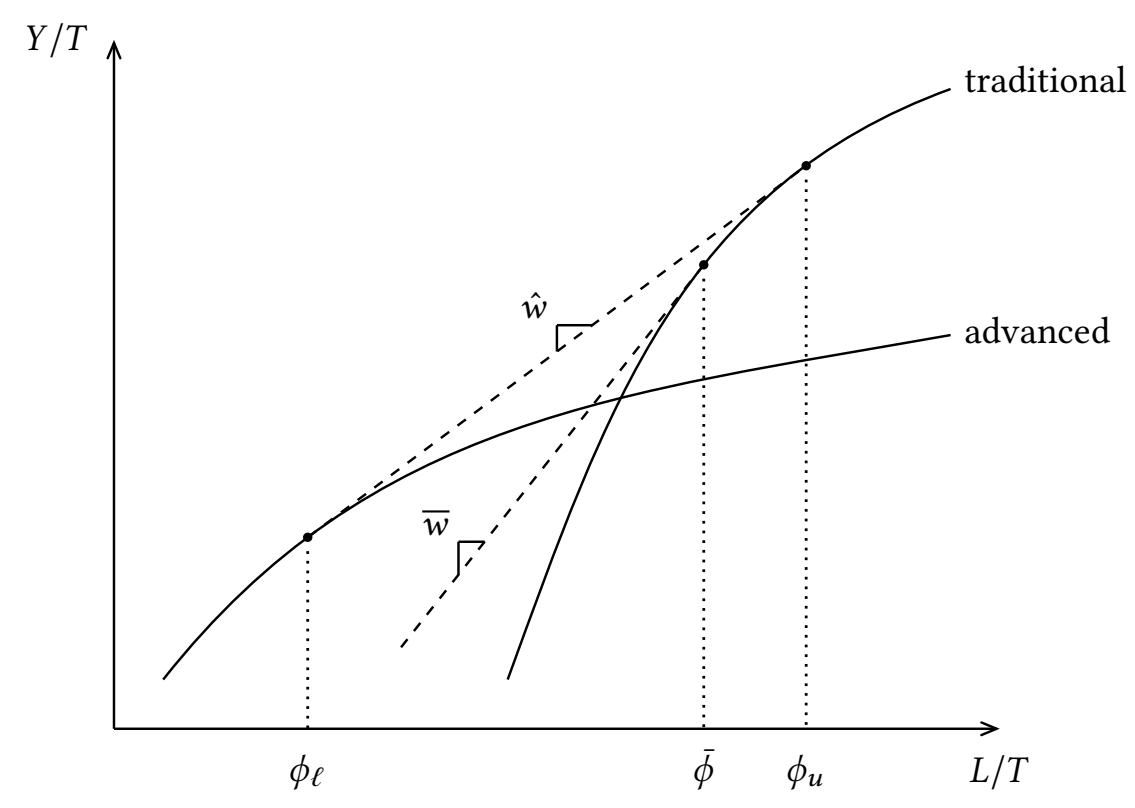


Figure 2: Illustration of natural quasi-experiment and core result, states grouped by exposure

(a) Average Mexican fraction of hired seasonal farm workers, 1954-1972

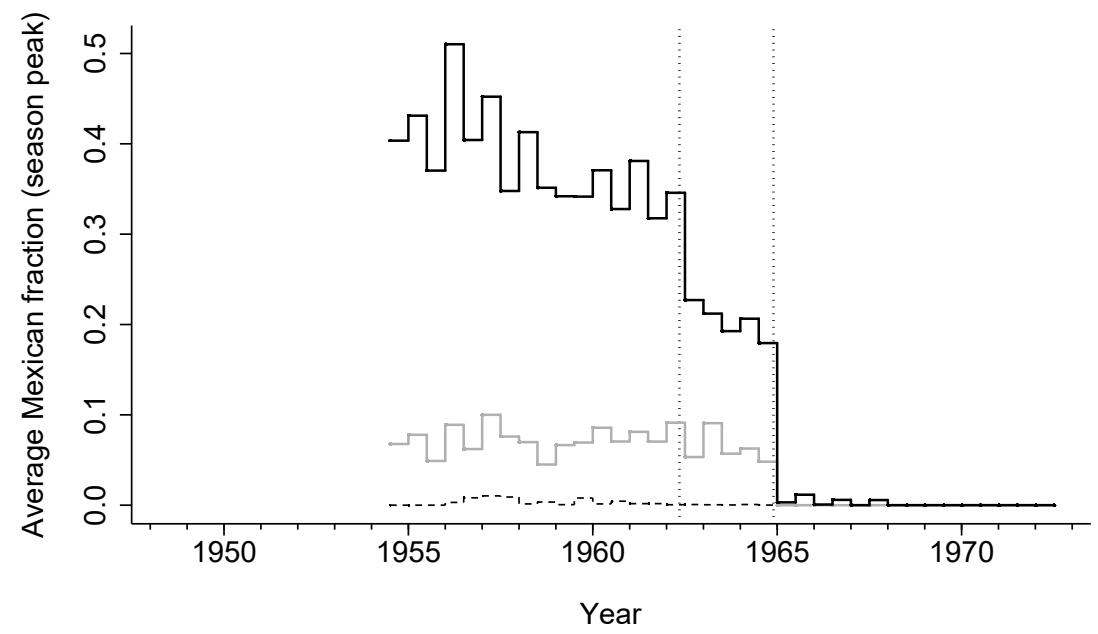

(b) Average real farm wages, 1948-1971

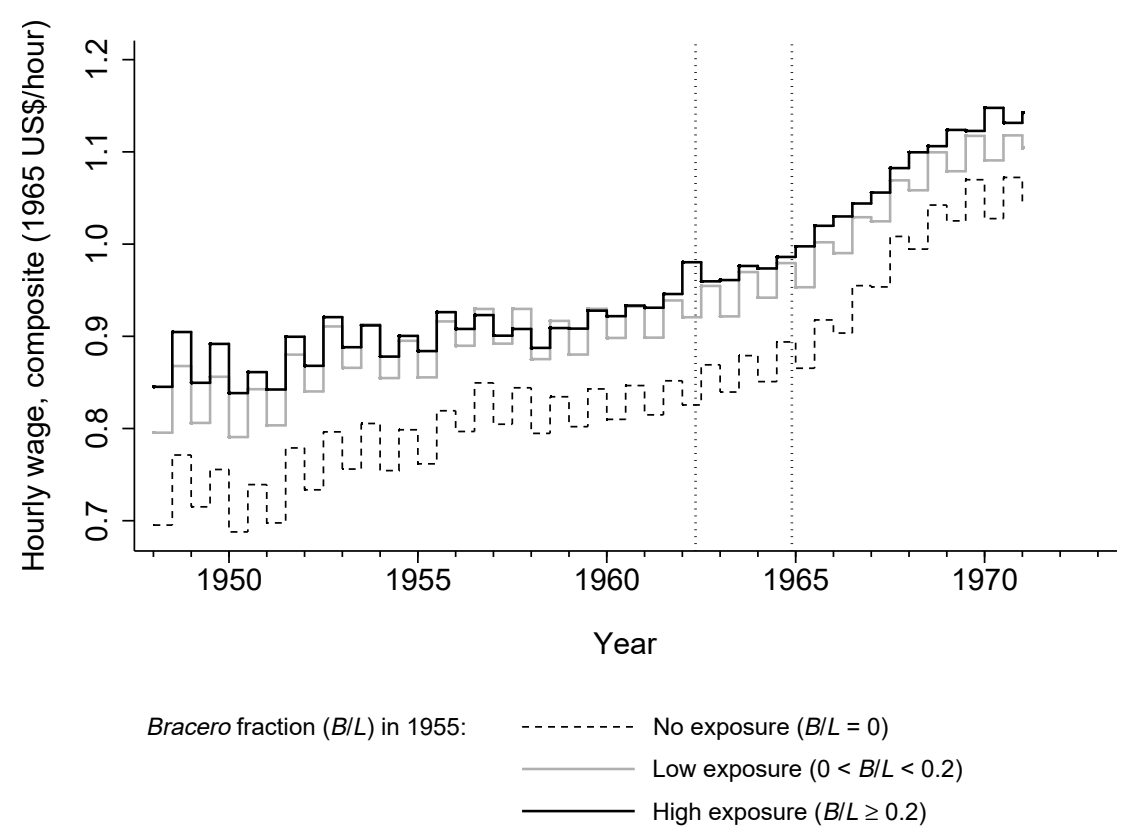

Average across states, by season, of each outcome. Each year is split into two seasons: the first half of each year is the early season (February to July), the second half of each year is the late season (August to November). The outcomes are (a) peak Mexican fraction of hired seasonal farm workers during any month in the season, and (b) average real hourly wage in the two quarters that comprise that season. Real wage adjusted by national Consumer Price Index. Vertical dotted lines show the beginning of government efforts toward bracero exclusion (March 1962) and near-complete exclusion at the termination of the program (December 1964). Highexposure group is AZ, CA, NE, NM, SD, TX. Low-exposure group is AR, CO, GA, ID, IL, IN, MI, MN, MO, MT, NV, OR, TN, UT, WA, WI, WY. No-exposure group is AL, CT, DE, FL, IA, KS, KY, LA, MA, MD, ME, MS, NC, ND, NJ, NY, OH, OK, PA, SC, VA, VT, WV. 
Table 1: Effects of bracero exclusion on real wages: Differences-in-differences with continuous treatment, quarterly

\begin{tabular}{|c|c|c|c|c|}
\hline \multirow[b]{3}{*}{$I_{t \geqslant 1965} \cdot \bar{\ell}_{s}^{1955}$} & \multicolumn{2}{|c|}{ Wage, all years } & \multicolumn{2}{|c|}{ Wage, 1960-1970 } \\
\hline & $\begin{array}{l}\text { Hourly } \\
\text { composite }\end{array}$ & $\begin{array}{c}\text { Daily } \\
\text { w/o board }\end{array}$ & $\begin{array}{l}\text { Hourly } \\
\text { composite }\end{array}$ & $\begin{array}{c}\text { Daily } \\
\text { w/o board }\end{array}$ \\
\hline & $\begin{array}{c}-0.0356 \\
(0.0426)\end{array}$ & $\begin{array}{c}-0.385 \\
(0.495)\end{array}$ & $\begin{array}{c}-0.0401 \\
(0.0315)\end{array}$ & $\begin{array}{r}-0.0247 \\
(0.309)\end{array}$ \\
\hline \multicolumn{5}{|l|}{ Fixed effects: } \\
\hline State & Yes & Yes & Yes & Yes \\
\hline Quarter-by-year & Yes & Yes & Yes & Yes \\
\hline Std. err. clustered by & State & State & State & State \\
\hline$N$ & 4324 & 5813 & 2024 & 1901 \\
\hline adj. $R^{2}$ & 0.773 & 0.835 & 0.733 & 0.758 \\
\hline Clusters & 46 & 46 & 46 & 46 \\
\hline Semielasticity $\frac{\partial \ln w}{\partial(B / L)}$ & $\begin{array}{c}-0.0831 \\
(0.0654)\end{array}$ & $\begin{array}{l}-0.110 \\
(0.0916)\end{array}$ & $\begin{array}{c}-0.0750 \\
(0.0507)\end{array}$ & $\begin{array}{c}-0.0410 \\
(0.0541)\end{array}$ \\
\hline$p$-val. of $\chi^{2}$ test: $\frac{\partial \ln w}{\partial(B / L)}=0.1$ & {$[0.0075]$} & {$[0.0263]$} & [0.0012] & [0.0124] \\
\hline
\end{tabular}

'Treatment' is the degree of exposure to exclusion. Observations are state-quarters. Standard errors clustered by state in parentheses. $\bar{\ell}_{1955}$ is average fraction of Mexicans among the state's total hired seasonal workers across the months of 1955 . Wages in constant 1965 US \$ deflated by CPI. Hourly wage has full state coverage but fewer years (1948-1971); daily wage has more years (1942-1975) but missing three states (CA, OR, WA). Farm worker stocks missing in original sources for 1955 in Rhode Island and New Hampshire. Semielasticity is the coefficient on $I_{t \geqslant 1965} \cdot \bar{\ell}_{s}^{1955}$ in an otherwise identical regression with $\ln$ wage as the dependent variable. 
Figure 3: Number of seasonal farm workers employed, state averages grouped by exposure

(a) Mexican vs. domestic
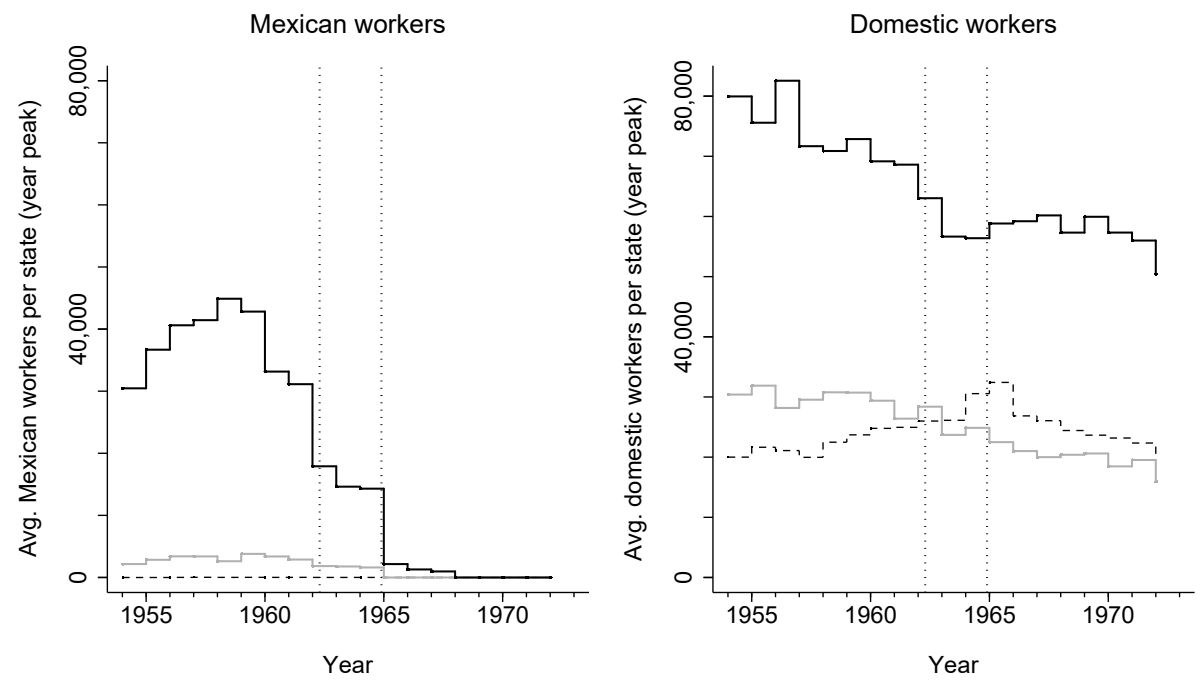

(b) Domestic, by type
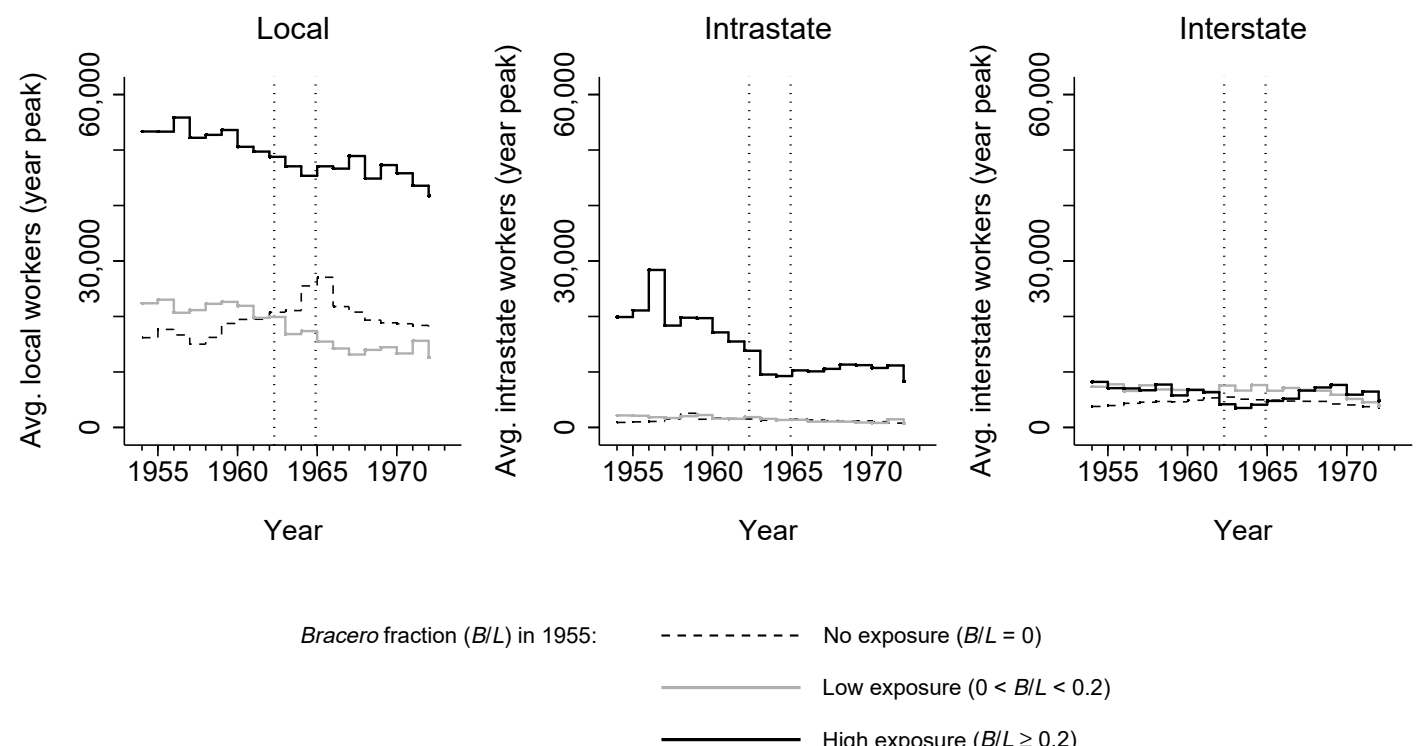

Average across states, in each year, of peak-month worker stock of each type. Vertical dotted lines show the beginning of major government efforts toward bracero exclusion (March 1962) and near-complete exclusion at the termination of the program (December 1964). 
Table 2: Effects of bracero exclusion on domestic seasonal agricultural employment: Differencesin-differences with continuous treatment, monthly

\begin{tabular}{|c|c|c|c|c|c|c|}
\hline \multirow{2}{*}{$\begin{array}{c}\text { Dep. var: Domestic } \\
\text { seasonal workers } \\
\text { Specification: }\end{array}$} & \multicolumn{2}{|c|}{$\begin{array}{l}\text { All states, } \\
\text { all years }\end{array}$} & \multicolumn{2}{|c|}{$\begin{array}{c}\text { All states, } \\
\text { years } 1960-1970\end{array}$} & \multicolumn{2}{|c|}{$\begin{array}{l}\text { Exposed states } \\
\text { only, all years }\end{array}$} \\
\hline & linear & $\ln$ & linear & $\ln$ & linear & $\ln$ \\
\hline$I_{t \geqslant 1965} \cdot \bar{\ell}_{s}^{1955}$ & $\begin{array}{l}-12801.7 \\
(13225.3)\end{array}$ & $\begin{array}{l}-0.419 \\
(0.553)\end{array}$ & $\begin{array}{l}-1648.3 \\
(8147.6)\end{array}$ & $\begin{array}{c}-0.0614 \\
(0.482)\end{array}$ & $\begin{array}{l}-4079.8 \\
(11300.6)\end{array}$ & $\begin{array}{l}-0.180 \\
(0.624)\end{array}$ \\
\hline \multicolumn{7}{|l|}{ Fixed effects: } \\
\hline State & Yes & Yes & Yes & Yes & Yes & Yes \\
\hline Month-by-year & Yes & Yes & Yes & Yes & Yes & Yes \\
\hline Std. err. clust. by & State & State & State & State & State & State \\
\hline$N$ & 9476 & 6369 & 5520 & 3707 & 4738 & 3174 \\
\hline adj. $R^{2}$ & 0.195 & 0.352 & 0.217 & 0.403 & 0.237 & 0.367 \\
\hline Clusters & 46 & 46 & 46 & 46 & 23 & 23 \\
\hline
\end{tabular}

'Treatment' is the degree of exposure to exclusion. Observations are state-months. Standard errors clustered by state in parentheses. $\bar{\ell}_{1955}$ is average fraction of Mexicans among the state's total hired seasonal workers across the months of $1955 .{ }^{*} p<0.10$, ${ }^{* *}$ $p<0.05,{ }^{* * *} p<0.01$. Covers only January 1954 to July 1973, as in original sources. Farm worker stocks missing in original sources for 1955 in Rhode Island and New Hampshire. If no workers reported for state-month in a month when source report was issued, assume zero. 'Exposed states' means states with nonzero bracero stocks in 1955 (i.e., only the 'high' and 'low' groups in the figures).

Table 3: Effects of bracero exclusion on the three types of domestic seasonal agricultural employment: Differences-in-differences with continuous treatment, monthly

\begin{tabular}{|c|c|c|c|c|c|c|}
\hline \multirow{2}{*}{$\begin{array}{r}\text { Specification: } \\
\text { Dep. var.: }\end{array}$} & \multicolumn{3}{|c|}{ linear } & \multicolumn{3}{|c|}{$\ln$} \\
\hline & $\begin{array}{c}\text { Local } \\
\text { domestic }\end{array}$ & $\begin{array}{l}\text { Intrastate } \\
\text { domestic }\end{array}$ & $\begin{array}{l}\text { Interstate } \\
\text { domestic }\end{array}$ & $\begin{array}{c}\text { Local } \\
\text { domestic }\end{array}$ & $\begin{array}{l}\text { Intrastate } \\
\text { domestic }\end{array}$ & $\begin{array}{l}\text { Interstate } \\
\text { domestic }\end{array}$ \\
\hline$I_{t \geqslant 1965} \cdot \bar{\ell}_{s}^{-1955}$ & $\begin{array}{c}-6929.2 \\
(7327.0)\end{array}$ & $\begin{array}{c}-9851.2 \\
(9637.5)\end{array}$ & $\begin{array}{c}-233.2 \\
(1160.8)\end{array}$ & $\begin{array}{c}-0.638 \\
(0.780)\end{array}$ & $\begin{array}{r}-1.140^{*} \\
(0.652)\end{array}$ & $\begin{array}{c}-0.559 \\
(0.524)\end{array}$ \\
\hline$N$ & 9476 & 6366 & 6367 & 6611 & 4675 & 5720 \\
\hline adj. $R^{2}$ & 0.166 & 0.066 & 0.117 & 0.297 & 0.198 & 0.242 \\
\hline Clusters & 46 & 46 & 46 & 46 & 46 & 46 \\
\hline
\end{tabular}

'Treatment' is the degree of exposure to exclusion. Observations are state-months. Standard errors clustered by state in parentheses. $\bar{\ell}_{1955}$ is average fraction of Mexicans among the state's total hired seasonal workers across the months of 1955 . ${ }^{*} p<0.10$, ** $p<0.05,{ }^{* * *} p<0.01$. Covers only January 1954 to July 1973, as in original sources. Farm worker stocks missing in original sources for 1955 in Rhode Island and New Hampshire. If no workers reported for state-month in a month when source report was issued, assume zero. 
Table 4: Parametric fixed-effects regression of real wage on bracero stock, quarterly, under nonzero bracero stocks

\begin{tabular}{|c|c|c|c|c|c|c|}
\hline \multirow[t]{3}{*}{ Specification: } & \multicolumn{4}{|c|}{ Fixed effects } & \multicolumn{2}{|c|}{ Fixed effects, $A R(1)$ err. } \\
\hline & \multicolumn{2}{|c|}{$\begin{array}{c}\text { Real wage } \\
\text { (Hourly composite) }\end{array}$} & \multicolumn{2}{|c|}{$\begin{array}{c}\text { Real wage } \\
\text { (Daily w/o board) }\end{array}$} & $\begin{array}{l}\text { Real wage } \\
\text { (Hourly } \\
\text { composite) }\end{array}$ & $\begin{array}{l}\text { Real wage } \\
\text { (Daily w/o } \\
\text { board) }\end{array}$ \\
\hline & $\begin{array}{r}0.00855^{*} \\
(0.00452)\end{array}$ & $\begin{array}{c}0.00482 \\
(0.00512)\end{array}$ & $\begin{array}{l}0.0681^{* * *} \\
(0.0236)\end{array}$ & $\begin{array}{c}0.0189 \\
(0.0254)\end{array}$ & $\begin{array}{l}0.0102^{* *} \\
(0.00393)\end{array}$ & $\begin{array}{l}0.0558^{* * *} \\
(0.0184)\end{array}$ \\
\hline $\ln \left(L-L^{\mathrm{mex}}\right)$ & & $\begin{array}{c}0.0109 \\
(0.0133)\end{array}$ & & $\begin{array}{c}0.0318 \\
(0.0415)\end{array}$ & $\begin{array}{c}0.0532^{* * *} \\
(0.00517)\end{array}$ & $\begin{array}{l}0.0810^{\text {*** }} \\
(0.0307)\end{array}$ \\
\hline $\begin{array}{l}\text { Fixed effects: } \\
\text { State } \\
\text { Quarter-by-year }\end{array}$ & $\begin{array}{l}\text { Yes } \\
\text { Yes }\end{array}$ & $\begin{array}{l}\text { Yes } \\
\text { Yes }\end{array}$ & $\begin{array}{l}\text { Yes } \\
\text { Yes }\end{array}$ & $\begin{array}{l}\text { Yes } \\
\text { Yes }\end{array}$ & $\begin{array}{l}\text { Yes } \\
\text { Yes }\end{array}$ & $\begin{array}{l}\text { Yes } \\
\text { Yes }\end{array}$ \\
\hline $\begin{array}{l}\text { Std. err. clustered by } \\
\text { Assumed error struc. }\end{array}$ & $\begin{array}{c}\text { State } \\
-\end{array}$ & $\begin{array}{c}\text { State } \\
-\end{array}$ & $\begin{array}{c}\text { State } \\
-\end{array}$ & $\begin{array}{c}\text { State } \\
-\end{array}$ & $\overline{\operatorname{AR}(1)}$ & $\overline{\operatorname{AR}(1)}$ \\
\hline $\begin{array}{l}N \\
\text { adj. } R^{2} \\
\text { Clusters }\end{array}$ & $\begin{array}{l}499 \\
0.571 \\
30\end{array}$ & $\begin{array}{l}429 \\
0.498 \\
29\end{array}$ & $\begin{array}{l}654 \\
0.492 \\
29\end{array}$ & $\begin{array}{l}377 \\
0.619 \\
26\end{array}$ & $\begin{array}{l}400 \\
0.686 \\
-\end{array}$ & $\begin{array}{l}351 \\
0.903 \\
-\end{array}$ \\
\hline
\end{tabular}

Observations are state-quarters. Standard errors clustered by state in parentheses. $L^{\text {mex }}$ is stock of Mexican hired seasonal agricultural workers at the beginning of each quarter, by state; $L$ is total stock of hired seasonal agricultural workers of any nationality (domestic and foreign), by state. ${ }^{*} p<0.10,{ }^{* *} p<0.05,{ }^{* * *} p<0.01$. The hourly wage has full state coverage but fewer years (1948-1971); the daily wage has more years (1942-1975) but is missing three states (CA, OR, WA).

Table 5: Parametric fixed-effects regression of domestic farm employment on bracero stock, by state-month

\begin{tabular}{lcccc}
\hline & \multicolumn{3}{c}{ ln Employment of domestic seasonal farm workers } \\
\cline { 2 - 5 } & $\begin{array}{c}\text { Total } \\
\text { domestic }\end{array}$ & $\begin{array}{c}\text { Local } \\
\text { domestic }\end{array}$ & $\begin{array}{c}\text { Intrastate } \\
\text { domestic }\end{array}$ & $\begin{array}{c}\text { Interstate } \\
\text { domestic }\end{array}$ \\
$\ln \left(L^{\text {mex }}\right)$ & $0.242^{* * *}$ & $0.195^{* * *}$ & $0.238^{* * *}$ & $0.401^{* * *}$ \\
& $(0.0380)$ & $(0.0398)$ & $(0.0521)$ & $(0.0512)$ \\
\hline Fixed effects: & & & & Yes \\
$\quad$ State & Yes & Yes & Yes & Yes \\
$\quad$ Month-by-year & Yes & Yes & Yes & State \\
Std. err. clustered by & State & State & State & 1263 \\
\hline$N$ & 1377 & 1358 & 1185 & 31 \\
\hline Clusters & 31 & 31 & 29 &
\end{tabular}

Observations are state-months. Standard errors clustered by state in parentheses. $L^{\text {mex }}$ is stock of Mexican hired seasonal agricultural workers in each month, by state. "Total domestic" is the sum of "local domestic", "intrastate domestic", and "interstate domestic". ${ }^{*} p<0.10,{ }^{* *} p<0.05,{ }^{* * *} p<0.01$ 
Figure 4: Baltagi-Li semiparametric fixed-effects regression of real hourly wage on bracero stock, quarterly, under nonzero bracero stocks (1942-1966)

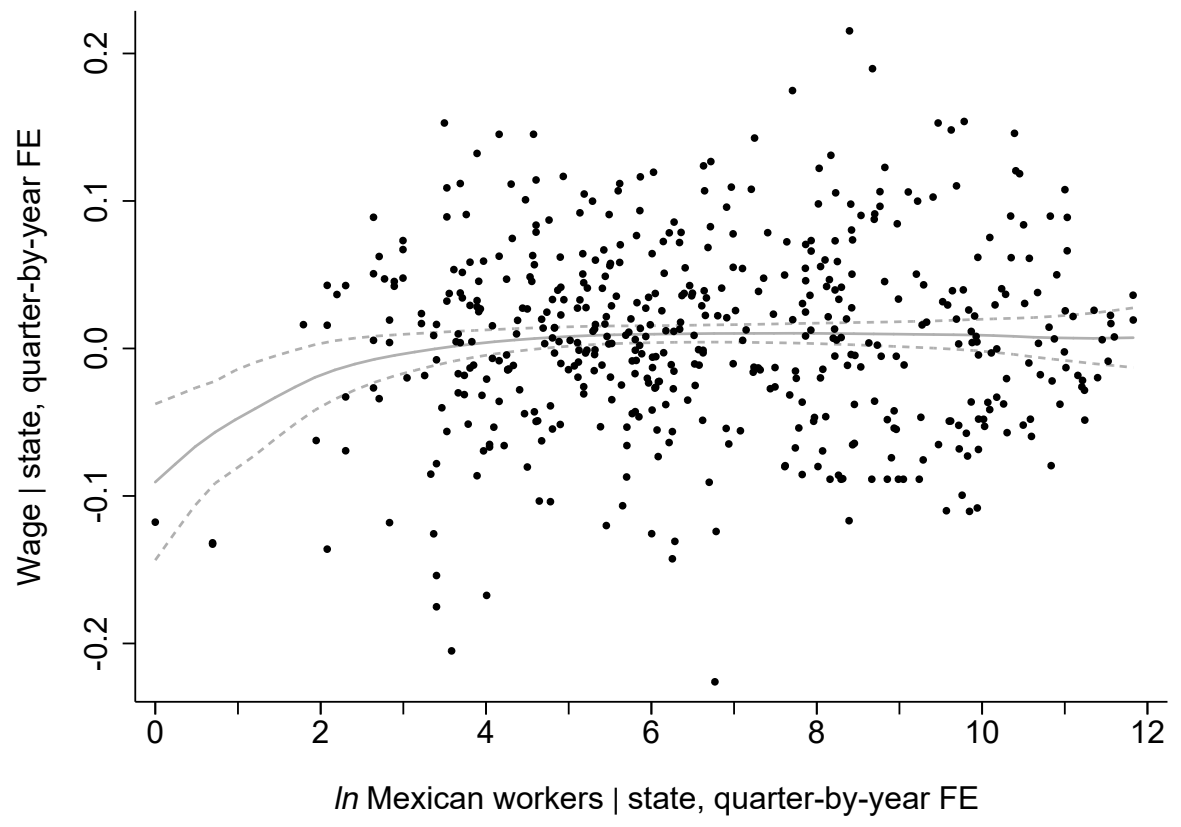

Baltagi and Li (2002) regression of quarterly state-average wage on ln bracero stock, with state and quarterby-year fixed effects, local linear with Epanechnikov kernel, bandwidth 2 log-points. Dashed lines show 95\% confidence interval. Real wage is hourly wage deflated to 1965 US $\$$ by Consumer Price Index.

Table 6: U.S. employment of Mexican hired seasonal labor by crop, 1964

\begin{tabular}{|c|c|c|c|c|}
\hline \multirow[b]{2}{*}{ Crop } & \multicolumn{2}{|c|}{ Thousand man-months } & \multirow[b]{2}{*}{$\begin{array}{c}\text { Foreign/ } \\
\text { total, } \%\end{array}$} & \multirow[b]{2}{*}{$\begin{array}{c}\% \text { of all } \\
\text { foreign labor }\end{array}$} \\
\hline & $\begin{array}{l}\text { Total } \\
\text { labor }\end{array}$ & $\begin{array}{l}\text { Foreign } \\
\text { labor }\end{array}$ & & \\
\hline Tomatoes & 345.1 & 90.5 & 26.2 & 14.3 \\
\hline Citrus & 319.8 & 69.1 & 21.6 & 10.9 \\
\hline Lettuce & 122.5 & 67.8 & 55.3 & 10.7 \\
\hline Cotton & 1769.4 & 65.2 & 3.7 & 10.3 \\
\hline Strawberries & 308.5 & 42.5 & 13.8 & 6.7 \\
\hline Sugar beets & 160.6 & 31.9 & 19.9 & 5.0 \\
\hline Cucumbers & 105.5 & 28.9 & 27.4 & 4.6 \\
\hline Melons & 64.7 & 18.4 & 28.4 & 2.9 \\
\hline Celery & 44.4 & 14.4 & 32.4 & 2.3 \\
\hline Asparagus & 60.5 & 11.5 & 19.0 & 1.8 \\
\hline
\end{tabular}

From Hirsch $(1966,6)$. For these crops the 'foreign labor' employed was almost entirely Mexican labor. Two other crops had a comparable intensity of foreign labor-tobacco and sugarcane harvesting-but these employed primarily non-Mexican hired seasonal workers. 
Figure 5: Baltagi-Li semiparametric fixed-effects regression of domestic seasonal farm employment on bracero stock, by state-month

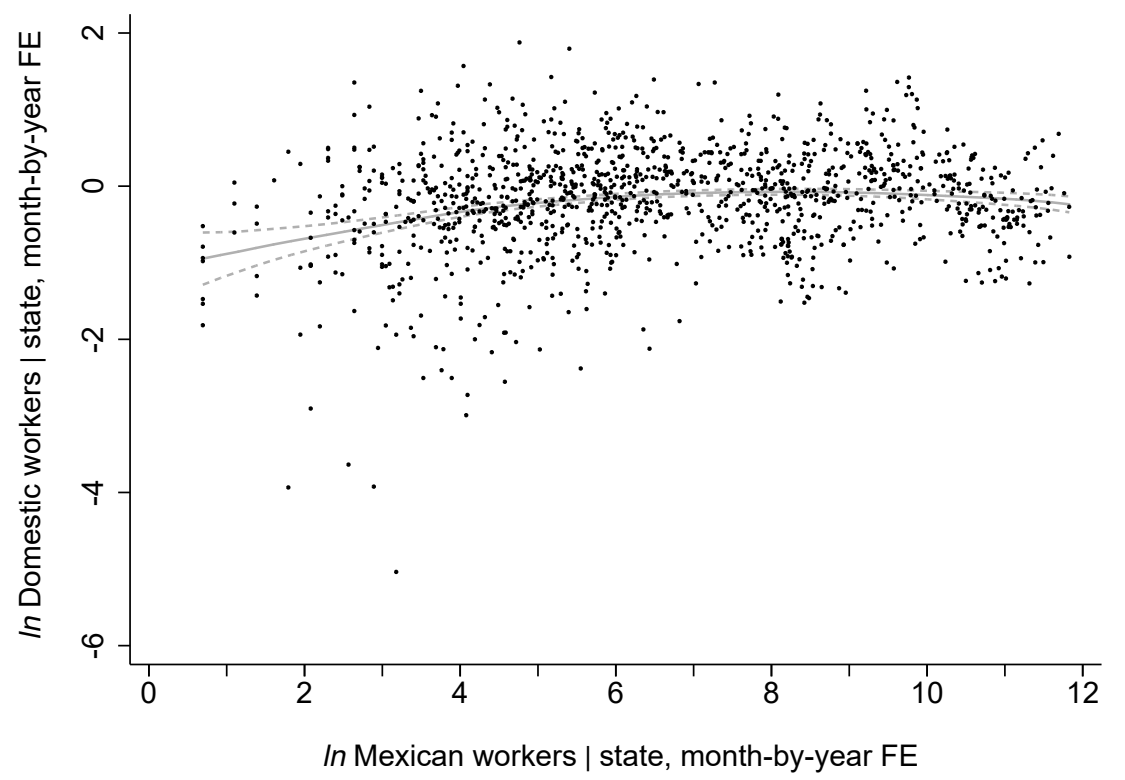

Baltagi and Li (2002) regression of monthly stock of ln employed domestic seasonal farm workers on ln bracero stock, with state and month-by-year fixed effects, local linear with Epanechnikov kernel, bandwidth 2 log-points. Dashed lines show $95 \%$ confidence interval.

Table 7: Cotton and sugar beet mechanization, annual

\begin{tabular}{|c|c|c|c|c|c|c|}
\hline \multirow{3}{*}{$\begin{array}{r}\text { Specification: } \\
\text { Dep. var. } \\
I_{t \geqslant 1965} \cdot \bar{\ell}_{s}^{1955}\end{array}$} & \multicolumn{2}{|c|}{ Diffs-in-diffs } & \multicolumn{4}{|c|}{ Fixed effects } \\
\hline & $\begin{array}{l}\text { Cotton } \\
\text { mech. }\end{array}$ & $\begin{array}{c}\text { Sugar } \\
\text { beet mech. }\end{array}$ & $\begin{array}{r}\text { Cot } \\
\text { mechan }\end{array}$ & $\begin{array}{l}\text { ton } \\
\text { ization }\end{array}$ & $\begin{array}{r}\text { Sugar } \\
\text { mechan }\end{array}$ & $\begin{array}{l}\text { beet } \\
\text { ization }\end{array}$ \\
\hline & $\begin{array}{c}0.0120^{* * *} \\
(0.00258)\end{array}$ & $\begin{array}{c}0.0136^{* * *} \\
(0.00384)\end{array}$ & & & & \\
\hline $\ln \left(L^{\mathrm{mex}}\right)$ & & & $\begin{array}{c}-0.00118^{* * *} \\
(0.000300)\end{array}$ & $\begin{array}{c}-0.000927^{* * *} \\
(0.000226)\end{array}$ & $\begin{array}{c}-0.000764^{* * *} \\
(0.000176)\end{array}$ & $\begin{array}{c}-0.000658^{* * * *} \\
(0.000141)\end{array}$ \\
\hline $\ln \left(L-L^{\mathrm{mex}}\right)$ & & & & $\begin{array}{c}-0.00176 \\
(0.00114)\end{array}$ & & $\begin{array}{r}-0.00127^{* *} \\
(0.000468)\end{array}$ \\
\hline Years & 1951-1972 & $1960-1965$ & $1951-1967$ & $1951-1967$ & $1960-1965$ & 1960-1965 \\
\hline$N$ & 344 & 48 & 97 & 91 & 32 & 32 \\
\hline adj. $R^{2}$ & 0.105 & 0.129 & 0.232 & 0.288 & 0.253 & 0.322 \\
\hline Clusters & 16 & 12 & 9 & 9 & 11 & 11 \\
\hline
\end{tabular}

Observations are state-years. For cotton, mechanization fraction is the fraction of production harvested by machine (USDA 1974, 218). For sugar beets, mechanization fraction is fraction of production thinned and/or weeded by machine (Rogers and Cohen 1963 , 22, Table 3). Diffs-in-diffs regressions include state-years with zero braceros; fixed-effects regressions use logged regressor and thus omit state-years with zero braceros. ${ }^{*} p<0.10,{ }^{* *} p<0.05,{ }^{* * *} p<0.01$ 
Figure 6: Annual bracero flows compared to apprehensions of Mexicans

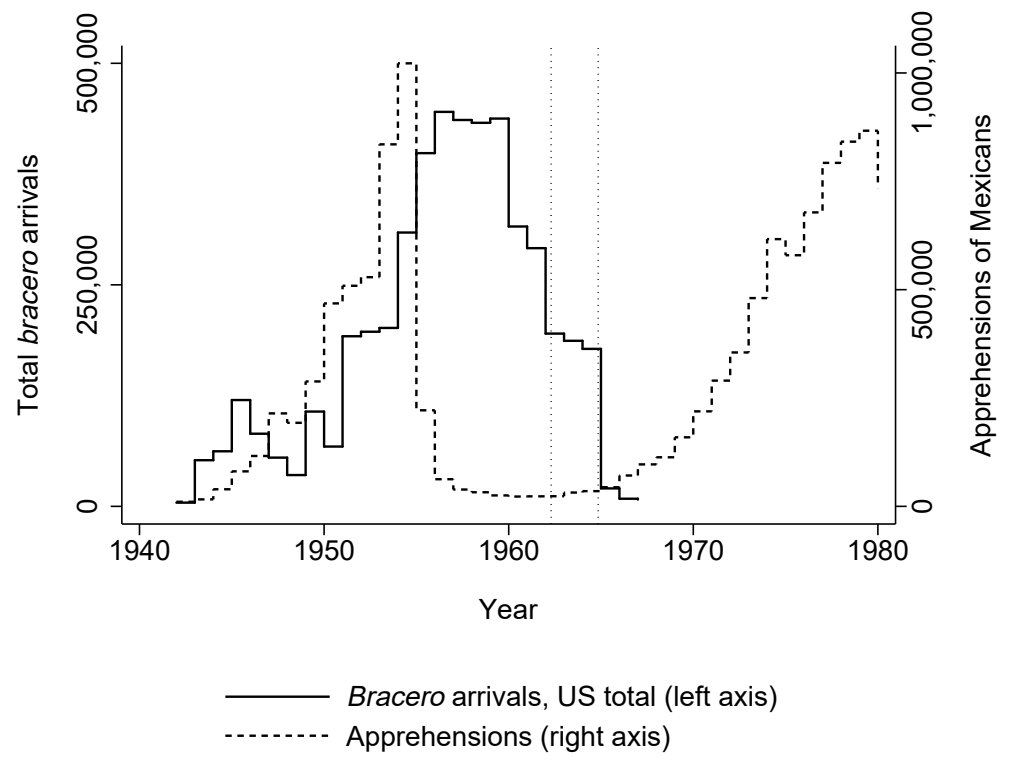

Mexican nationals only in both series. Total bracero arrivals per year from Gastelúm (1991, 54, Cuadro 3). Apprehensions of unauthorized Mexican nationals (also "Mexican deportable aliens located") from Statistical Yearbook of the Immigration and Naturalization Service and Yearbook of Immigration Statistics, various editions 1960-2013. Vertical dotted lines show start of major efforts toward exclusion (March 1962) and near-complete exclusion (December 1964). 
Figure 7: Peak annual bracero stock and mechanization of the tomato harvest, in the two states with mechanization time series

(a) California

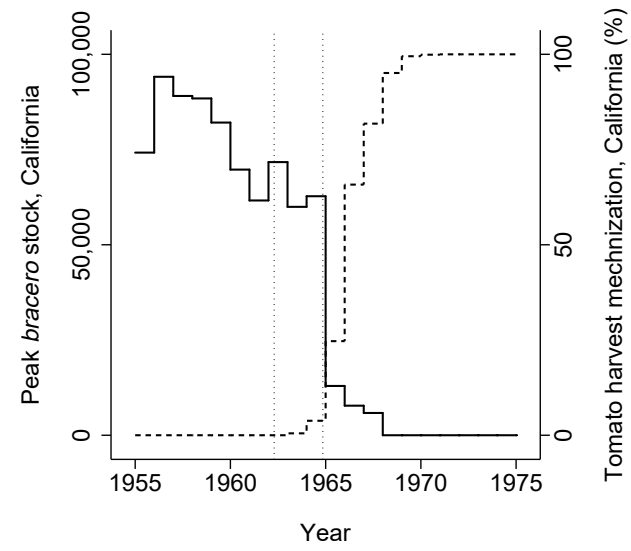

Peak annual bracero stock (left axis)

......- Tomato harvest mechnization (right axis) (b) Ohio

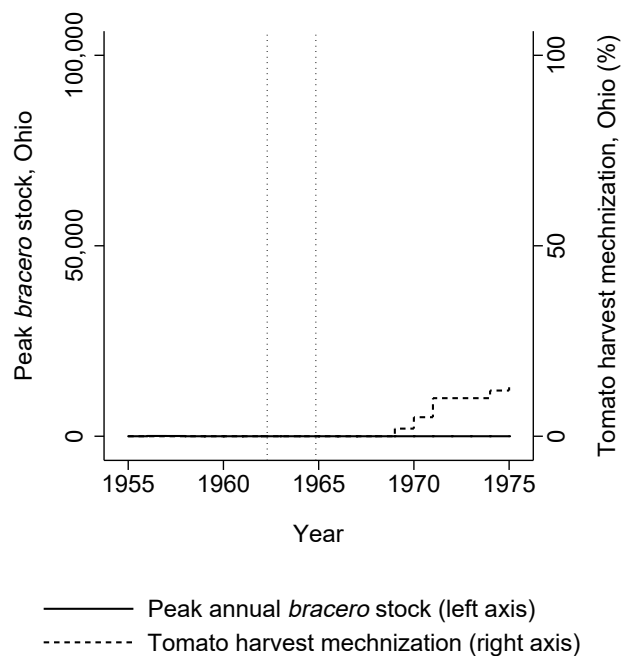

Left axis shows the total number of braceros working in state in the peak month of each year (almost always October). 'Mechanization' means that tomatoes were harvested with the Blackwelder tomato harvester, reported by Vandermeer (1986). Vertical dotted lines show the beginning of major government efforts toward bracero exclusion (March 1962) and near-complete exclusion at the termination of the program (December 1964). There were 74 and 64 braceros in Ohio in the peak month 1956 and 1957, respectively, zero in all other years.

Figure 8: Mechanization versus bracero stock, during program
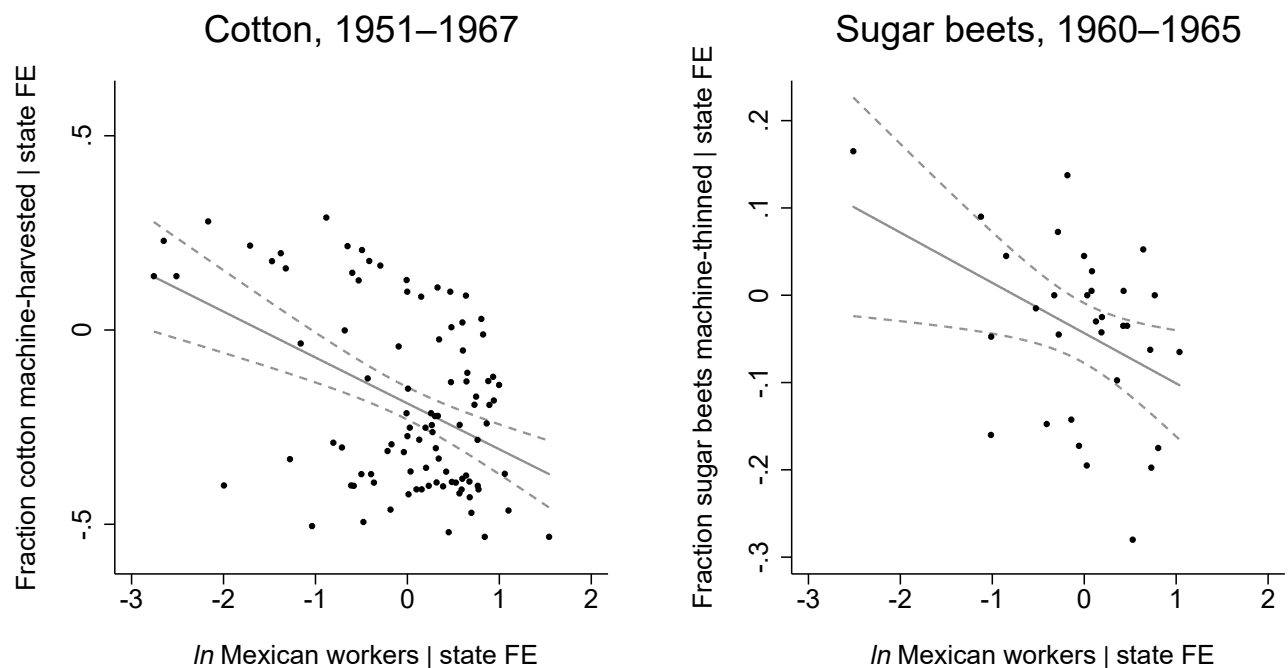

Observations are state-years. For cotton, mechanization fraction is the fraction of production harvested by machine. For sugar beets, mechanization fraction is fraction of production thinned and/or weeded by machine. 
Figure 9: Event study regression coefficients: crop physical production index
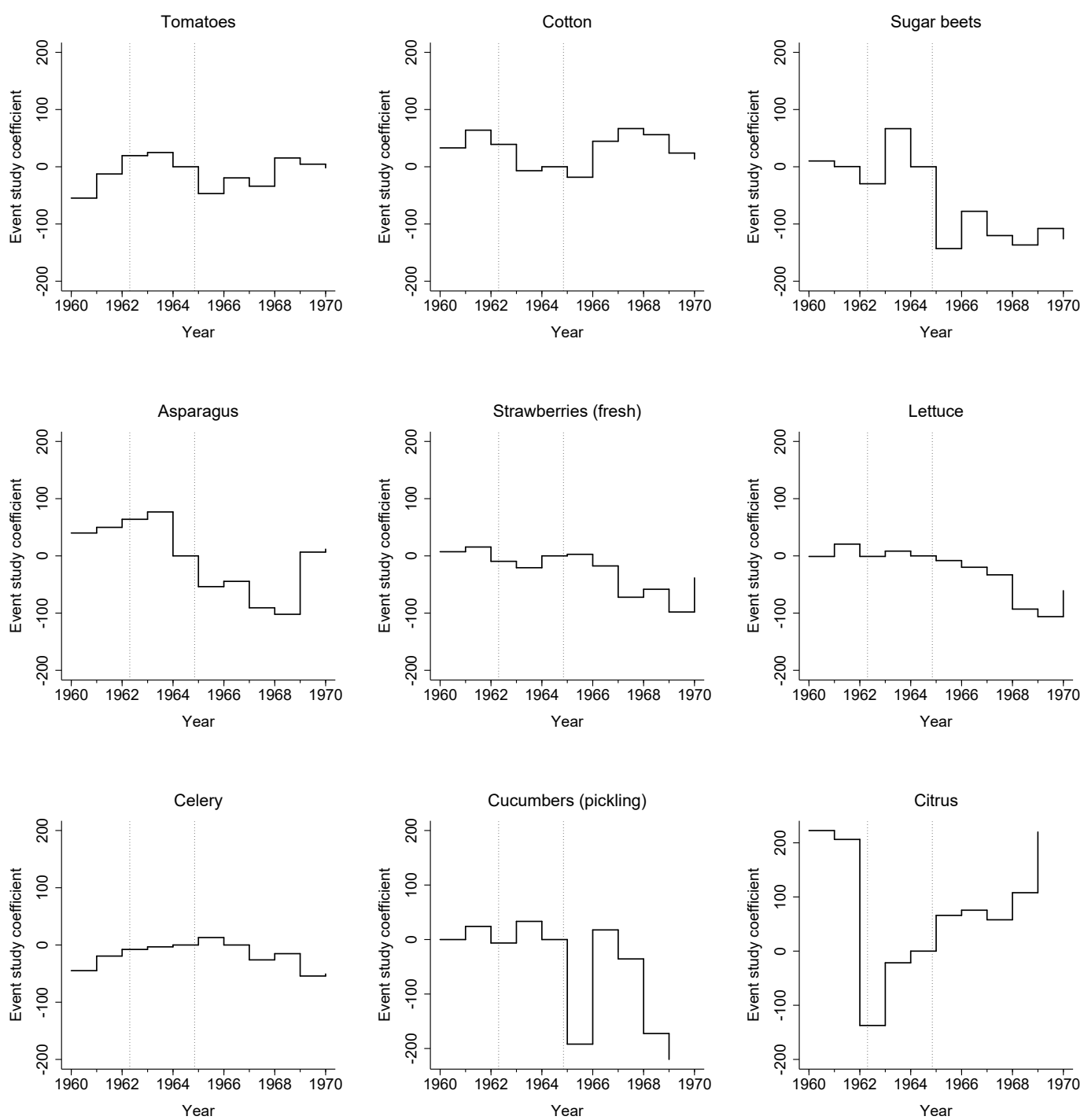

Observations are state-years, and vertical axis shows event-study regression coefficients from equation (15). For each crop, the dependent variable is a production index normalized so that each state's physical production of the crop in 1964 is 100 . Vertical dotted lines show the beginning of major government efforts toward bracero exclusion (March 1962) and near-complete exclusion at the termination of the program (December 1964). The graphs for cucumbers and citrus are truncated at \pm 200 in order to preserve the same vertical range across all graphs for comparability. 


\section{Online Appendix \\ "Labor Market Effects of Immigration Restrictions: Evidence from the Mexican Bracero Exclusion"}

\section{A1 Data sources}

\section{A1.1 State-level stocks of Mexican and non-Mexican farm workers}

This section describes our construction of a novel database of monthly stocks of seasonal agricultural workers in the 48 continental United States, 1943-1973. It offers full monthly coverage of all 48 states from April 1953 to July 1973, with three minor gaps (July 1953, October 1953, and January-March 1970). This is the period that is relevant for the analysis in the present paper. The database also covers the earlier period of 1943-1953, but with some important gaps: state coverage is complete from June 1943 to December 1947 (except April 1944), but for the period January 1948 to March 1953, only four states have complete coverage, while another 11 states have partial coverage. Details follow below.

April 1953-June 1973, the relevant period for the present paper: Agricultural worker data from April 1953 to July 1973 was compiled as follows. Data for each month is typically reported in the month following (e.g. April 1953 worker statistics reported in May 1953 publication issue). The dates in this section refer to the month of employment, not the month of publication. Farm employment data are typically published in a clearly labeled appendix to each issue; the title of the relevant table varies slightly but is typically "Estimated employment and origin of seasonally hired workers in agriculture and food processing by State and selected agricultural reporting areas." Though data are reported at a sub-state level for some locations, we collect aggregate state information only. These reports were published seasonally, typically excluding winter months when minimal farm work occurred. ${ }^{37}$ Data for July 1953, October 1953, and January-March 1970 were missing from all locations.

- April to September 1953: Farm Labor Market Developments (Library of Congress).

- November 1953: Farm Labor Market Developments Employment and Wage Supplement (National Agricultural Library).

- May 1954 to May 1957: Farm Labor Market Developments Employment and Wage Supplement (Library of Congress).

- June 1957: Farm Labor Market Developments Employment and Wage Supplement (National Agricultural Library).

- July 1957: Farm Labor Market Developments Employment and Wage Supplement (Library of Congress).

- August 1957: Farm Labor Market Developments Employment and Wage Supplement (National Agricultural Library).

- September 1957 to November 1957: Farm Labor Market Developments Employment and Wage Supplement (Library of Congress).

- May 1958: Farm Labor Market Developments Employment and Wage Supplement (National Agricultural Library).

- June 1958: Farm Labor Market Developments Employment and Wage Supplement (Library of Congress).

\footnotetext{
${ }^{37}$ Omitted months are December to April for 1954, 1958, 1961, and 1962; December to March for 1955, 1956, and 1957; January to May for 1959; January to April for 1960; November and December for 1967.
} 
- July 1958: Farm Labor Market Developments Employment and Wage Supplement (National Agricultural Library).

- August 1958 to December 1959: Farm Labor Market Developments Employment and Wage Supplement (Library of Congress).

- May 1960 to May 1962: Farm Labor Market Developments Employment and Wage Supplement (Wirtz Labor Library).

- June 1962 to November 1962: Farm Labor Market Developments Employment and Wage Supplement (Library of Congress).

- December 1962 to November 1963: Farm Labor Market Developments Employment and Wage Supplement (Wirtz Labor Library).

- December 1963 to November 1964: Farm Labor Market Developments Employment and Wage Supplement (National Agricultural Library).

- December 1964 to October 1967: Farm Labor Developments Employment and Wage Supplement (National Agricultural Library).

- January 1968 to July 1970: Farm Labor Developments (National Agricultural Library).

- August 1970 to July 1973: Rural Manpower Developments (National Agricultural Library).

Fune 1943-December 1947: Hired seasonal farm worker statistics by state for June 1943 to December 1947 are reported in the United States Department of Agriculture National Agricultural Statistics Service's monthly Farm Labor publication, made available online through Cornell University's Mann Library. Each issue features a table of "foreign workers employed in or available for agricultural work by country of origin and state of employment." The date of reference for these tables varies; for those dated at the beginning of a month, we assume the workers reported were present in the month prior. For example, figures for workers present in April 1944 were taken from the May 1944 issue of Farm Labor. The publication reports all major groups of foreign workers present: typically Mexican, Bahamian, and Jamaican. The April 1944 issue reports only Bahamian and total numbers; there is no separate category for Mexican workers. Data for April 1945 is missing.

fanuary 1948-March 1953: To our knowledge there is no primary- or secondary-source national compilation of state-level hired seasonal farm worker data for January 1948 to March 1953. We initially sought such a compilation in six archival locations. ${ }^{38}$ U.S. National Archives staff supported the hypothesis that due to bureaucratic reorganization during this time period-responsibility for this data collection shifted from the Department of Agriculture to the Department of Labor-no such collation either existed or was made public. Since the ES-223 form was implemented by local employment service offices, we found it plausible that if any such data existed, it might be on a state level. We were able to track down at least partial data for fifteen states for this time period from twelve university libraries and archival locations. We were able to fill the gap entirely for four states: Arizona, California, Michigan, and Virginia. Data for individual states was sourced as follows (we exclude other available publication volumes that did not provide sufficiently granular information for inclusion in the database):

- Arizona (1948-1953): 1948: Post-Season Farm Labor Report for 1948, table on p. 7 (Arizona State University); 1949: Post-Season Farm Labor Report for 1949, domestic numbers from table on p. 14 and bracero numbers from text on p. 20 (Arizona State University); 1950-1953: Agricultural Employment in Arizona 1950-1964, table on p. 10 (Wirtz Labor Library).

\footnotetext{
${ }^{38}$ U.S. National Archives (College Park, MD), U.S. Department of Agriculture National Agricultural Library (Beltsville, MD), U.S. Department of Labor Wirtz Labor Library (Washington, DC), Library of Congress (Washington, DC), Harry S. Truman Presidential Library (Independence, MO), Dwight D. Eisenhower Presidential Library (Abilene, KS).
} 
- Arkansas (1951-1953): 1951: Arkansas Agricultural Activities 1951, table on p. 49, data from first semi-monthly period; 1952: Arkansas Agricultural Activities 1952, table on p. 45, data from first semi-monthly period; 1953: Arkansas Annual Agricultural Report 1953, table on p. 13 qualified by text on pp. 5-6 (all from University of Arkansas).

- California (1948-1953): 1948, 1949, 1950: Recruitment and Placement of Farm Laborers in California 1950 (Special and Partial Report of the Joint Legislative Committee on Agriculture and Livestock Problems, California Senate), table on p. 22 (Wirtz Labor Library); 1951 \& 1952: California Annual Farm Labor Report 1952, table on p. 33 (University of Colorado Boulder); 1953: California Annual Farm Labor Report 1954, table on p. 7 (Wirtz Labor Library).

- Colorado (1949, 1950, 1953): 1949: Colorado Post Season Farm Report 1949, text on p. 13; 1950: Colorado Post Season Farm Report 1950, text on p. 14; 1953: Colorado Post Season Farm Report 1953, text on p. 16 (all from Colorado State Library).

- Indiana (1950, 1952, 1953): 1950: Indiana Post Season Farm Labor Report 1950, table on p. 47; 1952: Indiana Farm Labor Report 1952, table entitled "Out of State Workers Employed in Seasonal Agricultural and Food Processing Activities," n.p. 1953: Indiana Farm Labor Report 1953, table entitled "Out of State Workers Employed in Seasonal Agricultural and Food Processing Activities," n.p. (all from Wirtz Labor Library).

- Louisiana (1952, 1953): 1952: Louisiana Post-Season Agricultural and Food Processing Report 1952, text on p. 10; 1953: Louisiana Annual Farm Labor Report 1953, table on p. 19 qualified by text on p. 20 (all from Wirtz Labor Library).

- Maryland (1948, 1949, 1953): 1948 \& 1949: The Maryland Farm Labor Program 1948-1949, text on page beginning "A careful appraisal of each crew leader ...", n.p. (Wirtz Labor Library); 1953: Maryland's Farm Labor Report 1953, text pp. 14-15 (University of Maryland College Park).

- Michigan (1948-1953): 1948: Post Season Farm Labor Report State of Michigan 1948, table p. 18 (University of Michigan HathiTrust); 1949: Characteristics of Migratory Farm Labor in Michigan, table entitled "Agricultural and Food Processing Industries Seasonal Labor Force for 1949", n.p. (Truman Presidential Library, President's Committee on Migratory Labor (Record Group 220), Box 8, Folder "Hearing statements, Saginaw, Michigan, September 11-12, 1950"); 1950: Characteristics of Migratory Farm Labor in Michigan, table entitled "Agricultural and Food Processing Industries Seasonal Labor Force for 1950”, n.p. (Truman Presidential Library, President's Committee on Migratory Labor (Record Group 220), Box 8, Folder "Hearing statements, Saginaw, Michigan, September 11-12, 1950"); 1951: Post Season Farm Labor Report State of Michigan 1951, table p. 13 (Wirtz Labor Library); 1952: Post Season Farm Labor Report State of Michigan 1952, table p. 12 (Wirtz Labor Library); 1953: Post Season Farm Labor Report 1953, table p. 33 (Wirtz Labor Library).

- Minnesota (1950-1953): 1950: Post Season Agricultural and Food Processing Report 1950, summed by month from table entitled "Seasonal Agricultural Workers Hired for Principal Minnesota Farm Crops - 1950", n.p. ; 1951: Post Season Agricultural and Food Processing Report 1951, summed by month from table p. 14; 1952: Post Season Agricultural and Food Processing Report 1952, summed by month from table p. 14; 1953: Post Season Agricultural and Food Processing Report 1953, summed by month from table entitled "Seasonal Labor Used for Principal Farm Crops - 1953", n.p. (all from Minnesota Historical Society).

- New fersey (1949): Post-Season Agricultural and Food Processing Report for State of New Jersey 1949, text from p. 10 (Wirtz Labor Library).

- New Mexico (1948, 1953): 1948: Annual Report Farm Placement in New Mexico 1949, text from p. 12; 1953: Annual Report Farm Placement in New Mexico 1955, text from p. 6 in comparison with "Exhibit C: State Summary - Employment," n.p. (both from University of New Mexico). 
- New York (1950): 1950 Annual Report Farm and Food Processing Labor, text from p. 9 (Wirtz Labor Library).

- Oregon (1950, 1952, 1953): 1950: Oregon's Farm Labor Market, table entitled "Number of Hired Seasonal Agricultural Workers by Type of Worker, 1950," n.p. (Truman Presidential Library, President's Committee on Migratory Labor (Record Group 220), Box 8, Folder "Hearing statements, Portland, Oregon, October 16-18, 1950"); 1952: Post-Season Farm Labor Report 1952, Table C ("Number of Hired Seasonal Workers in Agriculture by Local Office and Type of Worker - 1952)", qualified by text on page beginning "carried on through the Clearance Program ..." n.p. (Wirtz Labor Library); 1953: Post-Season Farm Labor Report 1953, Table 5 ("Number of Hired Seasonal Workers in Agriculture by Agricultural Area, Local Office, and Type of Worker - 1953"), qualified by text on page beginning "it was estimated early in the season ..." n.p. (Wirtz Labor Library).

- Virginia (1948-1953): 1948: Post-Season Farm Labor Report for 1948 State of Virginia, table on p. 12 qualified by text on p. 4 (Truman Presidential Library, President's Committee on Migratory Labor (Record Group 220), Box 8, Folder "Hearing statements, Washington, D.C., October 2-3, 1950"); 1949: Farm and Processing Labor Virginia 1949, text on p. 24 (University of Virginia); 1950: Farm and Food Processing Worker Placement Virginia 1950, text on p. 22 (Wirtz Labor Library); 1951: Farm Employment in Virginia 1951, table on p. 51 qualified by text on p. 45 (Wirtz Labor Library); 1952: Farm Employment in Virginia 1952, table on p. 44 qualified by text on p. 39 (Wirtz Labor Library); 1953: Farm Employment in Virginia 1953, table on p. 32 qualified by text on pp. 23-24 (Wirtz Labor Library).

- Washington (1951, 1953): 1951: Annual Farm Placement Report 1951, Attachment 4A ("State of Washington Estimated Employment of Hired Seasonal Workers in Agriculture in 1951"), data from first semi-monthly period, n.p. ; 1953: Annual Farm Placement Report 1953, text from p. 11 (both from Wirtz Labor Library).

Measures of Mexican contract workers, local (domestic, nonmigratory) workers, intrastate migrants, and interstate migrants were consistent across the full time period. Information on other foreign workers was inconsistently collated in different publications. Jamaican and Bahamian workers were identified as such from 1943-1947; combined under the umbrella "British West Indies" from 1946 to 1954 and 1959 to 1973; and aggregated as "British West Indies and others" from 1953-1958. A similar trend holds for Canadians, identified as a single group from 1943 to 1954 and 1966 to 1972 and aggregated into "Canadians and others" from 1959-1964. "Other foreign" workers are reported from 1944-1954 and 1964-1966. Data on Puerto Rican workers are reported for the full time period.

\section{A1.2 Wages}

All farm wage data were sourced from the Department of Agriculture publication Farm Labor on a quarterly basis. The daily wage without board measure was consistently reported for the relevant quarter: for example, July 1945 rates reported in the July 1945 publication issue. Hourly composite wage rates are available beginning in January 1948. This composite index was computed by "converting the monthly, weekly, and daily rates to an hourly basis and weighting the rates by approximate distributions of workers hired by the different arrangement." (USDA 1969, 16). The measure was rebased with new weights from a 1948 agriculture survey in the January 1951 edition of Farm Labor; we source data for January 1948 to October 1950 from this issue. Beginning in January 1951, hourly composite rates are reported alongside the daily without board rate in the relevant quarterly issue. The hourly wage has full state coverage but fewer years (1948-1971); the daily wage has more years (1942-1975) but is missing three states (CA, OR, WA) for most years (1951-1962 and 1965-1975). In order to balance the panel, we set the latter measure for these three states to missing for all years. 


\section{A1.3 Data availability, entry, and reconciliation}

We began the search for missing worker data from 1948 to 1953 at the National Archives in College Park, Maryland. Data prior to 1948 was collected by the Bureau of Agricultural Economics in the Department of Agriculture; these records fall under Archives Record Group 83. Upon the abolition of this office in 1953, the Office of Employment Security of the Department of Labor assumed responsibility for collating and publishing data on farm employment in 1954; these records fall under Record Group 183 (U.S. National Archives n.d.). Upon review of the relevant files for the years in question and consultation with archivists, it became clear that most of the National Archives content was correspondence and testimony. It was suggested that any historical statistical information would likely be stored within the Federal Depository Library system, charged with collecting and storing official government publications. Under the Superintendent of Documents Classification (SuDocs) system of the United States Government Publishing Office (GPO), the relevant files (Bureau of Employment Security) are held under SuDocs stem L7. Thanks to the help of Celina Nichols McDonald at the University of Maryland, we sent a request for this catalog entry to all US Federal Depository Libraries; none held the information we were looking for. With the help of Julie Day from the Department of Labor Wirtz Labor Library, we ascertained that Washington University in St. Louis, Missouri and the Dwight D. Eisenhower Presidential Library in Abilene, Kansas, possessed SuDocs L7 holdings. The former did not seem to include granular information on foreign workers; the latter not only held information under this call number, but also the full record of the President's Commission on Migratory Labor and supporting information, from 1938 to $1966 .{ }^{39}$

We therefore visited the Eisenhower Library in December 2016, pulling all archival material potentially related to bracero employment from 1948-1953. From record group 220 (U.S. President's Committee on Migratory Labor) this included boxes 1-4, 11-14, 62-76, 87-97, and 99. From the broader Migratory Labor subject guide, this included boxes 102, 139, 141, and 178 of the Mitchell papers; box 4 of the Eisenhower papers (Ann Whitman file), box 17 of the Oveta Culp Hobby papers, box 13 of the Clyde Wheeler papers, and boxes 10 and 20 of the White House Cabinet Secretariat records. We also visited the Harry S. Truman Presidential Library in Independence, Missouri for their nine boxes of material on the U.S. President's Committee on Migratory Labor. ${ }^{40}$ These searches yielded important yet sporadic worker data by state to fill the national level gap from 1948 to 1953, as well as qualitative background material and methodological information.

We also reviewed all potentially relevant congressional hearings for this period stored at the Library of Congress. Though some offered relevant information, most data reported was for hires/contracts or border crossings over a certain time period, not the monthly stock estimates of farm employment we sought. This extensive archival work in combination with a 1978 records disposal request authorizing the disposal of original ES-223 forms and related reports, gives us confidence that our dataset is complete to the fullest extent possible.

We outsourced the entry of both worker and wage data from scanned PDFs to Excel to two separate data entry professionals on Upwork, an online network for freelancers. These two individuals were selected through a rigorous sample data entry process; any discrepancies between the final dual entry datasets were hand-checked and harmonized in Stata to yield the final database.

\section{A1.4 U.S. state Mexican-born and total populations}

Census-year estimates of Mexican-born population by U.S. state are calculated directly from census $1 \%$ sample microdata in 1920, 1930, 1940, 1950, and 1960 from IPUMS-USA (Steven Ruggles, Katie Genadek, Ronald Goeken, Josiah Grover, and Matthew Sobek. Integrated Public Use Microdata Series: Version 6.0 [Machine-readable database]. Minneapolis: University of Minnesota, 2015). Annual estimates of total U.S.

\footnotetext{
${ }^{39}$ Full migratory labor subject guide available online.

${ }^{40}$ Box list available online.
} 
state populations 1920-1960 come from the U.S. Bureau of the Census, https://www.census.gov/popest/ data/state/asrh/1980s/80s_st_totals.html, accessed August 24, 2016.

\section{A2 Model derivation}

Portions of the model in the main text are dervied as follows.

\section{A2.1 Equilbrium output under traditional technology}

The expression for $Y_{0}$ at equilibrium is derived by noting that

$$
\begin{aligned}
r_{0} & =\left\{K_{0}^{\frac{\mu-1}{\mu}}+\left[a L^{\frac{\sigma-1}{\sigma}}+(1-a) T^{\frac{\sigma-1}{\sigma}}\right]^{\frac{\sigma}{\sigma-1} \frac{\mu-1}{\mu}}\right\}^{\frac{1}{\mu-1}} K_{0}^{-\frac{1}{\mu}} \\
\Longleftrightarrow r_{0}^{\mu-1} & =1+K_{0}^{\frac{1-\mu}{\mu}}\left[a L^{\frac{\sigma-1}{\sigma}}+(1-a) T^{\frac{\sigma-1}{\sigma}}\right]^{\frac{\sigma}{\sigma-1} \frac{\mu-1}{\mu}} \\
\Longleftrightarrow K_{0} & =\left(r_{0}^{\mu-1}-1\right)^{\frac{\mu}{1-\mu}}\left[a L^{\frac{\sigma-1}{\sigma}}+(1-a) T^{\frac{\sigma-1}{\sigma}}\right]^{\frac{\sigma}{\sigma-1}},
\end{aligned}
$$

and substituting into the production function we have that

$$
Y_{0}=\left(\frac{r_{0}^{\mu-1}}{r_{0}^{\mu-1}-1}\right)^{\frac{\mu}{\mu-1}}\left[a L^{\frac{\sigma-1}{\sigma}}+(1-a) T^{\frac{\sigma-1}{\sigma}}\right]^{\frac{\sigma}{\sigma-1}} .
$$

\section{A2.2 Change in wage with and without capital adjustment}

Expression (7) uses the fact that $\frac{\partial \ln w}{\partial \ln (L / T)}=\left(\frac{\mu}{\mu-1}-1\right)\left(1-s_{K}\right) \frac{\sigma}{\sigma-1} \frac{\mu-1}{\mu} \frac{\sigma-1}{\sigma} \frac{s_{L}}{1-s_{K}}+\frac{\mu-\sigma}{(\sigma-1) \mu} \frac{s_{L}}{1-s_{K}} \frac{\sigma-1}{\sigma}+\frac{-1}{\sigma}$ (by differentiating (6)) - and expressions for factor shares under the traditional technology, which are:

$$
\begin{aligned}
s_{K} & =\frac{r_{0} K_{0}}{Y_{0}}=\left\{K_{0}^{\frac{\mu-1}{\mu}}+\left[a L^{\frac{\sigma-1}{\sigma}}+(1-a) T^{\frac{\sigma-1}{\sigma}}\right]^{\frac{\sigma}{\sigma-1} \frac{\mu-1}{\mu}}\right\}^{-1} K_{0}^{\frac{\mu-1}{\mu}} \\
1-s_{K} & =\left\{K_{0}^{\frac{\mu-1}{\mu}}+\left[a L^{\frac{\sigma-1}{\sigma}}+(1-a) T^{\frac{\sigma-1}{\sigma}}\right]^{\frac{\sigma}{\sigma-1} \frac{\mu-1}{\mu}}\right\}^{-1}\left[a L^{\frac{\sigma-1}{\sigma}}+(1-a) T^{\frac{\sigma-1}{\sigma}}\right]^{\frac{\sigma}{\sigma-1} \frac{\mu-1}{\mu}} \\
s_{L} & =a\left\{K_{0}^{\frac{\mu-1}{\mu}}+\left[a L^{\frac{\sigma-1}{\sigma}}+(1-a) T^{\frac{\sigma-1}{\sigma}}\right]^{\frac{\sigma}{\sigma-1} \frac{\mu-1}{\mu}}\right\}^{-1}\left[a L^{\frac{\sigma-1}{\sigma}}+(1-a) T^{\frac{\sigma-1}{\sigma}}\right]^{\frac{\sigma}{\sigma-1} \frac{\mu-1}{\mu}-1} L^{\frac{\sigma-1}{\sigma}} \\
\frac{s_{L}}{1-s_{K}} & =\left[a L^{\frac{\sigma-1}{\sigma}}+(1-a) T^{\frac{\sigma-1}{\sigma}}\right]^{-1} a L^{\frac{\sigma-1}{\sigma}},
\end{aligned}
$$

with $s_{L}+s_{T}=1-s_{K}$. After capital adjusts,

$$
w=\left(\frac{r_{0}^{\mu-1}}{r_{0}^{\mu-1}-1}\right)^{\frac{\mu}{\mu-1}}\left[a\left(\frac{L}{T}\right)^{\frac{\sigma-1}{\sigma}}+(1-a)\right]^{\frac{1}{\sigma-1}} a\left(\frac{L}{T}\right)^{-\frac{1}{\sigma}} .
$$

Thus $\frac{\partial \ln w}{\partial(B / L)} \approx-\frac{\partial \ln w}{\partial \ln (L / T)}=-\left[\frac{1}{\sigma-1} \frac{\sigma-1}{\sigma} \frac{s_{L}}{1-s_{K}}+\left(-\frac{1}{\sigma}\right)\right]=\frac{s_{T}}{s_{L}+s_{T}} \frac{1}{\sigma}$. 


\section{A2.3 Change in average wages under differentiated skill}

Expression (12) uses the change in the average wages of skilled and unskilled workers as follows. Consider the traditional technology modified by the two labor types, $S$ and $U$. The corresponding wages are

$$
\begin{aligned}
w_{U} & =\alpha_{L} \cdot a\left(\frac{r_{0}^{\mu-1}}{r_{0}^{\mu-1}-1}\right)^{\frac{\mu}{\mu-1}}\left[a+(1-a)\left(\frac{L}{T}\right)^{-\frac{\sigma-1}{\sigma}}\right]^{\frac{1}{\sigma-1}}\left[\alpha_{L} U^{\frac{\rho-1}{\rho}}+\left(1-\alpha_{L}\right) S^{\frac{\rho-1}{\rho}}\right]^{\frac{1}{\rho-1}} U^{-\frac{1}{\rho}} \\
w_{S} & =\left(1-\alpha_{L}\right) \cdot a\left(\frac{r_{0}^{\mu-1}}{r_{0}^{\mu-1}-1}\right)^{\frac{\mu}{\mu-1}}\left[a+(1-a)\left(\frac{L}{T}\right)^{-\frac{\sigma-1}{\sigma}}\right]^{\frac{1}{\sigma-1}}\left[\alpha_{L} U^{\frac{\rho-1}{\rho}}+\left(1-\alpha_{L}\right) S^{\frac{\rho-1}{\rho}}\right]^{\frac{1}{\rho-1}} S^{-\frac{1}{\rho}} \\
w_{U} U+w_{S} S & =a\left(\frac{r_{0}^{\mu-1}}{r_{0}^{\mu-1}-1}\right)^{\frac{\mu}{\mu-1}}\left[a+(1-a)\left(\frac{L}{T}\right)^{-\frac{\sigma-1}{\sigma}}\right]^{\frac{1}{\sigma-1}}\left[\alpha_{L} U^{\frac{\rho-1}{\rho}}+\left(1-\alpha_{L}\right) S^{\frac{\rho-1}{\rho}}\right]^{\frac{\rho}{\rho-1}} .
\end{aligned}
$$

And in this setup define $s_{L} \equiv \frac{w_{U} U+w_{S} S}{Y_{0}}$ and $s_{U} \equiv \frac{w_{U} U}{Y_{0}}$. Then

$$
\frac{s_{U}}{s_{L}}=\left[\alpha_{L} U^{\frac{\rho-1}{\rho}}+\left(1-\alpha_{L}\right) S^{\frac{\rho-1}{\rho}}\right]^{-1} \alpha_{L} U^{\frac{\rho-1}{\rho}} .
$$

Note that the expression for $w_{U} U+w_{S} S$ can be also be used to show that the expression for average wages remains as it was before,

$$
w=\frac{w_{U} U+w_{S} S}{L}=a\left(\frac{r_{0}^{\mu-1}}{r_{0}^{\mu-1}-1}\right)^{\frac{\mu}{\mu-1}}\left[a+(1-a)\left(\frac{L}{T}\right)^{-\frac{\sigma-1}{\sigma}}\right]^{\frac{1}{\sigma-1}},
$$

since $L=\left[\alpha_{L} U^{\frac{\rho-1}{\rho}}+\left(1-\alpha_{L}\right) S^{\frac{\rho-1}{\rho}}\right]^{\frac{\rho}{\rho-1}}$. This expression for $w$ is equivalent to the expression for $w$ in the preceding subsection.

One can also use the above expressions to show

$$
d \ln w_{U}=d \ln w-\frac{1}{\rho}\left(1-\frac{s_{U}}{s_{L}}\right) d \ln \left(\frac{U}{S}\right),
$$

since $w_{U}=w \cdot \alpha_{L}\left[\alpha_{L} U^{\frac{\rho-1}{\rho}}+\left(1-\alpha_{L}\right) S^{\frac{\rho-1}{\rho}}\right]^{\frac{1}{\rho-1}} U^{-\frac{1}{\rho}}=w \cdot \alpha_{L}\left[\alpha_{L}+\left(1-\alpha_{L}\right)\left(\frac{U}{S}\right)^{-\frac{\rho-1}{\rho}}\right]^{\frac{1}{\rho-1}}$. Similarly,

$$
d \ln w_{S}=d \ln w+\frac{1}{\rho} \frac{s_{U}}{s_{L}} d \ln \left(\frac{U}{S}\right)
$$

since $w_{S}=w \cdot\left(1-\alpha_{L}\right)\left[\alpha_{L}\left(\frac{U}{S}\right)^{\frac{\rho-1}{\rho}}+\left(1-\alpha_{L}\right)\right]^{\frac{1}{\rho-1}}$.

\section{A2.4 Alternative Nesting}

The qualitative results presented are not dependent on the particular nesting of the CES structure used in the main text (nor are they even dependent on the CES functional form - see Figure 1). In particular, consider this alternative nesting: 


$$
Y_{j}=\left\{T_{j}^{\frac{\mu-1}{\mu}}+\left[a_{j} L_{j}^{\frac{\sigma-1}{\sigma}}+\left(1-a_{j}\right) K_{j}^{\frac{\sigma-1}{\sigma}}\right]^{\frac{\sigma}{\sigma-1} \frac{\mu-1}{\mu}}\right\}^{\frac{\mu}{\mu-1}},
$$

where $j \in\{0, A\}$, where $a_{0}>a_{A}$, where $L_{j}, K_{J}$ and $T_{j}$ denote the amount of labor, capital, and land applied to production process $j$, with $T_{A}+T_{0}=\bar{T}, L_{A}+L_{0}=\bar{L}$ and the kind of capital used in process $j$ is supplied elastically at price $r_{j}$. This is similar to the model in section 2, except capital is now in the inner nest of the CES form. (In the main text $a \equiv a_{0}$ and $b \equiv a_{A}$.)

Capital can no longer be simply factored out of this functional form, so define $k_{j}=K_{j} / T_{j}$ as the equilibrium capital/land ratio in process $j$ (if it is used). So now the cone of diversification is defined by the $k_{0}$, $k_{A}, \phi_{\ell}$ and $\phi_{u}$ that are the solution to the system of four equations

$$
\begin{gathered}
r_{0}=\left(1-a_{0}\right)\left\{1+\left[a_{0} \phi_{u}^{\frac{\sigma-1}{\sigma}}+\left(1-a_{0}\right) k_{0}^{\frac{\sigma-1}{\sigma}}\right]^{\frac{\sigma}{\sigma-1} \frac{\mu-1}{\mu}}\right\}^{\frac{\mu}{\mu-1}-1}\left[a_{0} \phi_{u}^{\frac{\sigma-1}{\sigma}}+\left(1-a_{0}\right) k_{0}^{\frac{\sigma-1}{\sigma}}\right]^{\frac{\sigma}{\sigma-1} \frac{\mu-1}{\mu}-1} k_{0}^{-\frac{1}{\sigma}} \\
r_{A}=\left(1-a_{A}\right)\left\{1+\left[a_{A} \phi_{\ell}^{\frac{\sigma-1}{\sigma}}+\left(1-a_{A}\right) k_{A}^{\frac{\sigma-1}{\sigma}}\right]^{\frac{\sigma}{\sigma-1} \frac{\mu-1}{\mu}}\right\}^{\frac{\mu}{\mu-1}-1}\left[a_{A} \phi_{\ell}^{\frac{\sigma-1}{\sigma}}+\left(1-a_{A}\right) k_{A}^{\frac{\sigma-1}{\sigma}}\right]^{\frac{\sigma}{\sigma-1} \frac{\mu-1}{\mu}-1} k_{A}^{-\frac{1}{\sigma}} \\
\hat{w} \equiv a_{0}\left\{1+\left[a_{0} \phi_{u}^{\frac{\sigma-1}{\sigma}}+\left(1-a_{0}\right) k_{0}^{\frac{\sigma-1}{\sigma}}\right]^{\frac{\sigma}{\sigma-1} \frac{\mu-1}{\mu}}\right\}^{\frac{\mu}{\mu-1}-1}\left[a_{0} \phi_{u}^{\frac{\sigma-1}{\sigma}}+\left(1-a_{0}\right) k_{0}^{\frac{\sigma-1}{\sigma}}\right]^{\frac{\sigma}{\sigma-1} \frac{\mu-1}{\mu}-1} \phi_{u}^{-\frac{1}{\sigma}} \\
=a_{A}\left\{1+\left[a_{A} \phi_{\ell}^{\frac{\sigma-1}{\sigma}}+\left(1-a_{A}\right) k_{A}^{\frac{\sigma-1}{\sigma}}\right]^{\frac{\sigma}{\sigma-1} \frac{\mu-1}{\mu}}\right\}^{\frac{\mu}{\mu-1}-1}\left[a_{A} \phi_{\ell}^{\frac{\sigma-1}{\sigma}}+\left(1-a_{A}\right) k_{A}^{\frac{\sigma-1}{\sigma}}\right]^{\frac{\sigma}{\sigma-1} \frac{\mu-1}{\mu}-1} \phi_{\ell}^{-\frac{1}{\sigma}} \\
\hat{r_{T}} \equiv\left\{1+\left[a_{0} \phi_{u}^{\frac{\sigma-1}{\sigma}}+\left(1-a_{0}\right) k_{0}^{\frac{\sigma-1}{\sigma}}\right]^{\frac{\sigma}{\sigma-1} \frac{\mu-1}{\mu}}\right\}^{\frac{\mu}{\mu-1}-1}=\left\{1+\left[a_{A} \phi_{\ell}^{\frac{\sigma-1}{\sigma}}+\left(1-a_{A}\right) k_{A}^{\frac{\sigma-1}{\sigma}}\right]^{\frac{\sigma}{\sigma-1} \frac{\mu-1}{\mu}}\right\}^{\frac{\mu}{\mu-1}-1} .
\end{gathered}
$$

By rearranging (A.4) and substituting into (A.3) one can show that $\phi_{\ell}=\phi_{u}\left(\frac{a_{0}}{a_{A}}\right)^{\sigma}<\phi_{u}$. Additional substitutions allow for closed form solutions for $k_{0}, k_{A}, \phi_{\ell}$ and $\phi_{u}, \hat{w}$ and $\hat{r_{T}}$.

In the absence of a viable alternative technology, the shutdown margin is the minimum labor/land ratio, $\bar{\phi}$, (and the capital/land ratio, $\bar{k}$ ) which solve the system:

$$
\begin{gathered}
\underline{r_{T}}+m=\left\{1+\left[a_{0} \bar{\phi}^{\frac{\sigma-1}{\sigma}}+\left(1-a_{0}\right) \bar{k}^{\frac{\sigma-1}{\sigma}}\right]^{\frac{\sigma}{\sigma-1} \frac{\mu-1}{\mu}}\right\}^{\frac{\mu}{\mu-1}-1} \\
r_{0}=\left(1-a_{0}\right)\left\{1+\left[a_{0} \bar{\phi}^{\frac{\sigma-1}{\sigma}}+\left(1-a_{0}\right) \bar{k}^{\frac{\sigma-1}{\sigma}}\right]^{\frac{\sigma}{\sigma-1} \frac{\mu-1}{\mu}}\right\}^{\frac{\mu}{\mu-1}-1}\left[a_{0} \bar{\phi}^{\frac{\sigma-1}{\sigma}}+\left(1-a_{0}\right) \bar{k}^{\frac{\sigma-1}{\sigma}}\right]^{\frac{\sigma}{\sigma-1} \frac{\mu-1}{\mu}-1} \bar{k}^{-\frac{1}{\sigma}}
\end{gathered}
$$

Together, these equations imply that wages will never exceed 


$$
\left.\bar{w}=a_{0}^{\frac{\sigma}{\sigma-1}}\left(\underline{r_{T}}+m\right)\left[\underline{\left(r_{T}\right.}+m\right)^{\mu-1}-1\right]^{-\frac{1}{\mu-1}}\left\{1-\left(1-a_{0}\right)^{\sigma}\left(\frac{\underline{r}_{T}+m}{r_{0}}\right)^{\sigma-1}\left[\left(\underline{r_{T}}+m\right)^{\mu-1}-1\right]^{-\frac{\sigma-1}{\mu-1}}\right\}^{-\frac{1}{\sigma-1}}
$$

\section{A3 Descriptive statistics}

Table A1 presents descriptive statistics for the variables used in the regressions in the main text.

\section{A4 Further characterization of worker stocks}

\section{A4.1 Effect of bracero exclusion on non-Mexican foreign seasonal farm labor}

Figure A1 shows that stocks of non-Mexican foreign seasonal agricultural workers remained very low after bracero exclusion.

\section{A4.2 States grouped by exposure to bracero exclusion, according to $1955 \mathrm{Mex}-$ ican fraction of hired seasonal workers}

Table A2 shows the fraction of total seasonal farm workers made up by Mexicans, averaged across the months of 1955, and the corresponding classification into groups of states with 'high', 'low', and 'no' exposure to bracero exclusion.

\section{A4.3 Seasonal variation in bracero stocks}

Figure A2 shows the distribution of bracero stocks on average over the course of a year, for the entire United States. In the 1950s and 1960s, the stock of bracero workers over the course of each year occurred in October. In the 1960s, almost all braceros present at any point in the year were present in or after the month of May.

\section{A5 Robustness checks}

The section checks the robustness of some assumptions underlying results in the main text.

\section{A5.1 State-specific time-trends}

Here we present a re-analysis of Tables 1 and 2 with added state-specific time trends. That is, we modify regression (13) to $y_{s t}=\boldsymbol{\alpha}^{\prime} \boldsymbol{I}_{\boldsymbol{s}}+\boldsymbol{\beta}^{\prime} \boldsymbol{I}_{\boldsymbol{t}}+\gamma\left(I_{t \geqslant 1965} \cdot \bar{\ell}_{s}^{1955}\right)+\boldsymbol{\xi}^{\prime} \boldsymbol{I}_{\boldsymbol{s}} \cdot \boldsymbol{t}^{\prime}+\varepsilon_{s t}$, where $\boldsymbol{\xi}^{\prime} \boldsymbol{I}_{\boldsymbol{s}}$ is a state-specific slope on the year $t^{\prime}$. The coefficient estimates shift but statistical inference is qualitatively unchanged, as shown in Table A3 and Table A4.

\section{A5.2 Alternative 'treatment' year: 1962}

Here we present re-analysis of main-text Tables 1 and 2 with the new assumption that 'treatment' begins in 1962, when the first major restrictions were placed on farms' hiring of braceros, rather than 1965 when the program was terminated. Table A5 shows the differences-in-differences analysis of wage effects under this new assumption, and Table A6 shows the analysis of employment effects. There are no substantial differences from the original results. 
Appendix Table A1: Descriptive statistics

\begin{tabular}{|c|c|c|c|c|c|}
\hline Variable & Mean & Std. Dev. & Min. & Max. & $\mathbf{N}$ \\
\hline \multicolumn{6}{|c|}{ State-by-quarter wage regressions } \\
\hline Year & 1958.128 & 9.6 & 1942 & 1975 & 6384 \\
\hline Quarter & 2.489 & 1.121 & 1 & 4 & 6384 \\
\hline Wage, hourly (1965 US\$) & 0.905 & 0.222 & 0.154 & 1.578 & 4512 \\
\hline Wage, daily (1965 US\$) & 8.604 & 2.28 & 2.087 & 15.169 & 6077 \\
\hline $\ln \left(L^{\text {mex }}\right)$ & 6.343 & 2.436 & 0 & 11.828 & 783 \\
\hline $\ln \left(L-L^{\operatorname{mex}}\right)$ & 9.118 & 1.44 & 2.89 & 12.431 & 1759 \\
\hline$I_{t \geqslant 1965} \cdot \bar{\ell}_{s}^{1955}$ & 0.016 & 0.068 & 0 & 0.609 & 6118 \\
\hline \multicolumn{6}{|c|}{ State-by-month employment regressions } \\
\hline Year & 1958.937 & 9.467 & 1942 & 1975 & 14544 \\
\hline Month & 6.505 & 3.339 & 1 & 12 & 14544 \\
\hline Total domestic & 13018.987 & 28336.885 & 0 & 260941 & 9888 \\
\hline Local domestic & 10302.629 & 23205.917 & 0 & 248050 & 9888 \\
\hline Intrastate domestic & 1627.777 & 5747.704 & 0 & 118315 & 6471 \\
\hline Interstate domestic & 2522.559 & 4359.725 & 0 & 46643 & 6472 \\
\hline ln Total domestic & 8.962 & 1.453 & 1.386 & 12.472 & 6474 \\
\hline ln Local domestic & 8.661 & 1.521 & 1.386 & 12.421 & 6719 \\
\hline ln Intrastate domestic & 6.047 & 1.893 & 0.693 & 11.681 & 4676 \\
\hline ln Interstate domestic & 6.828 & 1.784 & 0.693 & 10.75 & 5789 \\
\hline $\ln \left(L^{\mathrm{mex}}\right)$ & 6.233 & 2.467 & 0 & 11.828 & 2303 \\
\hline$I_{t \geqslant 1965} \cdot \bar{\ell}_{s}^{1955}$ & 0.018 & 0.072 & 0 & 0.609 & 13938 \\
\hline \multicolumn{6}{|c|}{ State-by-year mechanization regressions } \\
\hline Year & 1963 & 7.214 & 1951 & 1975 & 1200 \\
\hline Cotton mechanization & 0.526 & 0.375 & 0 & 1 & 344 \\
\hline Sugar beet mechanization & 0.414 & 0.263 & 0 & 0.92 & 52 \\
\hline $\ln \left(L^{\mathrm{mex}}\right)$ & 6.048 & 2.056 & 2.204 & 11.218 & 298 \\
\hline$I_{t \geqslant 1965} \cdot \bar{\ell}_{s}^{1955}$ & 0.022 & 0.08 & 0 & 0.609 & 1150 \\
\hline \multicolumn{6}{|c|}{ State-by-year crop production regressions } \\
\hline Year & 1958.5 & 9.814 & 1942 & 1975 & 1632 \\
\hline Tomatoes & 112.205 & 52.302 & 0 & 433.333 & 544 \\
\hline Cotton & 83.162 & 32.698 & 1.471 & 222.54 & 301 \\
\hline Sugar beets & 93.637 & 33.953 & 0 & 239.965 & 240 \\
\hline Asparagus & 99.406 & 24.755 & 0 & 162.264 & 144 \\
\hline Strawberries (fresh) & 107.856 & 64.745 & 10.087 & 520 & 434 \\
\hline Lettuce & 111.163 & 61.193 & 31.586 & 681.592 & 276 \\
\hline Celery & 131.24 & 113.755 & 41.176 & 986.667 & 162 \\
\hline Cucumbers (pickling) & 131.184 & 61.445 & 41.698 & 425.139 & 106 \\
\hline Citrus & 132.055 & 83.433 & 3.819 & 427.083 & 64 \\
\hline $\ln \left(L^{\text {mex }}\right)$ & 5.955 & 1.937 & 1.712 & 11.218 & 406 \\
\hline$I_{t \geqslant 1965} \cdot \bar{\ell}_{s}^{1955}$ & 0.016 & 0.07 & 0 & 0.609 & 1564 \\
\hline
\end{tabular}


Appendix Table A2: Mexican fraction of total seasonal farm workers, average across months of 1955

\begin{tabular}{|c|c|c|c|c|c|}
\hline \multicolumn{2}{|c|}{ High exposure } & \multicolumn{2}{|c|}{ Low exposure } & \multicolumn{2}{|c|}{ No exposure } \\
\hline NM & 0.609 & NV & 0.090 & $\mathrm{ME}$ & 0.000 \\
\hline $\mathrm{NE}$ & 0.323 & $\mathrm{AR}$ & 0.080 & NJ & 0.000 \\
\hline $\mathrm{AZ}$ & 0.269 & WY & 0.050 & $\mathrm{SC}$ & 0.000 \\
\hline TX & 0.241 & $\mathrm{CO}$ & 0.045 & LA & 0.000 \\
\hline $\mathrm{CA}$ & 0.231 & MI & 0.034 & $\mathrm{KY}$ & 0.000 \\
\hline \multirow[t]{20}{*}{ SD } & 0.212 & UT & 0.026 & $\mathrm{DE}$ & 0.000 \\
\hline & & MT & 0.025 & KS & 0.000 \\
\hline & & IN & 0.017 & ND & 0.000 \\
\hline & & $\mathrm{MO}$ & 0.015 & OK & 0.000 \\
\hline & & ID & 0.012 & $\mathrm{CT}$ & 0.000 \\
\hline & & $\mathrm{MN}$ & 0.010 & $\mathrm{NC}$ & 0.000 \\
\hline & & WI & 0.008 & $\mathrm{AL}$ & 0.000 \\
\hline & & IL & 0.007 & $\mathrm{MD}$ & 0.000 \\
\hline & & WA & 0.006 & WV & 0.000 \\
\hline & & $\mathrm{TN}$ & 0.006 & $\mathrm{PA}$ & 0.000 \\
\hline & & OR & 0.005 & $\mathrm{OH}$ & 0.000 \\
\hline & & GA & 0.003 & VT & 0.000 \\
\hline & & & & IA & 0.000 \\
\hline & & & & NY & 0.000 \\
\hline & & & & VA & 0.000 \\
\hline & & & & $\mathrm{FL}$ & 0.000 \\
\hline & & & & MA & 0.000 \\
\hline & & & & MS & 0.000 \\
\hline & & & & $\mathrm{NH}$ & - \\
\hline & & & & $\mathrm{RI}$ & - \\
\hline
\end{tabular}

Rhode Island and New Hampshire are missing in all regressions using the 1955 bracero fraction. The original sources do not report domestic or foreign farm worker stocks for those two states in 1955 (and most other years). 
Appendix Table A3: Effects of bracero exclusion on real wages, with linear state-specific quarter-by-year trends: Differences-in-differences with continuous treatment, quarterly

\begin{tabular}{|c|c|c|c|c|}
\hline \multirow[b]{3}{*}{$I_{t \geqslant 1965} \cdot \bar{\ell}_{s}^{1955}$} & \multicolumn{2}{|c|}{ Wage, all years } & \multicolumn{2}{|c|}{ Wage, 1960-1970 } \\
\hline & $\begin{array}{l}\text { Hourly } \\
\text { composite }\end{array}$ & $\begin{array}{c}\text { Daily } \\
\text { w/o board }\end{array}$ & $\begin{array}{l}\text { Hourly } \\
\text { composite }\end{array}$ & $\begin{array}{c}\text { Daily } \\
\text { w/o board }\end{array}$ \\
\hline & $\begin{array}{c}0.0228 \\
(0.0322)\end{array}$ & $\begin{array}{c}0.386 \\
(0.368)\end{array}$ & $\begin{array}{c}0.0498 \\
(0.0322)\end{array}$ & $\begin{array}{c}0.229 \\
(0.298)\end{array}$ \\
\hline \multicolumn{5}{|l|}{ Fixed effects: } \\
\hline State & Yes & Yes & Yes & Yes \\
\hline Quarter-by-year & Yes & Yes & Yes & Yes \\
\hline \multicolumn{5}{|l|}{ Linear quarter-by-year trends: } \\
\hline By state & Yes & Yes & Yes & Yes \\
\hline Std. err. clustered by & State & State & State & State \\
\hline$N$ & 4324 & 5813 & 2024 & 1901 \\
\hline adj. $R^{2}$ & 0.817 & 0.887 & 0.788 & 0.860 \\
\hline Clusters & 46 & 46 & 46 & 46 \\
\hline Semielasticity $\frac{\partial \ln w}{\partial(B / L)}$ & $\begin{array}{c}0.00649 \\
(0.0406)\end{array}$ & $\begin{array}{c}0.0339 \\
(0.0497)\end{array}$ & $\begin{array}{c}0.0387 \\
(0.0325)\end{array}$ & $\begin{array}{c}0.0263 \\
(0.0295)\end{array}$ \\
\hline$p$-val. of $\chi^{2}$ test: $\frac{\partial \ln w}{\partial(B / L)}=0.1$ & {$[0.0259]$} & [0.1903] & {$[0.0657]$} & {$[0.0161]$} \\
\hline
\end{tabular}

'Treatment' is the degree of exposure to exclusion. Observations are state-quarters. Standard errors clustered by state in parentheses. $\bar{\ell}_{1955}$ is average fraction of Mexicans among the state's total hired seasonal workers across the months of 1955 . Wages in constant 1965 US\$ deflated by CPI. ${ }^{*} p<0.10,{ }^{* *} p<0.05,{ }^{* * *} p<0.01$. The hourly wage has full state coverage but fewer years (1948-1971); the daily wage has more years (1942-1975) but is missing three states (CA, OR, WA). Farm worker stocks missing in original sources for 1955 in Rhode Island and New Hampshire. 'Linear quarter-by-year trends' means that the regression includes an interaction term of a dummy for each state and a time variable that takes a unique value for each quarter-by-year in ascending order (e.g. 1960Q1 = 1, 1960Q2 = 2, .., 1961Q1 = 5, etc.). 
Appendix Table A4: Effects of bracero exclusion on domestic seasonal agricultural employment, with linear state-specific month-by-year trends: Differences-in-differences with continuous treatment, monthly

\begin{tabular}{|c|c|c|c|c|c|c|}
\hline \multirow{2}{*}{$\begin{array}{l}\text { Dep. var: Domestic } \\
\text { seasonal workers } \\
\text { Specification: }\end{array}$} & \multicolumn{2}{|c|}{$\begin{array}{l}\text { All states, } \\
\text { all years }\end{array}$} & \multicolumn{2}{|c|}{$\begin{array}{c}\text { All states, } \\
\text { years } 1960-1970\end{array}$} & \multicolumn{2}{|c|}{$\begin{array}{c}\text { Exposed states } \\
\text { only, all years }\end{array}$} \\
\hline & linear & $\ln$ & linear & $\ln$ & linear & $\ln$ \\
\hline$I_{t \geqslant 1965} \cdot \bar{\ell}_{s}^{-1955}$ & $\begin{array}{c}7610.5 \\
(8507.2)\end{array}$ & $\begin{array}{c}0.454 \\
(0.473)\end{array}$ & $\begin{array}{c}3383.1 \\
(3958.5)\end{array}$ & $\begin{array}{c}0.283 \\
(0.599)\end{array}$ & $\begin{array}{c}6502.6 \\
(8126.9)\end{array}$ & $\begin{array}{r}0.0509 \\
(0.421)\end{array}$ \\
\hline $\begin{array}{l}\text { Fixed effects: } \\
\text { State } \\
\text { Month-by-year }\end{array}$ & $\begin{array}{l}\text { Yes } \\
\text { Yes }\end{array}$ & $\begin{array}{l}\text { Yes } \\
\text { Yes }\end{array}$ & $\begin{array}{l}\text { Yes } \\
\text { Yes }\end{array}$ & $\begin{array}{l}\text { Yes } \\
\text { Yes }\end{array}$ & $\begin{array}{l}\text { Yes } \\
\text { Yes }\end{array}$ & $\begin{array}{l}\text { Yes } \\
\text { Yes }\end{array}$ \\
\hline $\begin{array}{l}\text { Linear month-by-y } \\
\text { By state }\end{array}$ & $\begin{array}{c}\text { ar trends: } \\
\text { Yes }\end{array}$ & Yes & Yes & Yes & Yes & Yes \\
\hline Std. err. clust. by & State & State & State & State & State & State \\
\hline $\begin{array}{l}N \\
\text { adj. } R^{2} \\
\text { Clusters }\end{array}$ & $\begin{array}{c}9476 \\
0.281 \\
46\end{array}$ & $\begin{array}{c}6369 \\
0.437 \\
46\end{array}$ & $\begin{array}{l}5520 \\
0.252 \\
46\end{array}$ & $\begin{array}{c}3707 \\
0.447 \\
46\end{array}$ & $\begin{array}{c}4738 \\
0.291 \\
23\end{array}$ & $\begin{array}{c}3174 \\
0.424 \\
23\end{array}$ \\
\hline
\end{tabular}

'Treatment' is the degree of exposure to exclusion. Observations are state-months. Standard errors clustered by state in parentheses. $\bar{\ell}_{1955}$ is average fraction of Mexicans among the state's total hired seasonal workers across the months of 1955 . ${ }^{*} p<0.10,{ }^{* *}$ $p<0.05,{ }^{* * *} p<0.01$. Covers only January 1954 to July 1973, as in original sources. Farm worker stocks missing in original sources for 1955 in Rhode Island and New Hampshire. If no workers reported for state-month in a month when source report was issued, assume zero. 'Exposed states' means states with nonzero bracero stocks in 1955 (i.e., only the 'high' and 'low' groups in the figures). 'Linear month-by-year trends' means that the regression includes an interaction term of a dummy for each state and a time variable that takes a unique value for each month-by-year in ascending order (e.g. January $1960=1$, February $1960=2$, ..., January $1961=13$, etc. $)$. 
Appendix Table A5: Alternative 'treatment' year 1962: Effects of bracero exclusion on real wages: Differences-in-differences with continuous treatment, quarterly

\begin{tabular}{|c|c|c|c|c|}
\hline \multirow[b]{3}{*}{$I_{t \geqslant 1962} \cdot \bar{\ell}_{s}^{1955}$} & \multicolumn{2}{|c|}{ Wage, all years } & \multicolumn{2}{|c|}{ Wage, 1960-1970 } \\
\hline & $\begin{array}{c}\text { Hourly } \\
\text { composite }\end{array}$ & $\begin{array}{c}\text { Daily } \\
\text { w/o board }\end{array}$ & $\begin{array}{c}\text { Hourly } \\
\text { composite }\end{array}$ & $\begin{array}{c}\text { Daily } \\
\text { w/o board }\end{array}$ \\
\hline & $\begin{array}{c}-0.0167 \\
(0.0367)\end{array}$ & $\begin{array}{c}-0.323 \\
(0.454)\end{array}$ & $\begin{array}{c}-0.00626 \\
(0.0248)\end{array}$ & $\begin{array}{c}0.240 \\
(0.263)\end{array}$ \\
\hline \multicolumn{5}{|l|}{ Fixed effects: } \\
\hline State & Yes & Yes & Yes & Yes \\
\hline Quarter-by-year & Yes & Yes & Yes & Yes \\
\hline Std. err. clustered by & State & State & State & State \\
\hline$N$ & 4324 & 5813 & 2024 & 1901 \\
\hline adj. $R^{2}$ & 0.773 & 0.835 & 0.732 & 0.758 \\
\hline Clusters & 46 & 46 & 46 & 46 \\
\hline Semielasticity $\frac{\partial \ln w}{\partial(B / L)}$ & $\begin{array}{c}-0.0189 \\
(0.0414)\end{array}$ & $\begin{array}{c}-0.0373 \\
(0.0549)\end{array}$ & $\begin{array}{c}-0.00655 \\
(0.0260)\end{array}$ & $\begin{array}{c}0.0264 \\
(0.0290)\end{array}$ \\
\hline$p$-val. of $\chi^{2}$ test: $\frac{\partial \ln w}{\partial(B / L)}=0.1$ & {$[0.0041]$} & {$[0.0123]$} & {$[<0.001]$} & [0.0113] \\
\hline
\end{tabular}

'Treatment' is the degree of exposure to exclusion. Observations are state-quarters. Standard errors clustered by state in parentheses. $\bar{\ell}_{1955}$ is average fraction of Mexicans among the state's total hired seasonal workers across the months of 1955 . Wages in constant 1965 US\$ deflated by CPI. ${ }^{*} p<0.10,{ }^{* *} p<0.05,{ }^{* * *} p<0.01$. 
Appendix Table A6: Alternative 'treatment' year 1962: Effects of bracero exclusion on domestic seasonal agricultural employment: Differences-in-differences with continuous treatment, monthly

\begin{tabular}{|c|c|c|c|c|c|c|}
\hline \multirow{2}{*}{$\begin{array}{l}\text { Dep. var: Domestic } \\
\text { seasonal workers } \\
\text { Specification: }\end{array}$} & \multicolumn{2}{|c|}{$\begin{array}{l}\text { All states, } \\
\text { all years }\end{array}$} & \multicolumn{2}{|c|}{$\begin{array}{c}\text { All states, } \\
\text { years } 1960-1970\end{array}$} & \multicolumn{2}{|c|}{$\begin{array}{l}\text { Exposed states } \\
\text { only, all years }\end{array}$} \\
\hline & linear & $\ln$ & linear & $\ln$ & linear & $\ln$ \\
\hline$I_{t \geqslant 1962} \cdot \bar{\ell}_{s}^{1955}$ & $\begin{array}{c}-19008.2 \\
(15984.6)\end{array}$ & $\begin{array}{c}-0.592 \\
(0.460)\end{array}$ & $\begin{array}{l}-7575.2 \\
(10054.3)\end{array}$ & $\begin{array}{c}0.0474 \\
(0.391)\end{array}$ & $\begin{array}{l}-6839.0 \\
(13244.0)\end{array}$ & $\begin{array}{r}-0.115 \\
(0.551)\end{array}$ \\
\hline \multicolumn{7}{|l|}{ Fixed effects: } \\
\hline State & Yes & Yes & Yes & Yes & Yes & Yes \\
\hline Month-by-year & Yes & Yes & Yes & Yes & Yes & Yes \\
\hline Std. err. clust. by & State & State & State & State & State & State \\
\hline$N$ & 9476 & 6369 & 5520 & 3707 & 4738 & 3174 \\
\hline adj. $R^{2}$ & 0.197 & 0.353 & 0.217 & 0.402 & 0.237 & 0.367 \\
\hline Clusters & 46 & 46 & 46 & 46 & 23 & 23 \\
\hline
\end{tabular}

'Treatment' is the degree of exposure to exclusion. Observations are state-months. Standard errors clustered by state in parentheses. $\bar{\ell}_{1955}$ is average fraction of Mexicans among the state's total hired seasonal workers across the months of $1955 .{ }^{*} p<0.10,{ }^{* *}$ $p<0.05,{ }^{* * *} p<0.01$. Covers only January 1954 to July 1973, as in original sources. Farm worker stocks missing in original sources for 1955 in Rhode Island and New Hampshire. If no workers reported for state-month in a month when source report was issued, assume zero. 'Exposed states' means states with nonzero bracero stocks in 1955 (i.e., only the 'high' and 'low' groups in the figures). 


\section{A5.3 Sensitivity of wage graph to smoothing and wage measure}

Here we show smoothed and unsmoothed versions of the wage graph in the main text (Figure $2 b$ ), the hourly composite wage, in Figure A3a and Figure A3b. Where the graph in the main text averages wages by season (July and before, August and after) for comparability with the graph of Mexican fraction, Figure A3b shows the full quarterly data. The smoothed plots show Fan-Gijbels (1992) local linear regressions of state-quarter wage on quarter-by-year, Epanechnikov kernel, bandwidth 2 quarters. We also show the same analysis with a different measure of the wage-the average daily wage without board, which covers more years but omits three states (California, Oregon, and Washington)-with and without smoothing, in Figure A3c and Figure A3d.

\section{A5.4 Alternative assumptions about missing values}

In the differences-in-differences regressions in the main text with domestic employment as the dependent variable, we assume that when there were no domestic seasonal agricultural workers reported for a statemonth in a month when the source document was issued, there were zero domestic workers of each type in that state-month. This accords with inspection of the source documents, where missing values for a state-month typically precede or follow very low values for that state in other months, which would be expected if the report authors used nonreporting to represent zero.

Here we make the alternative assumption: for months in which the source report was issued, if there is no report of domestic workers stocks for a state-month, that stock is assumed to be missing, not zero. This is done in columns 1 and 3 of Table A7. The results in the main text are qualitatively invariant to this alternative assumption.

Of course, the logarithmic specification of these regressions in the main text takes zero values as missing by construction. To allow for such nonlinearity without truncating zeros from the dataset, we repeat the regressions of the main text using the inverse hyperbolic sine of domestic employment as the dependent variable (returning to the assumption that missing values in the original sources, in months were the source document was issued, represent zeros). These results are shown in columns 2 and 4 of Table A7. These results, too, are qualitatively the same as the results in the main text.

\section{A5.5 Compare independent measurements of bracero (outward) flows and in- ward stocks}

Figure A4 compares the annual total outflow of braceros reported by the government of Mexico (a) with snapshots of the national-total stocks of braceros reported in state-by-state data by the U.S. Department of Agriculture in various months (b). The quantities are not strictly comparable: the flow measure captures how many people made the trip at any point in the year, which will exceed the stock present in the U.S. at any given moment to a greater degree the shorter the duration of stay for each worker. But given that some braceros were contracted only for spring work rather than the fall harvest, and some fall workers' contracts for early-harvest crops ended before October, it is plausible that the stock of braceros present in October would be roughly 60 percent of the number that had departed for the U.S. at any point in the year-as is the case in the mid- to late-1950s. This comparison suggests that the stock measures collected from farmers by the U.S. Department of Agriculture were not severely undercounting the number of braceros present in each state. 
Appendix Table A7: Alternative handling of missing or zero worker stocks: Effects of bracero exclusion on domestic seasonal agricultural employment: Differences-in-differences with continuous treatment, monthly

\begin{tabular}{|c|c|c|c|c|}
\hline \multirow[b]{2}{*}{ Specification: } & \multicolumn{2}{|c|}{$\begin{array}{l}\text { Domestic seasonal } \\
\text { workers, all years }\end{array}$} & \multicolumn{2}{|c|}{$\begin{array}{c}\text { Domestic seasonal } \\
\text { workers, } 1960-1970\end{array}$} \\
\hline & linear & $\begin{array}{l}\text { inverse hyper- } \\
\text { bolic sine }\end{array}$ & linear & $\begin{array}{l}\text { inverse hyper- } \\
\text { bolic sine }\end{array}$ \\
\hline Missing vals assumed: & missing & zero & missing & zero \\
\hline$I_{t \geqslant 1965} \cdot \bar{\ell}_{s}^{1955}$ & $\begin{array}{l}-28012.1 \\
(25629.5)\end{array}$ & $\begin{array}{c}-0.918 \\
(1.370)\end{array}$ & $\begin{array}{r}-11041.3 \\
(14616.0)\end{array}$ & $\begin{array}{c}-0.744 \\
(1.143)\end{array}$ \\
\hline \multicolumn{5}{|l|}{ Fixed effects: } \\
\hline State & Yes & Yes & Yes & Yes \\
\hline Month-by-year & Yes & Yes & Yes & Yes \\
\hline Std. err. clustered by & State & State & State & State \\
\hline$N$ & 6369 & 9476 & 3707 & 5520 \\
\hline adj. $R^{2}$ & 0.171 & 0.603 & 0.194 & 0.620 \\
\hline Clusters & 46 & 46 & 46 & 46 \\
\hline
\end{tabular}

'Treatment' is the degree of exposure to exclusion. Observations are state-months. Standard errors clustered by state in parentheses. $\bar{\ell}_{1955}$ is average fraction of Mexicans among the state's total hired seasonal workers across the months of 1955 . ${ }^{*} p<0.10,{ }^{* *}$ $p<0.05,{ }^{* * *} p<0.01$. Covers only January 1954 to July 1973, as in original sources. Farm worker stocks missing in original sources for 1955 in Rhode Island and New Hampshire. If no workers reported for state-month in a month when source report was issued, assume missing in the regressions with linear dependent variable; assume zero in regressions with inverse hyperbolic sine dependent variable. 
Figure A1: Mexican versus other foreign seasonal farm workers in the U.S., total

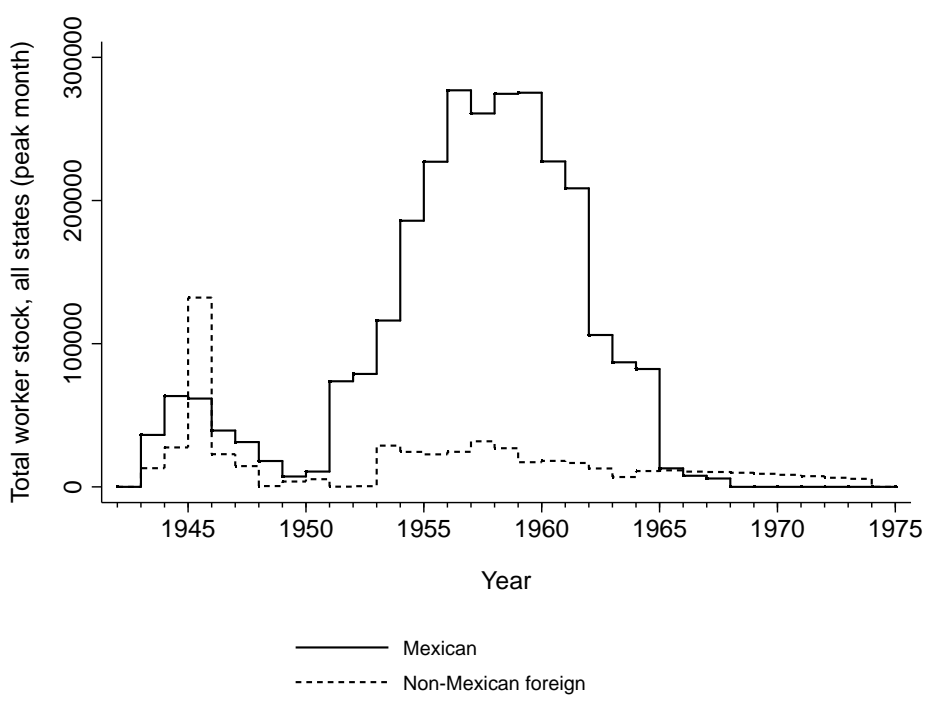

Total across all states, in each year, of that year's peak-month worker stock of each type. 'Non-Mexican foreign' for the purposes of this comparison includes nationals of Jamaica, the Bahamas, other British West Indes, and Canada, as well as U.S. nationals from Puerto Rico.

Figure A2: Fraction of annual maximum monthly stock of braceros present in each month, entire U.S.

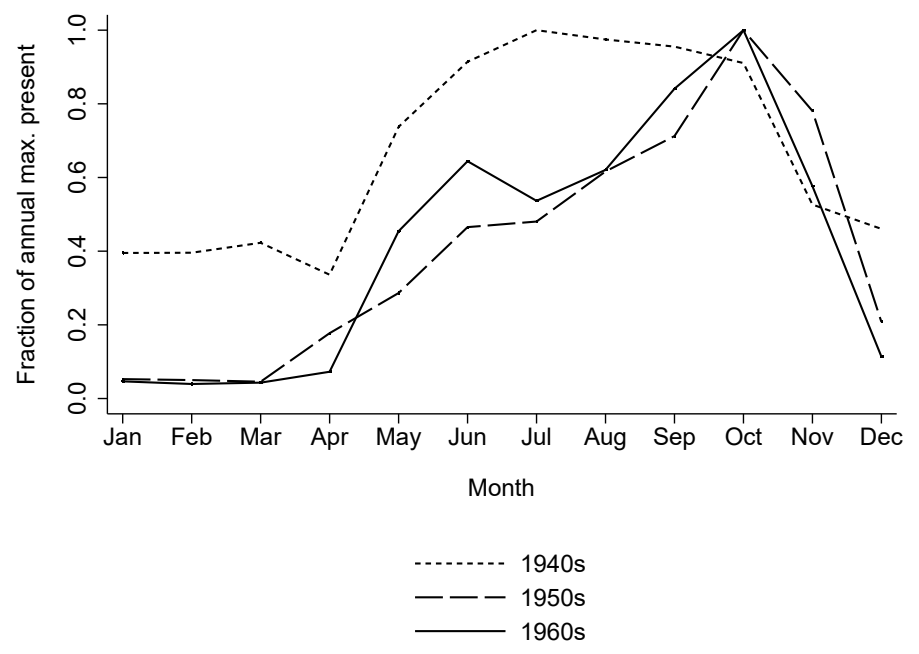

"1940s" is 1943-1949, "1960s" is 1960-1965. For each decade in each month, we sum the total stock of bracero workers present in that month across all the years of the decade in question, then divide that summed stock in each month by the maximum monthly stock. For example, for the 1950s the graph shows for month $m$ the quantity $\left(\sum_{y=1950}^{1959} \sum_{s \in S} b_{s, m, y}\right) /\left(\max _{m} \sum_{y=1950}^{1959} \sum_{s \in S} b_{s, m, y}\right)$, where $b_{s, m, y}$ is the stock of braceros in state $s$ in month $m$ in year $y$, and $S$ is the set of all states. Thus a value of 1 on the vertical axis means that in that month the sum of all bracero stocks in that month across the years of that decade is equal to the maximum such sum for any month. 

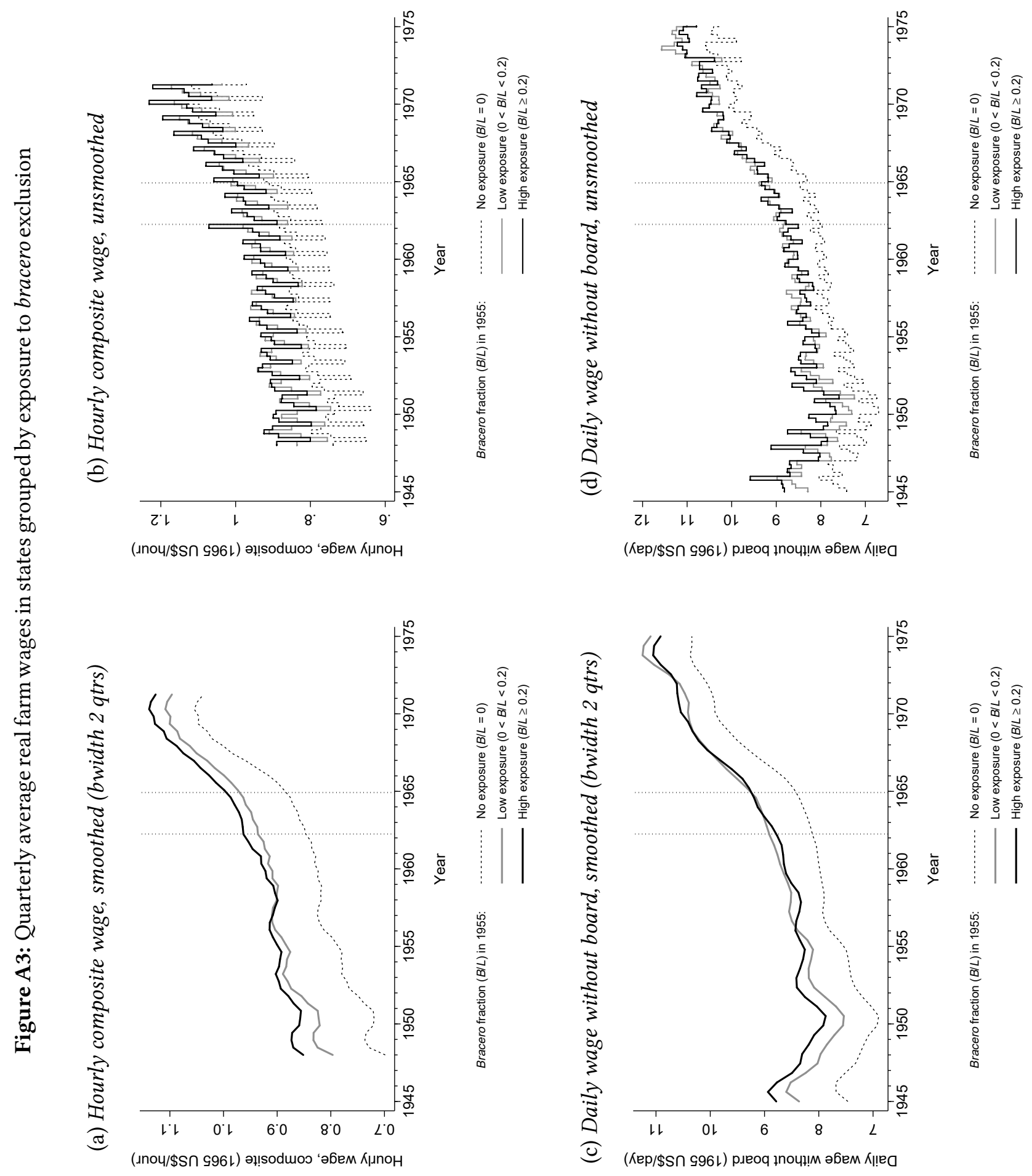
Figure A4: Comparing outward bracero flows reported by Mexico with inward stocks reported by U.S. Dept. of Agriculture

(a) Outflows from Mexico reported by Mexican government, entire year

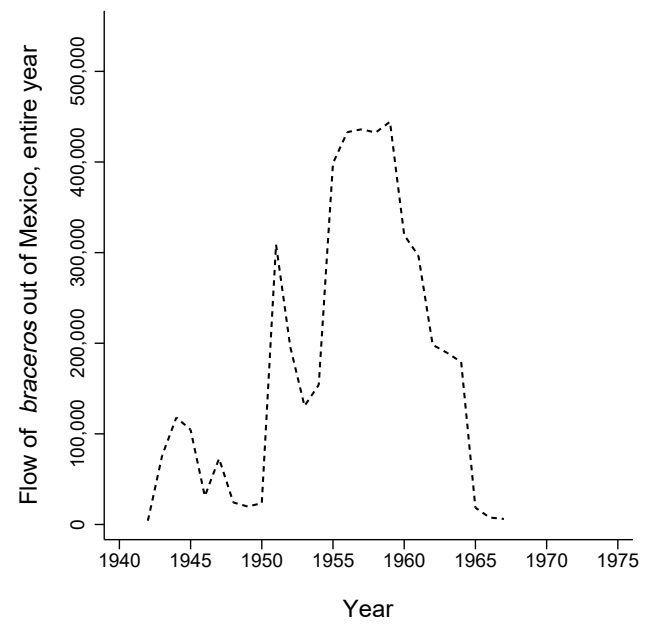

(b) Stocks reported in U.S. by U.S.

farmers, snapshot in various months

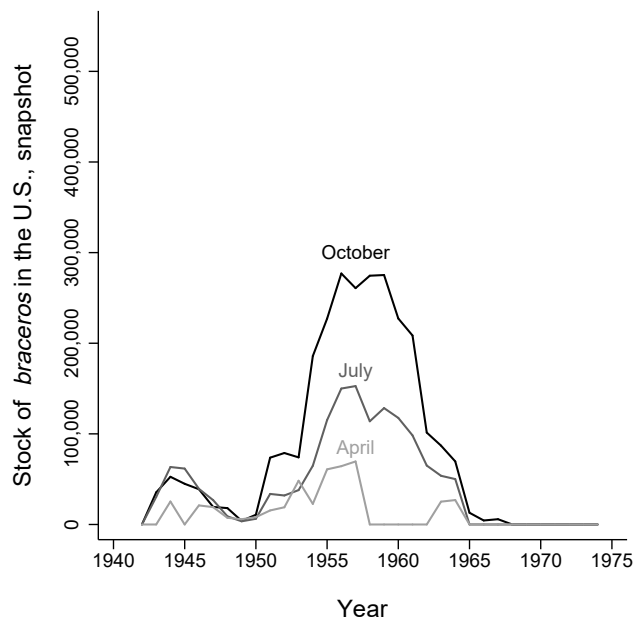

Sources: In Figure A4a the annual total outflow of braceros from Mexico to the U.S. is from González Navarro (1974, Vol. 2, Cuadro 39, p. 141), which sources principally the Anuario Estadístico de los Estados Unidos de México but contains data not reported in the Anuario, for years 1955-1957, gathered directly from the government by the author. 